University of Tennessee Health Science Center

UTHSC Digital Commons

\title{
Regulation of Pyruvate Dehydrogenase Kinase 4 by Thyroid Hormone / Role of Peroxisome Proliferator Activated Receptor Gamma Coactivator-1 alpha and Ccaat Enhancer Binding Protein
}

Ramy Naguib Attia

University of Tennessee Health Science Center

Follow this and additional works at: https://dc.uthsc.edu/dissertations

Part of the Medical Biochemistry Commons, and the Medical Cell Biology Commons

\section{Recommended Citation}

Attia, Ramy Naguib , "Regulation of Pyruvate Dehydrogenase Kinase 4 by Thyroid Hormone / Role of Peroxisome Proliferator Activated Receptor Gamma Coactivator-1 alpha and Ccaat Enhancer Binding Protein" (2009). Theses and Dissertations (ETD). Paper 20. http://dx.doi.org/10.21007/ etd.cghs.2009.0019.

This Dissertation is brought to you for free and open access by the College of Graduate Health Sciences at UTHSC Digital Commons. It has been accepted for inclusion in Theses and Dissertations (ETD) by an authorized administrator of UTHSC Digital Commons. For more information, please contact jwelch30@uthsc.edu. 


\title{
Regulation of Pyruvate Dehydrogenase Kinase 4 by Thyroid Hormone / Role of Peroxisome Proliferator Activated Receptor Gamma Coactivator-1 alpha and Ccaat Enhancer Binding Protein
}

\begin{abstract}
Pyruvate dehydrogenase kinase 4 (PDK4) regulates pyruvate oxidation through the phosphorylation and inhibition of the pyruvate dehydrogenase complex (PDC). The PDC catalyzes the conversion of pyruvate to acetyl-CoA and it is an important control point in glucose and pyruvate metabolism. Previous studies had reported that PDK4 gene expression is induced by thyroid hormone (T3). These studies did not investigate the mechanisms by which T3 regulated PDK4 gene expression. I have examined the role of the thyroid hormone receptor (TR), transcriptional coactivators especially the peroxisome proliferator activated receptor gamma coactivator-1 (PGC-1 $\alpha$ ) and other transcription factors that act as accessory factors in $\mathrm{T} 3$ actions.

Thyroid hormone receptors (TR $\alpha$ or TR $\beta$ ) are part of the nuclear receptor family and have been implicated in the induction of many genes by T3. The nuclear receptors constitute a broad class of transcription factors that have the ability to bind to DNA and regulate the expression of the genes in a ligand dependent manner. To identify a binding site for the TR $\beta$ in the promoter of the PDK4 gene, I transfected serial deletions of this promoter ligated to the luciferase reporter gene into the human hepatoma (HepG2) cells. The TR $\beta$ binding site was characterized by gel shift mobility assays, site directed mutagenesis and in vivo and in vitro luciferase constructs transfection techniques. In addition, I have used the chromatin immunoprecipitation (ChIP) technique to confirm the binding of the TR $\beta$ to the PDK4 gene promoter.
\end{abstract}

Transcription coregulators bind to nuclear receptors to facilitate or inhibit the transcription of the target genes. I have explored the role of several coregulators including the transcriptional coactivator peroxisome proliferator activated receptor gamma coactivator-1 (PGC-1 $\alpha$ ). Previous studies demonstrated that PGC- $1 \alpha$ could induce the PDK4 gene. Here, I found that T3 increases PGC-1 $\alpha$ abundance and association with the PDK4 gene. In addition, adenoviral shRNA-mediated knock-down of PGC- $1 \alpha$ reduced the T3 induction of PDK4 and several other genes. These data suggest that PGC-1 $\alpha$ participates in the T3 induction of multiple genes in the liver. In addition, I investigated the role of several transcription factors including estrogen related receptor (ERR $\alpha), C C A A T / e n h a n c e r$ binding protein beta (C/EBPß) and the forkhead transcription factor (FOXO1) in the activation of the PDK4 gene by T3. ERR $\alpha$ and FoxO1 recruit PGC-1 $\alpha$ to the proximal PDK4 promoter and are involved in the synergistic stimulation of the PDK4 gene by T3 and PGC-1 $\alpha$. C/EBPß was identified as an important accessory factor in the T3 induction of the PDK4 gene. Knock-down of C/EBPß with adenoviral shRNA decreased both the basal expression and T3 stimulation of PDK4. Overall, my results showed that T3 induces PDK4 gene expression through a TR $\beta$ binding site in the promoter of the PDK4 gene and that the two transcription coregulators PGC- $1 \alpha$ and $\mathrm{C} / \mathrm{EBP} \beta$ enhance this induction.

Finally, I have tested the ability of T3 to induce a group of transcriptional regulators and metabolic genes. After 24 hours, 27 gens were found to be induced by T3 including several coactivators. These results suggest that T3 may induce a network of transcriptional regulators to further amplify the actions of T3.

Thus, my studies have characterized the mechanism of the activation of an important metabolic gene, PDK4 gene, by T3 and identified the transcription factors that are involved in this mechanism. Also, my studies have provided a broad insight of the hepatic transcription factors network that work coordinately to facilitate the action of the T3 in the liver. This work may open a door to further investigate therapeutic targets in this network to modulate metabolic disease processes that are affected by the thyroid hormone. 


\author{
Document Type \\ Dissertation \\ Degree Name \\ Doctor of Philosophy (PhD) \\ Program \\ Biomedical Sciences \\ Research Advisor \\ Edwards A. Park, Ph.D. \\ Keywords \\ C/EBP beta, PGC-1 alpha, Pyruvate dehydrogenase kinase 4, Thyroid hormone

\section{Subject Categories} \\ Medical Biochemistry | Medical Cell Biology | Medicine and Health Sciences
}




\title{
REGULATION OF PYRUVATE DEHYDROGENASE KINASE 4 BY THYROID HORMONE: ROLE OF PEROXISOME PROLIFERATOR ACTIVATED RECEPTOR GAMMA COACTIVATOR-1 ALPHA AND CCAAT ENHANCER BINDING PROTEIN
}

\author{
A Dissertation \\ Presented for \\ The Graduate Studies Council \\ The University of Tennessee \\ Health Science Center
}

\author{
In Partial Fulfillment \\ Of the Requirements for the Degree \\ Doctor of Philosophy \\ From The University of Tennessee
}

By

Ramy Naguib Attia

May 2009 
Copyright (C) 2009 by Ramy Raafat Naguib Attia

All rights reserved 


\section{DEDICATION}

This dissertation is dedicated to my precious parents

Mr. \& Mrs. Raafat Naguib Attia

And to my lovely wife

Dr. Riham Ishak

And to my sweet son

Mr. Ryan Ramy Naguib

And to my beloved brother

Dr. Raed Raafat Naguib 


\section{ACKNOWLEDGEMENTS}

I would like to thank my major advisor and mentor, Dr. Edwards A. Park for his direction, support, and guidance throughout this whole work. During the time I spent in Dr. Park's lab, Dr. Park showed a tremendous understanding of the mentor-student relationship and he was always encouraging and training me to develop a scientific and logical way of thinking in order to identify the scientific meaning of each experiment and to solve the problems that faced me during my research. I am also very grateful to my committee members, Dr. George A. Cook, Dr. John V. Cox, Dr. Marshall B. Elam and Dr. Parker Suttle for their valuable scientific suggestions and directions for my research.

I would like to thank the members of Dr. Park's lab, Sarah Connaughton, Fang Wang \& Shulan Song for their supportive and their great help with some of the experiments provided in this dissertation and throughout the entire period I spent in Dr. Park's lab. I am also grateful to the members of Dr. Elam's, Dr. Cook's and Dr. Ness' labs for their significant collaborations with me.

Finally I would like to give special thanks and salute for my parents who grew in me since my childhood the love of science and discovery, without their support for sure I would not be here. Also, I would like to thanks my beloved brother who strengthens me to continue through this long journey. And at last I would like to thank the one who made all this possible my lovely supportive wife Dr. Riham Ishak, she was my inspiration, strength and motivation for all my success in life. 


\begin{abstract}
Pyruvate dehydrogenase kinase 4 (PDK4) regulates pyruvate oxidation through the phosphorylation and inhibition of the pyruvate dehydrogenase complex (PDC). The PDC catalyzes the conversion of pyruvate to acetyl-CoA and it is an important control point in glucose and pyruvate metabolism. Previous studies had reported that PDK4 gene expression is induced by thyroid hormone (T3). These studies did not investigate the mechanisms by which T3 regulated PDK4 gene expression. I have examined the role of the thyroid hormone receptor (TR), transcriptional coactivators especially the peroxisome proliferator activated receptor gamma coactivator-1 (PGC-1 $\alpha$ ) and other transcription factors that act as accessory factors in T3 actions.

Thyroid hormone receptors $(\mathrm{TR} \alpha$ or $\mathrm{TR} \beta$ ) are part of the nuclear receptor family and have been implicated in the induction of many genes by T3. The nuclear receptors constitute a broad class of transcription factors that have the ability to bind to DNA and regulate the expression of the genes in a ligand dependent manner. To identify a binding site for the TR $\beta$ in the promoter of the PDK4 gene, I transfected serial deletions of this promoter ligated to the luciferase reporter gene into the human hepatoma (HepG2) cells. The TR $\beta$ binding site was characterized by gel shift mobility assays, site directed mutagenesis and in vivo and in vitro luciferase constructs transfection techniques. In addition, I have used the chromatin immunoprecipitation (ChIP) technique to confirm the binding of the TR $\beta$ to the PDK 4 gene promoter.
\end{abstract}

Transcription coregulators bind to nuclear receptors to facilitate or inhibit the transcription of the target genes. I have explored the role of several coregulators including the transcriptional coactivator peroxisome proliferator activated receptor gamma coactivator-1 (PGC-1 $\alpha$ ). Previous studies demonstrated that PGC-1 $\alpha$ could induce the PDK4 gene. Here, I found that T3 increases PGC- $1 \alpha$ abundance and association with the PDK4 gene. In addition, adenoviral shRNA-mediated knock-down of PGC- $1 \alpha$ reduced the T3 induction of PDK4 and several other genes. These data suggest that PGC-1 $\alpha$ participates in the T3 induction of multiple genes in the liver. In addition, I investigated the role of several transcription factors including estrogen related receptor $(\mathrm{ERR} \alpha), \mathrm{CCAAT} /$ enhancer binding protein beta $(\mathrm{C} / \mathrm{EBP} \beta)$ and the forkhead transcription factor (FOXO1) in the activation of the PDK4 gene by T3. ERR $\alpha$ and FoxO1 recruit $\mathrm{PGC}-1 \alpha$ to the proximal PDK4 promoter and are involved in the synergistic stimulation of the PDK4 gene by T3 and PGC-1 $\alpha$. C/EBP $\beta$ was identified as an important accessory factor in the T3 induction of the PDK4 gene. Knock-down of $\mathrm{C} / \mathrm{EBP} ß$ with adenoviral shRNA decreased both the basal expression and T3 stimulation of PDK4. Overall, my results showed that T3 induces PDK4 gene expression through a TR $\beta$ binding site in the promoter of the PDK4 gene and that the two transcription coregulators PGC- $1 \alpha$ and $\mathrm{C} / \mathrm{EBP} \beta$ enhance this induction.

Finally, I have tested the ability of $\mathrm{T} 3$ to induce a group of transcriptional regulators and metabolic genes. After 24 hours, 27 gens were found to be induced by T3 
including several coactivators. These results suggest that $\mathrm{T} 3$ may induce a network of transcriptional regulators to further amplify the actions of $\mathrm{T} 3$.

Thus, my studies have characterized the mechanism of the activation of an important metabolic gene, PDK4 gene, by T3 and identified the transcription factors that are involved in this mechanism. Also, my studies have provided a broad insight of the hepatic transcription factors network that work coordinately to facilitate the action of the $\mathrm{T} 3$ in the liver. This work may open a door to further investigate therapeutic targets in this network to modulate metabolic disease processes that are affected by the thyroid hormone. 


\section{TABLE OF CONTENTS}

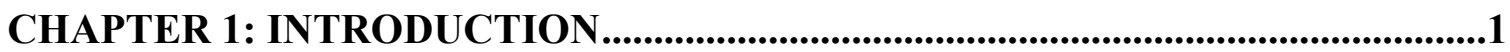

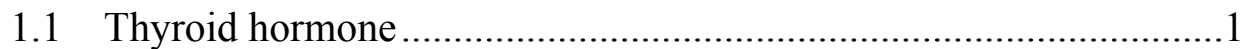

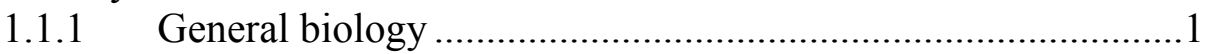

1.1.2 Thyroid hormone receptors ……….........................................

1.1.3 Thyroid hormone effects on glucose and fatty acids metabolism ..........................................................................

1.1.4 Mechanism of the regulation of genes by thyroid

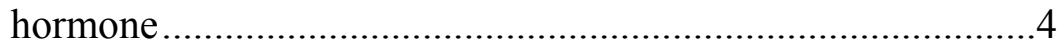

1.2 Transcription factors and coactivators ...........................................5

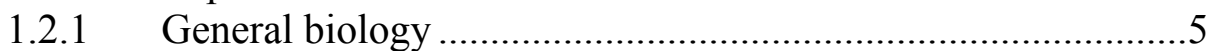

1.2.2 PGC- $1 \alpha$ as a transcription coactivator.....................................

1.2.3 $\mathrm{C} / \mathrm{EBP} \beta$ as a transcription factor ............................................

1.3 Pyruvate dehydrogenase kinase 4 (PDK4) ....................................12

1.3.1 General biology ............................................................12

1.3.2 The role of the PDK in the regulation of the PDC .................12

1.3.3 PDK gene expression ...........................................................14

1.3.4 The role of the PDK4 gene in metabolic processes.................15

CHAPTER 2: RESEARCH OBJECTIVES AND SPECIFIC AIMS ..........................17

2.1 Research objectives ......................................................................17

2.1.1 Characterize the regulation of PDK4 gene by thyroid hormone............................................................................ 17

2.1.2 Study the network of the transcription factors involved in the early response of hepatic metabolic genes to thyroid hormone ....................................................................17

2.2 Specific aims ............................................................................. 18

CHAPTER 3: RESULTS AND EXPERIMENTAL PROCEDURES..........................19

3.1 Results .................................................................................19

3.1.1 Identifying thyroid response elements (TREs) sites within the rPDK4 gene promoter

3.1.2 Association of the TR $\beta$, PGC- $1 \alpha$ and C/EBP $\beta$ with the PDK4 gene promoter in vivo ................................................23

3.1.3 Thyroid hormone treatment increases the mRNA of both the PDK4 and PGC-1 $\alpha$ genes in primary rat hepatocytes. .....28

3.1.4 PGC-1 $\alpha$ enhances the thyroid hormone induction of the PDK4 gene and the role of the forkhead transcription factor (FOXO1) and the estrogen related receptor $\alpha$ $(E R R \alpha)$ in this enhancement.

3.1.5 Knocking down of the PGC- $1 \alpha$ in rat primary hepatocytes affects the ability of thyroid hormone to induce different metabolic genes. 
3.1.6 Overexpression of $\mathrm{C} / \mathrm{EBP} \beta$ induces the rPDK4 gene luciferase promoter................................................................. 38

3.1.7 Thyroid hormone treatment increases the C/EBP $\beta$ protein abundance in primary hepatocytes................................38

3.1.8 $\mathrm{C} / \mathrm{EBP} \beta$ enhances the thyroid hormone induction of rPDK4 gene.

3.1.9 Knocking down C/EBP $\beta$ reduces the ability of thyroid hormone to induce PDK4 gene expression in primary rat hepatocytes.

3.1.10 Thyroid hormone treatment induces a network of transcription factors and different metabolic genes in primary rat hepatocytes.

3.2 Experimental procedures ...........................................................51

3.2.1 Transient transfection of luciferase vectors............................51

3.2.2 Site directed mutagenesis of the rPDK4 promoter...................51

3.2.3 In vivo luciferase transfection...............................................51

3.2.4 Electrophoretic mobility shift..............................................53

3.2.5 Chromatin immunoprecipitation (ChIP) assay .......................53

3.2.6 Real-time PCR ..................................................................54

3.2.7 Western blot .....................................................................56

3.2.8 Adenoviral infection..........................................................56

3.2.9 Superarray ${ }^{\circledR}$ real time PCR ................................................56

CHAPTER 4: DISCUSSION ............................................................................................62

4.1 Regulation of the PDK4 gene expression........................................62

4.1.1 The role of the thyroid hormone in the PDK4 gene expression.

4.1.2 The role of the PGC- $1 \alpha$ in the induction of the PDK4 by thyroid hormone

4.1.3 The role of the C/EBP $\beta$ in the induction of the PDK4 by thyroid hormone.....

4.2 Transcription factors and metabolic genes involved in the thyroid hormone network in primary hepatocytes

LIST OF REFERENCES.

APPENDIX: SUPPLEMENTAL DATA FOR CHAPTER 4

VITA 


\section{LIST OF FIGURES}

Figure 1.1: Schematic model for the action of T3 on the regulation of gene

transcription in liver cells..........................................................................6

Figure 1.2: The upstream signaling events and downstream gene regulatory actions for the PGC- $1 \alpha$ coactivator in different body tissues.

Figure 1.3: The role of the PDK and PDP in the regulation process of the PDC and the related metabolic processes............................................................13

Figure 3.1: Localization and identification of the $\mathrm{T} 3$ responsive regions within the rPDK4 promoter that enhance T3 responsiveness. ..............................20

Figure 3.2: $\quad$ TR $\beta$ binding site in the $\mathrm{PPDK} 4$ promoter...............................................24

Figure 3.3: $\quad \mathrm{TR} \beta, \mathrm{C} / \mathrm{EBP} \beta$ and PGC-1 $\alpha$ are associated with the $\mathrm{rPDK} 4$ gene promoter in vivo.

Figure 3.4: Thyroid hormone increases PDK 4 and PGC- $1 \alpha$ mRNA and protein abundance in primary hepatocytes..........................................................29

Figure 3.5: $\quad$ PGC-1 $\alpha$ enhances the T3 induction of rPDK4 gene.

Figure 3.6: The effect of knocking down the PGC- $1 \alpha$ on the induction gene expression of the PDK4, CPT-1a, PEPCK and C/EBP $\beta$ by T3.

Figure 3.7: Overexpression of $\mathrm{C} / \mathrm{EBP} \beta$ induces the $\mathrm{rPDK} 4$ promoter.

Figure 3.8: Thyroid hormone increases the $\mathrm{C} / \mathrm{EBP} \beta$ protein abundance in primary hepatocytes.

Figure 3.9: $\quad \mathrm{C} / \mathrm{EBP} \beta$ enhances the $\mathrm{T} 3$ induction of the $\mathrm{rPDK} 4$ gene.

Figure 3.10: The effect of inhibiting the C/EBP, FOS and CREB on the induction of rPDK4 by $\mathrm{T} 3$.

Figure 3.11: The effect of knocking down the $\mathrm{C} / \mathrm{EBP} \beta$ on the induction gene expression of the PDK4 gene by T3.

Figure 3.12: Effect of $\mathrm{T} 3$ on transcription factor and metabolic gene abundance in primary rat hepatocytes.

Figure 4.1: PGC-1 $\alpha$ is a coactivator in the T3 induction of the PDK4 gene expression.

Figure A.1: $\quad$ PGC-1 $\alpha$ association with T3 responsive genes is elevated in hyperthyroid rats. 


\section{LIST OF ABBREVIATIONS}

CBP cAMP response element-binding protein (CREB) binding protein

$\mathrm{C} / \mathrm{EBP} \alpha$ CCAAT enhancer binding protein alpha

$\mathrm{C} / \mathrm{EBP} \beta$ CCAAT enhancer binding protein beta

ChIP .Chromatin Immunoprecipitation

CPT-1 .carnitine palmitoyltransferase-1

CREB .cAMP response element-binding protein

DBD DNA binding domain

DR4 direct repeats 4

ERR $\alpha$. . estrogen-related receptor alpha

ERR $\gamma$ estrogen-related receptor gamma

Fabp. fatty acid binding protein

FAS fatty acid synthetase

FOXO forkhead transcription factor

G6pase glucose-6-phosphatase

GR glucocorticoid receptor

HAT histone acetyltransferase

HDAC histone deacetylase

HNF-4 hepatic nuclear factor 4

LBD. ligand binding protein

MCAD. medium chain acyl-CoA dehydrogenase MEF2C. myocyte enhancer factor $2 \mathrm{C}$ $\mathrm{NAD}^{+}$ nicotinamide adenine dinucleotide

$\mathrm{NADH}$ nicotinamide adenine dinucleotide hydride

NcoR nuclear corepressor

NRF-1 nuclear respiratory factor 1 
$\mathrm{p} / \mathrm{CAF}$ .p300/CBP-associated factor

PDC .pyruvate dehydrogenase complex PDK pyruvate dehydrogenase kinase

PDP pyruvate dehydrogenase phosphatase

PEPCK phosphoenolpyruvate carboxykinase PGC-1 $1 \alpha$ ..peroxisome proliferator-activated receptor gamma coactivator 1 alpha PGC-1 $1 \beta$ .peroxisome proliferator-activated receptor gamma coactivator 1 beta PPAR $\alpha$ peroxisomal proliferator activated receptor alpha

$\operatorname{PPAR} \delta$ peroxisomal proliferator activated receptor delta

PPAR $\gamma$ peroxisomal proliferator activated receptor gamma

PRC PGC-1 related coactivator rPDK4 rat pyruvate dehydrogenase kinase 4 RXR retinoid X receptor shRNA short hairpin RNA

SMRT silencing mediator for RXR and TR

SRC-1 steroid receptor coactivator 1

$\mathrm{T} 3$ triiodothyronine $\mathrm{T} 4$ tetraiodothyronine

TR thyroid receptor

TRE thyroid response element

$\mathrm{TSH}$ thyroid stimulating hormone

UCP-1 uncoupling protein 1

UCP-2 uncoupling protein 2

UCP-3 uncoupling protein 3 


\section{CHAPTER 1: INTRODUCTION}

This chapter provides an overview of the topics examined in this dissertation including thyroid hormone biology, the functions of the transcription coregulators and finally the role and the regulation of pyruvate dehydrogenase kinase 4 .

\subsection{Thyroid hormone}

\subsubsection{General biology}

Thyroid hormone plays an important role on various aspects of metabolism, development and differentiation of cells (Yen, 2001). The thyroid gland secretes the thyroid hormones, T4 and the more biologically active form T3. Most of the T4 undergoes peripheral 5'-deiodination into the T3 form (Braverman et al., 1970; Kohrle, 2000). T3 increases the metabolic rate by stimulating almost every tissue in the body to produce mitochondrial proteins and by increasing the oxygen utilization in cells (Oppenheimer et al., 1987). Early studies showed that T3 treatment of hypothyroid rats triggers RNA synthesis in liver and alters the transcription of target genes (Miksicek \& Towle, 1982; Tata et al., 1963; Tata \& Widnell, 1966). T3 mediates its effect on gene expression through binding to the thyroid hormone receptors (TRs) (Munoz et al., 1988; Schueler et al., 1990). Thyroid hormone receptors belong to the superfamily of nuclear hormone receptors, which are a class of ligand activated proteins that, when bound to specific sequences of DNA serve as transcriptional regulators within the cell nucleus. This family of nuclear receptors controls the development and differentiation of skin, bone, behavioral centers in the brain as well as the continual regulation of reproductive tissues and metabolism (Alaynick, 2008; Chung \& Cooney, 2003; Francis et al., 2003). Currently about 48 nuclear hormone receptors have been discovered in human and they have been categorized according to their sequence homology into 6 subfamilies (Laudet, 1997; Zhang et al., 2004c).

The specific sequence that TRs bind to in the DNA sequence are known as T3 response elements (TREs). TRs can bind to these sequences with or without ligand to produce its positive or negative regulation on the target genes (Rastinejad et al., 1995; Samuels et al., 1988). A putative consensus hexamer half-site sequence of [(G/A)GGT(C/G)A] was characterized for the TREs, based on mutational and sequence comparison studies. There is considerable variation in the primary nucleotide sequence as well as the number, spacing, and orientation of the half-sites (Cheng, 2000; Williams \& Brent, 1995). The half-sites for the TREs can be arranged as palindromes (TRE $\left.\mathrm{Tal}_{\mathrm{pa}}\right)$, direct repeats (DRs), and inverted palindromes (IPs) and the optimal spacing between these half-site arrangements are zero, four, and six nucleotides, respectively. The most common TRE contains a direct repeat separated by 4 nucleotides (DR4) (Glass, 1994; Williams \& Brent, 1995). 


\subsubsection{Thyroid hormone receptors}

There are two major TR isoforms encoded on separate genes, designated as TR $\alpha$ and TR $\beta$. The primary transcript for each gene can be alternatively spliced, generating four thyroid hormone-binding receptors, namely $\mathrm{TR} \alpha_{1}, \mathrm{TR} \alpha_{2}, \mathrm{TR} \beta_{1}, \mathrm{TR} \beta_{2}$ and $\mathrm{TR} \beta_{3}$ (Chassande, 2003; Williams, 2000). All the TR isoforms bind thyroid hormone and mediate gene regulation except for $\mathrm{TR} \alpha_{2}$ which encodes an altered ligand binding domain of unknown function (Munroe \& Lazar, 1991). The TR isoforms in human, rat and mouse are highly homologous with respect to their amino acid sequences (Lazar, 1993). The TRs have several conserved domains including an A/B domain in the amino terminus and a DNA binding domains containing two zinc fingers. Importantly, the ligand binding domain (LBD) contains the activation function-2 (AF-2) peptide that interacts with coactivators. $\mathrm{TR} \alpha_{1}, \mathrm{TR} \alpha_{2}, \mathrm{TR} \beta_{1}$ and $\mathrm{TR} \beta_{3}$ are expressed in most of the rat, mouse, and human tissues although their tissue specific abundance differs greatly (Bradley et al., 1992; Hodin et al., 1990). However, the $\mathrm{TR} \beta_{2}$ is restricted to pituitary and particular brain regions of the rodent (Bradley et al., 1992; Hodin et al., 1990; Lechan et al., 1994; Wood et al., 1991) and has not yet been detected in the human. Although both $\operatorname{TR} \alpha_{1}$ and $\operatorname{TR} \beta_{1}$ are expressed in most tissues, $\mathrm{TR} \alpha_{1}$ is highly expressed in skeletal muscle and brown adipose tissue whereas the $\mathrm{TR} \beta_{1}$ is the most abundant form of TR in liver, kidney and brain (Lazar, 1993). In heart, $\mathrm{TR} \alpha_{1}$ is most predominant TR isoform and is responsible for mediating thyroid hormone action in myocardiocytes, while in liver TR $\beta_{1}$ mediates the action of the thyroid hormone (Dillmann \& Gloss, 2002).

TRs can bind to the TREs as a monomer, homodimer or heterodimer with the retinoid X receptor ( $\mathrm{RXR}$ ). This heterodimerization with RXR enables the TRs to bind to asymmetric TREs and direct repeats separated by four nucleotides. In the great majority of genes, TR binds as a heterodimer with RXR (Glass, 1994; Ribeiro et al., 1994).

Thyroid hormone plays an important role in the regulation of genes involved in metabolism and development. The development of transgenic and knockout mouse models for the different TRs isoforms have helped us in understanding the molecular mechanisms of T3 action in normal and disease states. For example, the role of the thyroid hormone in pituitary gland had been identified by knockout studies done on the $\mathrm{TR} \beta_{2}$ isoform, and it showed that $\mathrm{TR} \beta_{2}$ may be playing the predominant role in regulating the thyroid stimulating hormone (TSH) (Abel et al., 1999). In heart knockout studies for the $\mathrm{TR} \alpha_{1}$ and $\mathrm{TR} \beta$ had showed that T3 maintains baseline heart rate through the $\mathrm{TR} \alpha_{1}$, whereas T3 stimulates heart rate through TR $\beta$ (Johansson et al., 1999). In addition, the role of T3 in lipid synthesis and degradation had been examined in mice expressing the mutant TR $\beta$. These mice had elevated serum cholesterol levels compared with control animals in both hypothyroid and hyperthyroid states (Hayashi et al., 1996). Moreover, using a mouse model of resistance to thyroid hormone where a point mutation in the ligand-binding domain of TR $\beta$ abolished its ability to bind to T3, Koshi Hashimoto reported cross talk between the liver $X$ receptor $\alpha(\operatorname{LXR} \alpha)$ and the $\operatorname{TR} \beta$ to regulate the cholesterol uptake and metabolism in liver. (Hashimoto et al., 2006). On the other hand, $\mathrm{TR}^{-/-}$mice showed lowered stimulation of the cholesterol 7- $\alpha$ hydroxylase gene (CYP7A) mRNA level by $\mathrm{T}_{3}$ but not in $\mathrm{TR} \alpha_{1}^{-/-}$mice. These results indicate that $\mathrm{TR} \beta$ not 
the TR $\alpha$ is the mediator of $T_{3}$ action on CYP7A gene, the rate limiting enzyme in the process of the degradation of the cholesterol into bile acids, and consequently it is one of the major regulators of cholesterol metabolism in vivo. However, $\mathrm{T}_{3}$-deficient $\mathrm{TR} \beta^{-/-}$mice showed an augmented CYP7A response after challenge with dietary cholesterol, and these animals did not develop hypercholesterolemia to the extent as did wild type controls. The latter results lend strong support to the concept that TRs may exert regulatory effects in vivo independent of T3 (Gullberg et al., 2000).

\subsubsection{Thyroid hormone effects on glucose and fatty acids metabolism}

Lipid and glucose metabolism are among the many physiological processes that are regulated by thyroid hormone. In fact, there is a strong link between thyroid hormone disorders and number of widespread metabolic diseases including diabetes (Crunkhorn \& Patti, 2008; Johnson, 2006; Wu, 2007), obesity (Kozlowska \& Rosolowska-Huszcz, 2004; Naslund, 2000; Ribeiro, 2008) and cardiovascular disease (Gomberg-Maitland \& Frishman, 1998; Klein \& Ojamaa, 2001). Along with heart and muscle, the liver is one of the main organs affected by T3 (Weitzel, 2003).

In liver, T3 increases the abundance of a number of genes potentially involved in hepatic triglyceride production, including spot 14 and fatty acid transporter protein as well as a range of genes involved in hepatic lipogenesis and low density lipoprotein receptor expression (Feng et al., 2000; Ness \& Zhao, 1994). Paradoxically, T3 simultaneously induces genes involved in lipolysis including lipoprotein lipase (Pykalisto et al., 1976; Wahrenberg et al., 1994).

Regarding glucose metabolism, T3 stimulates almost all aspects of carbohydrate metabolism, including enhancement of insulin-dependent entry of glucose into cells and increased gluconeogenesis through elevating the transcription of key gluconeogenic enzymes, such as glucose-6-phosphatase (G6P) and phosphoenolpyruvate carboxykinase (PEPCK) (Fowden et al., 2001; Park et al., 1997). In addition, T3 promotes glycogenolysis to generate free glucose (Johnson, 2006).

Previous studies had detected at least two different gene expression pattern mediated by T3. Whereas limited number of genes were rapidly induced by T3 within 6 hours only of in vivo T3 treatment, the majority of T3 regulated genes needed 24-48 hours to be induced by the T3 treatment (Weitzel et al., 2003a; Weitzel et al., 2001). This observation led to the assumption that $\mathrm{T} 3$ can mediate gene expression by several mechanisms. One direct mechanism for the T3 mediated gene regulation is through binding of T3 to its TRE site on targeted gene promoter. The other mechanism is through the induction of an intermediate factor such as, the peroxisome proliferator activated receptor gamma coactivator-1 or the nuclear respiratory factor or CCAAT/enhancer binding protein beta that can in turn promote the induction of the targeted gene (Park et al., 1997; Weitzel et al., 2001; Zhang et al., 2004b). 
Although detailed investigations have been performed to identify the mechanism by which T3 regulated different metabolic genes including phosphoenolpyruvate carboxykinase (PEPCK), carnitine palmitoyltransferase 1a (CPT-1a), apolipoprotein B (ApoB) and uncoupling protein 3 (UCP3) (de Lange et al., 2007; Jackson-Hayes et al., 2003; Mukhopadhyay et al., 2003; Park et al., 1999; Zhang et al., 2004b), the mechanism of the induction of the pyruvate dehydrogenase kinase 4 (PDK4) gene by T3 had not been identified (Sugden et al., 1996). Understanding the mechanism of activation of PDK4 by T3 is an important step to fully understand the metabolic effect of the T3 on fatty acid and glucose metabolism as PDK4 is a key regulator in the pyruvate metabolism, which in turn affects both glucose and fatty acid metabolism (Jeoung \& Harris, 2008; Sugden \& Holness, 2002).

\subsubsection{Mechanism of the regulation of genes by thyroid hormone}

The thyroid gland produces tetraiodothyronine (T4), triiodothyronine (T3), and 3,3',5'-triiodothyronine (rT3), however, the T4 is quantitatively the major secretory product (Moreno et al., 2008). There are three types of deiodinases, and they are responsible for the peripheral 5'-deiodination of T4 and T3 (Bianco et al., 2002; Kuiper et al., 2005). The first type is deioidinase I (D1) which is found in peripheral tissues such as liver and kidney and is responsible for the conversion of the majority of T4 to T3 in the blood circulation, while deiodinase II (D2) is predominant in brain, pituitary, and brown adipose tissue and primarily converts T4 to T3 for intracellular use. The third type is deioidinase III (D3), which is responsible for the generation of reverse T3 (rT3), which is the inactive form of the hormone. D3 is found primarily in placenta, brain, and skin (Yen, 2001). D1 and D3 are also involved in the further degradation of T3 or T4 to distinct diiodothyronines: 3, 5-diiodothyronine (T2); 3, 3'-diiodothyronine (3, 3'-T2); and 3', 5'diiodothyronine (3', 5'-T2). And finally these, in turn, can be transformed into monoiodothyronine (T1) and subsequently into thyronine (T0) (Moreno et al., 2008).

T3 binds to the thyroid hormone receptor (TR) which in turn binds to the thyroid response element (TRE) to modulate the transcription of target genes. However, the unliganded TRs can still bind to the TRE in the promoter of the targeted gene and can repress basal transcription of positively T3 regulated genes (Baniahmad et al., 1992; Brent et al., 1989). This basal repression is due to the direct interaction of unliganded TRs with corepressor molecules that typically posses the histone deacetylase activity and can interfere with the assembly of a functional preinitiation complex at the promoter of the target gene (Baniahmad et al., 1993; Tong et al., 1995). Nuclear receptor corepressor $(\mathrm{NCoR})$ and the silencing mediator for retinoic acid receptor and thyroid receptor (SMRT) are corepressors that interact with unligaded TR (Horlein et al., 1995; Lee et al., 1995). The consensus LXXI/HIXXXI/L sequences within the NCoR and SMRT interact with the amino acid residues on helices 3,5 , and 6 , which are part of the ligand pocket and hinge region of the TRs (Nagy et al., 1999; Perissi et al., 1999). These corepressors interacts with other repressors as Sin 3 and histone deacetylase 1 (HDAC1), which in turn promotes histone deactylation and results in basal transcription repression (Heinzel et al., 1997; Nagy et al., 1997). 
When the ligand $\mathrm{T} 3$ is bound to the $\mathrm{TR}$, it triggers significant conformational changes (Bourguet et al., 2000), including the repositioning of the helix 12 containing the core of AF-2 in the TR LBD (Glass \& Rosenfeld, 2000), that results in release of the corepressor complex and recruitment of a coactivator complex to enhance transcription of the target gene (Onate et al., 1995). Most of the characterized coactivators interact with the LBDs of the TRs, through helical LXXLL motifs present within these coactivators (Heery et al., 1997). Several coactivators for the thyroid hormone transcription induction have been identified including the CREB binding protein (CBP) and the p300 protein complex, steroid receptor coactivator-1 (SRC-1) and PGC-1 $\alpha$ (Chakravarti et al., 1996; Kamei et al., 1996; Rosenfeld et al., 2006; Weiss et al., 1999; Wu et al., 2002; Zhang et al., 2004b). These coactivators such as the CREB/p300 complex in turn interact and recruit the PCAF (p300/CBP-associated factor) to TRE site of the target gene. The PCAF has a histone acetyltransferase activity (HAT) which promotes hisone acetylation and transcription activation (Ogryzko et al., 1998).

Therefore, the TR can shift between the unligaded and liganded form with T3 causing the association or dissociation of coactivators or corepressors of the transcription machinery for the target genes (Figure 1.1) (Yen, 2001; Yen et al., 2006). As I mentioned before T3 can increase cardiac function via the $\mathrm{TR} \alpha$ while elevating hepatic metabolism via TR $\beta$. Thus, developing therapeutic agents that can promote the induction of metabolic genes by activating specific isoform of the TR can be beneficial for treating metabolic diseases as hypercholesteremia or obesity without provoking T3 cardiac side effects. Preliminary studies in animals with TRß selective agonists have led to a lowering of the triglyceride and cholesterol levels in animal models with less cardiac side effects (Baxter et al., 2004; Grover et al., 2004; Perra et al., 2008; Trost et al., 2000). All these facts show that understanding of the mechanism by which T3 regulate metabolic genes can lead to the identification of more therapeutic targets within its network of regulated genes for curing of related metabolic diseases.

\subsection{Transcription factors and coactivators}

\subsubsection{General biology}

Transcription factors and their coregulators coordinately regulate many biological programs at the transcriptional level (Handschin \& Spiegelman, 2006; Schrem et al., 2002). Transcription factors control gene expression by binding to specific sequences frequently in the promoter upstream of the DNA of target genes and thereby control the transcription of their genetic information from DNA to RNA (Karin, 1990; Latchman, 1997). Transcription factors are composed of two essential functional regions: a DNAbinding domain and a transactivation domain. The DNA-binding domain is composed of amino acids that recognize specific DNA bases, while the activator domain of transcription factors contain the amino acids responsible for interacting with the components of the transcriptional apparatus (RNA polymerase) and with other regulatory proteins (transcription coactivators) (Agalioti et al., 2000; Senger et al., 2000). 


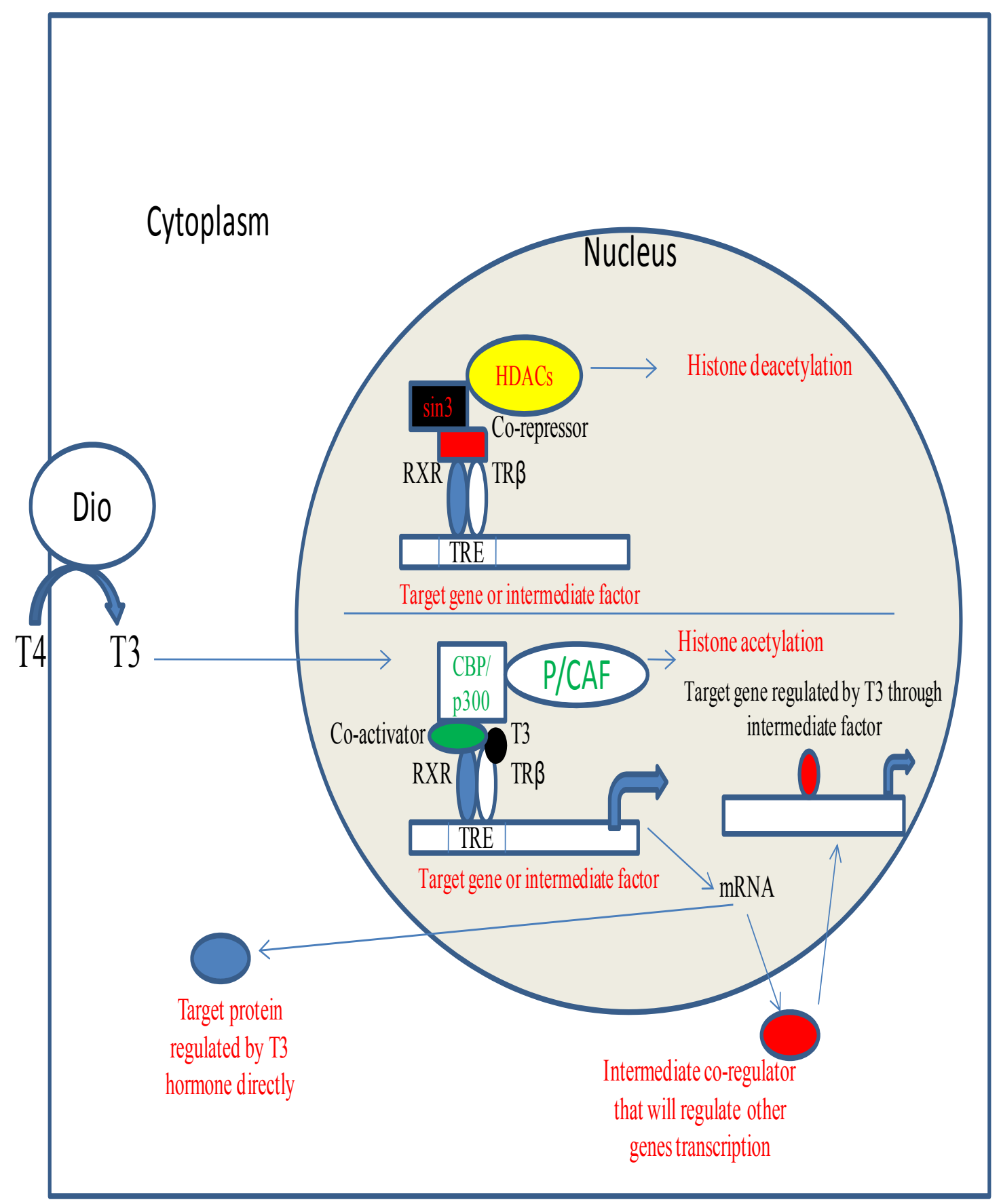

Figure 1.1: Schematic model for the action of $T 3$ on the regulation of gene transcription in liver cells.

Abbreviations: CBP, cAMP-response element-binding protein; HDAC, histone deacetylase; P/CAF, p300/CBP-associated factor; RXR, retinoid X receptor; TR $\beta$, thyroid hormone receptor beta; TRE, thyroid hormone-response element. 
Transcription coregulators are those proteins that either activate or repress the transcription of specific genes by interacting and regulating the transcription factors (Glass \& Rosenfeld, 2000). Transcription coactivators are the coregulators that activate gene transcription, while those that repress it are known as corepressors. Transcriptional coactivators or corepressors regulate the transcription by binding to other DNA-bound factors without directly contacting DNA themselves (McKenna et al., 1999; Xu, 2005). Two different mechanisms have been identified for transcription coregulators to regulate the transcription of genes. The first mechanism for transcription coregulators is to modify chromatin structure through covalent modification of histones by acetylation, phosphorylation or methylation (Glass \& Rosenfeld, 2000; Nowak \& Corces, 2004; Stewart et al., 2005). The second mechanism is to modify the conformation of chromatin by an ATP-dependent process through altering chromatin structure by changing the location or conformation of the nucleosome. These structural changes do not involve covalent modification, and can either activate or repress the transcription (Aoyagi et al., 2005; Kingston \& Narlikar, 1999).

Based on the structure of its DNA-binding domain, transcription factors are typically categorized into four groups including: basic domains, zinc-coordinating domains, helix-turn-helix domains and beta-scaffold domains with minor grove contacts (Stegmaier et al., 2004). The thyroid hormone receptor (TR) belongs to a zinc finger type of transcription factors, while the CCAAT/enhancer binding protein beta $(\mathrm{C} / \mathrm{EBP} \beta)$ belongs to the transcription factors with basic domains (leucine zipper type). On the other hand, one common feature of nuclear receptor coactivators is that they contain one or more LXXLL binding motifs. Different examples of transcription coactivators are listed here, androgen receptor associated protein, cAMP response element-binding proteinbinding protein (CBP), coactivator-associated arginine methyltransferase 1 (CARM1), steroid receptor coactivator (SRC), p300/CBP associating factor ( $\mathrm{p} / \mathrm{CAF}$ ), and proliferator activated receptor gamma coactivator 1 (PGC-1) (Cai et al., 2005; El Messaoudi et al., 2006; Xu et al., 1999).

In this dissertation I am focusing on the effect of two transcription factors the TR and the $\mathrm{C} / \mathrm{EBP} \beta$ on the activation of the PDK4 gene and the role of one transcription coactivator, the PGC-1 $\alpha$. I have discussed the thyroid receptor biology and function in the first part of this chapter and I will give an overview on the PGC- $1 \alpha$ and the C/EBP $\beta$ in the following part of the introduction.

\subsubsection{PGC-1 $\alpha$ as a transcription coactivator}

Mitochondrial biogenesis, hepatic gluconeogenesis, and $\beta$-oxidation of fatty acids are among many metabolic processes that are regulated by the transcription coactivator proliferator activated receptor gamma coactivator-1 alpha (PGC-1 $\alpha$ ) (Puigserver \& Spiegelman, 2003). PGC-1 $\alpha$ belongs to a family of transcriptional coactivators that includes PGC-1 $\beta$ and PGC-1 related coactivator (PRC) (Finck \& Kelly, 2006). PGC-1 $\alpha$ and PGC-1 $\beta$ are expressed in brown adipose tissue (BAT), heart, skeletal muscle, brain, kidney and liver (Finck \& Kelly, 2006), but there is less information about the expression 
patterns of PRC (Andersson \& Scarpulla, 2001). Physiological conditions that demand increased mitochondrial energy production such as exercising, fasting and cold exposure highly induce the expression of PGC-1 $\alpha$ in skeletal muscle, in the heart, liver and brown adipose tissue (Baar et al., 2002; Lehman et al., 2000; Puigserver et al., 1998; Rhee et al., 2003; Terada et al., 2002). Interestingly, fasting but not cold exposure induces PGC-1 $\beta$, indicating that there are unique regulatory mechanisms of regulation for each coactivator and each activator may be involved in different metabolic pathways (Lin et al., 2002; Lin et al., 2003).

PGC-1 has been implicated in the activation of many transcription factors including a number of nuclear receptors such as the peroxisome proliferator-activated receptors (PPAR) both the $\alpha$ and the $\beta / \delta$ isoforms (Vega et al., 2000; Wang et al., 2003), retinoid receptors (Puigserver et al., 1998), glucocorticoid receptor (Knutti et al., 2000), estrogen receptor (Knutti et al., 2000; Puigserver et al., 1998), farnesyl X receptor (FXR) (Zhang et al., 2004a), pregnane X receptor (PXR) (Bhalla et al., 2004), hepatic nuclear factor-4 (HNF-4) (Rhee et al., 2003), liver X receptor (LXR) (Lin et al., 2005b), and the estrogen-related receptors (ERRs) (Huss et al., 2002; Schreiber et al., 2003).

PGC-1 $\alpha$ was originally discovered as a cold-inducible transcription coactivator of adaptive thermogenesis in brown adipose tissue (BAT) (Puigserver et al., 1998). PGC-1 $\alpha$ promotes mitochondrial biogenesis both in BAT and skeletal muscles through regulating the nuclear respiratory factors (NRF-1 and NRF-2) (Leone et al., 2005; Wu et al., 1999). Recent evidence also implicates PGC- $1 \alpha$ in the regulation of glucose metabolism in muscles as it activates expression of glucose transporter 4 (GLUT4) in cultured skeletal muscle cells by coactivating myocyte enhancer factor-2 (MEF-2c) (Michael et al., 2001). Moreover, PGC-1 $\alpha$ regulated fatty acid oxidation and fuel selection in muscle by activating the expression of the gene encoding pyruvate dehydrogenase kinase 4 via its NR partner, ERR $\alpha$ (Wende et al., 2005). Finally in liver and heart, PGC-1 $\alpha$ promotes different metabolic processes. First, PGC-1 $\alpha$ activate expression of PPAR $\alpha$ target genes involved in hepatic and cardiac fatty acid oxidation (Huss \& Kelly, 2004; Leone et al., 2005; Vega et al., 2000). Second, PGC-1 $\alpha$ coactivates HNF-4 $\alpha$ and FOXO1 to drive expression of genes involved in gluconeogenesis in liver (Puigserver et al., 2003). Third, PGC-1 $\alpha$ activates mitochondrial biogenesis in cultured cardiac myocytes (Lehman et al., 2000).

PGC-1 $\alpha$ knockout mice further emphasized its important role for appropriate adaptation to the metabolic and physiologic stressors. Leone et al showed that PGC-1 $\alpha^{-/-}$ mice were unable to maintain core body temperature following exposure to cold, consistent with an altered thermogenic response (Leone et al., 2005). Also, they develop hepatic steatosis after a short period of starvation due to a combination of reduced mitochondrial respiratory capacity and an increased expression of lipogenic genes (Leone et al., 2005). On the other hand, the Spiegelman group reported that PGC-1 $\alpha^{-/-}$mice are paradoxically lean and resistant to diet-induced obesity and that they did not develop hepatic steatosis. They showed diminished expression of genes involved in mitochondrial fatty acid oxidation, the TCA cycle, and oxidative phosphorylation (Lin et al., 2004). The mechanistic basis for the dissimilarities between the 2 lines of PGC-1 $\alpha^{-/-}$mice is unclear (Finck \& Kelly, 2006). However, both of them reported that PGC-1 $\alpha^{-/-}$mice are cold 
intolerant and they have a marked vacuolar lesions in the central nervous system together with compromised the capacity of their hearts to perform basal and strenuous aerobic work. Moreover, M. Patti had supported the central role of the PGC-1 system in human body metabolism as she reported that decreased PGC- $1 \alpha$ and PGC-1 $\beta$ expression in human may be responsible for decreased expression of NRF-dependent genes, contributing to the metabolic disturbances characteristic of insulin resistance in type 2 diabetes mellitus patients (Patti et al., 2003).

The expression and activity of PGC-1 $\alpha$ are linked to a variety of upstream cellular signaling pathways. Glucocorticoids and cAMP increased PGC-1 $\alpha$ gene transcription in liver (Bernal-Mizrachi et al., 2003; Puigserver et al., 1998). While in muscles, the AMPactivated protein kinase (AMPK), calcineurin $\mathrm{A}$ and calcium/calmodulin-dependent protein kinase (CaMK) and p38 mitogen-activated protein kinase (p38 MAPK) have been shown to activate PGC-1 $\alpha$ (Fan et al., 2004; Schaeffer et al., 2004; Zong et al., 2002). The upstream signaling events and downstream gene regulatory actions for the PGC-1 $\alpha$ coactivator in different body tissues are illustrated in Figure 1.2 (Finck \& Kelly, 2006; Lin et al., 2005a).

The most important aspect regarding the PGC-1 coactivator system related to this dissertation is the ability of PGC-1 $\alpha$ to coactivate the thyroid receptor and to induce the PDK4 gene (Puigserver et al., 1998; Wende et al., 2005). In addition, previous studies had reported that T3 highly induced the hepatic PGC-1 $\alpha$ mRNA expression (Weitzel et al., 2001). Moreover, previous studies from our lab had reported that overexpression of the PGC-1 $\alpha$ enhanced the induction of carnitine palmitoyltransferase 1a (CPT-1a) by thyroid hormone. All this information had linked the T3 effect on metabolic processes with the PGC- $1 \alpha$, but the role of the PGC- $1 \alpha$ in the induction of PDK4 by T3 had not been investigated. Therefore, this dissertation aimed to answer this question, is the PGC$1 \alpha$ is important for the hepatic action of T3 on PDK4 gene and other metabolic genes?

\subsubsection{C/EBP $\beta$ as a transcription factor}

The CCAAT/enhancer binding protein beta $(\mathrm{C} / \mathrm{EBP} \beta)$ is a heat-stable DNAbinding protein found in rat liver nuclei. It belongs to a distinct subfamily of transcription factors called C/EBPs with several members $(\mathrm{C} / \mathrm{EBP} \alpha, \mathrm{C} / \mathrm{EBP} \beta, \mathrm{C} / \mathrm{EBP} \gamma, \mathrm{C} / \mathrm{EBP} \delta$, $\mathrm{C} / \mathrm{EBP} \varepsilon$, and $\mathrm{C} / \mathrm{EBP} \zeta)$. They are encoded by separate genes located on different chromosomes (Landschulz et al., 1988; Williams et al., 1991). The C/EBPs are characterized by their ability to regulate different metabolic genes through binding selectively to the CCAAT motif in the promoters of these genes (Schrem et al., 2004). This group of proteins shares the highly conserved two homologous domains, the Cterminal basic DNA binding domain and the leucine zipper dimerization domain. In addition, they contain two other less homologous domains, the N-terminal activation domain and the attenuation domain (Arizmendi et al., 1999).

The expression patterns for the $\mathrm{C} / \mathrm{EBP}$ isoforms are quite different as the $\mathrm{C} / \mathrm{EBP} \alpha$ is expressed in liver, adipose, intestine, lung, adrenal gland, placenta, ovary and peripheral blood mononuclear cells (PBMCs), while both $\mathrm{C} / \mathrm{EBP} \beta$ and $\mathrm{C} / \mathrm{EBP} \delta$ are 


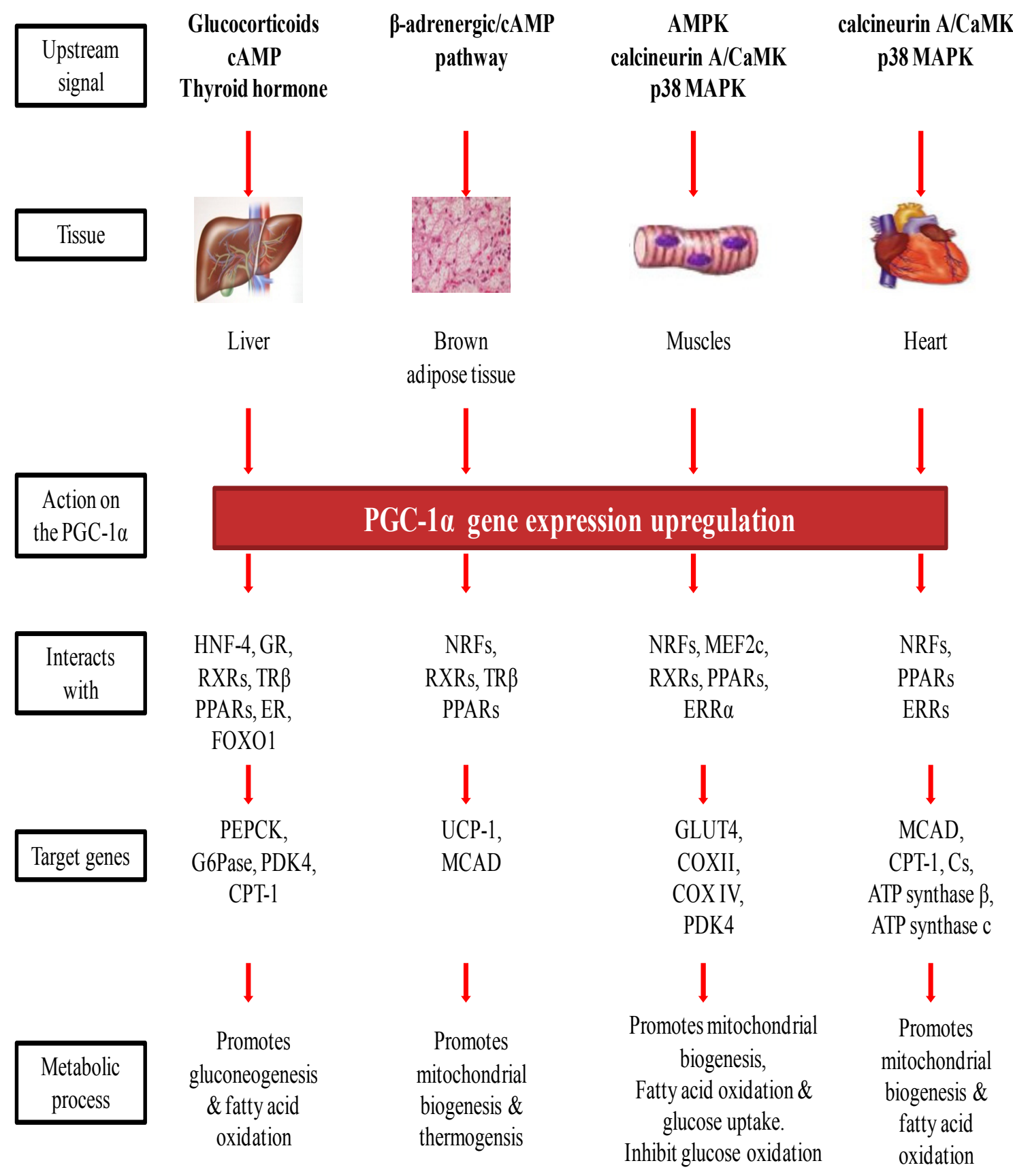

Figure 1.2: The upstream signaling events and downstream gene regulatory actions for the PGC-1 $\alpha$ coactivator in different body tissues.

The schematic indicates the upstream signaling events and downstream gene regulatory cascade for the actions of the PGC-1 $\alpha$ coactivator in different tissues. Interaction of PGC-1 $\alpha$ with its cognate transcription factor targets is shown linked to specific organ systems, together the target genes regulated and the altered metabolic process due to this regulation. 
expressed in liver, intestine, lung and adipose tissue.C/EBP $\beta$ is also detectable in kidney, heart, and spleen by Northern analysis in the mouse (Cao et al., 1991). On the other hand, $\mathrm{C} / \mathrm{EBP} \varepsilon$ is expressed only in myeloid and lymphoid lineages. Finally, $\mathrm{C} / \mathrm{EBP} \gamma$ and $\mathrm{C} / \mathrm{EBP} \zeta$ are expressed ubiquitously (Lekstrom-Himes \& Xanthopoulos, 1998).

It is noteworthy that C/EBPs can bind to the DNA as homodimers or as heterodimers with other transcription factors (Schrem et al., 2004). Previous studies had demonstrated the ability of the C/EBP family to form hetrodimers with members of the cAMP-responsive-element-binding protein/ activating transcription factor (CREB/ATF) family of transcription factors especially ATF-2 and C/ATF (Fawcett et al., 1999; Shuman et al., 1997; Vallejo et al., 1993). C/EBP-ATF heterodimers bind to selective DNA sequences that are uniquely different than that for the $\mathrm{C} / \mathrm{EBP}$ and $\mathrm{ATF}$ homodimers, as the $\mathrm{C} / \mathrm{EBP}-\mathrm{ATF}$ heterodimers bind to a so-called $\mathrm{C} / \mathrm{EBP}-\mathrm{ATF}$ composite site in the promoter region of regulated genes. $\mathrm{C} / \mathrm{ATF}-\mathrm{C} / \mathrm{EBP} \beta$ heterodimers bind to a subclass of asymmetric cAMP response elements exemplified by those in the phosphoenolpyruvate carboxykinase and proenkephalin genes (Vallejo et al., 1993).

C/EBP $\beta$ expression is highly induced by lipopolysaccharide (LPS), IL-6, IL-1, dexamethasone, and glucagon, suggesting a role in the mediation of the inflammatory response (Alam et al., 1992; An et al., 1996; Matsuno et al., 1996). In adipose tissue, $\mathrm{C} / \mathrm{EBP} \beta$ is involved in the transcription of fat-specific genes (Christy et al., 1989; Yeh et al., 1995) and participates in the differentiation of pre-adipocytes (Bezy et al., 2007; Hamm et al., 2001). In addition, C/EBP $\beta$ regulates carbohydrate and lipid metabolism through binding and activating a variety of genes encoding key metabolic enzymes including, but not limited to, phosphoenolpyruvate carboxykinase (PEPCK) and tyrosine aminotransferase (Garlatti et al., 1993; Park et al., 1990; Park et al., 1999; Wang et al., 1996), fatty acid synthesis enzyme acetyl-CoA carboxylase (Tae et al., 1994) and the albumin gene (Friedman et al., 1989).

Several hormones including insulin, glucocorticoids and thyroid hormone regulate the transcription of the $\mathrm{C} / \mathrm{EBP} \beta$ and through this regulation they further control the expression of gluconeogenic genes (Duong et al., 2002; Ghosh et al., 2001; Menendez-Hurtado et al., 1997; Park et al., 1999). However, the most relevant point regarding this dissertation is the effect of thyroid hormone on the expression of $\mathrm{C} / \mathrm{EBP} \beta$ that had been reported by Menendez-Hurtado (Menendez-Hurtado et al., 1997). He found that during development, congenital hypothyroidism caused a significant decrease in both $\mathrm{C} / \mathrm{EBP} \alpha$ and $\mathrm{C} / \mathrm{EBP} \beta$ gene expression at early stages of postnatal development in liver (Menendez-Hurtado et al., 1997). This effect was tissue-specific since thyroid hormone had no effect on both C/EBPs mRNA levels in brown fat. Upon injection of those hypothyroid animals with thyroid hormone, there was a slow recovery of hepatic $\mathrm{C} / \mathrm{EBP} \alpha$ and $\mathrm{C} / \mathrm{EBP} \beta$ mRNA levels. Also, hypothyroid neonates had shown diminished $\mathrm{C} / \mathrm{EBP} \alpha$ and $\mathrm{C} / \mathrm{EBP} \beta$ protein levels, and the kinetics of induction of these proteins by thyroid hormone was faster than the one observed for the corresponding transcripts suggesting a translational or post-translational regulation of these genes as the major component of 
thyroid hormone action on these proteins (Menendez-Hurtado et al., 1997). Also, studies from our lab had linked C/EBP $\beta$ with the induction of PEPCK by thyroid hormone (Park et al., 1999). These information led us to investigate the role of $\mathrm{C} / \mathrm{EBP} \beta$ in induction of another important metabolic gene, the PDK4, by thyroid hormone.

\subsection{Pyruvate dehydrogenase kinase 4 (PDK4)}

\subsubsection{General biology}

The pyruvate dehydrogenase complex (PDC) catalyzes the irreversible oxidative decarboxylation of pyruvate into acetyl-CoA. This reaction links the utilization of glycogen, glucose, and lactate with the citric acid cycle as well as fatty acid oxidation and synthesis, since acteyl-CoA can be used for fatty acid and cholesterol synthesis in the liver and fatty acid synthesis in adipose tissue. Prolonged fasting or high fat diets inactivate the PDC in order to minimize loss of pyruvate carbon to conserve it for maintaining the blood glucose levels needed through gluconeogensis. Another important reason for inactivating the PDC is to promote the usage of fatty acids as their primary energy source in as many tissues as possible. This in turn conserves body protein because amino acids are not oxidized for energy and less amino acid carbon has to be used for glucose synthesis (Randle, 1986; Sugden et al., 2001b).

All these observations indicate that regulating PDC is an important step in fuel selection for energy production in animals during different nutritional and hormonal states. Thus, the regulation of PDC is critical in glucose and fatty acids metabolism. PDC is regulated by the reversible phosphorylation reaction. Pyruvate dehydrogenase kinase (PDK) inactivates PDC by phosphorylation and pyruvate dehydrogenase phosphatase (PDP) activates PDC by dephosphorylation. Figure 1.3 illustrates the role of the PDK and PDP genes in the overall regulation process of the PDC activity (Sugden \& Holness, 2003).

\subsubsection{The role of the PDK in the regulation of the PDC}

The mammalian pyruvate dehydrogenase complex is composed of three components: Pyruvate dehydrogenase (E1), the dihydrolipoamide acetyltransferase subunits (E2) and the dihydrolipoamide dehydrogenase (E3). E2 forms the core of the complex, while E1 is the enzyme responsible for decarboxylation of pyruvate. E1 binds noncovalently to an E1-binding domain on E2 as heterotetrameric $\alpha_{2} \beta_{2}$ structure. E3 is the enzyme responsible for oxidation of the reduced lipoyl groups of E2 and the subsequent production of NADH, and it binds to the complex by the E3-binding protein (E3BP), as twelve E3-binding proteins anchor 12 E3 homodimers to each pyruvate dehydrogenase complex. Thus, each pyruvate dehydrogenase complex is composed of 216 subunits (60 E2, $60 \mathrm{E} 1 \alpha, 60 \mathrm{E} 1 \beta, 12 \mathrm{E} 3 \mathrm{BP}$, and $24 \mathrm{E} 3$ ) that sum up to about $9.5 \mathrm{MD}$ (Harris et al., 2002). 


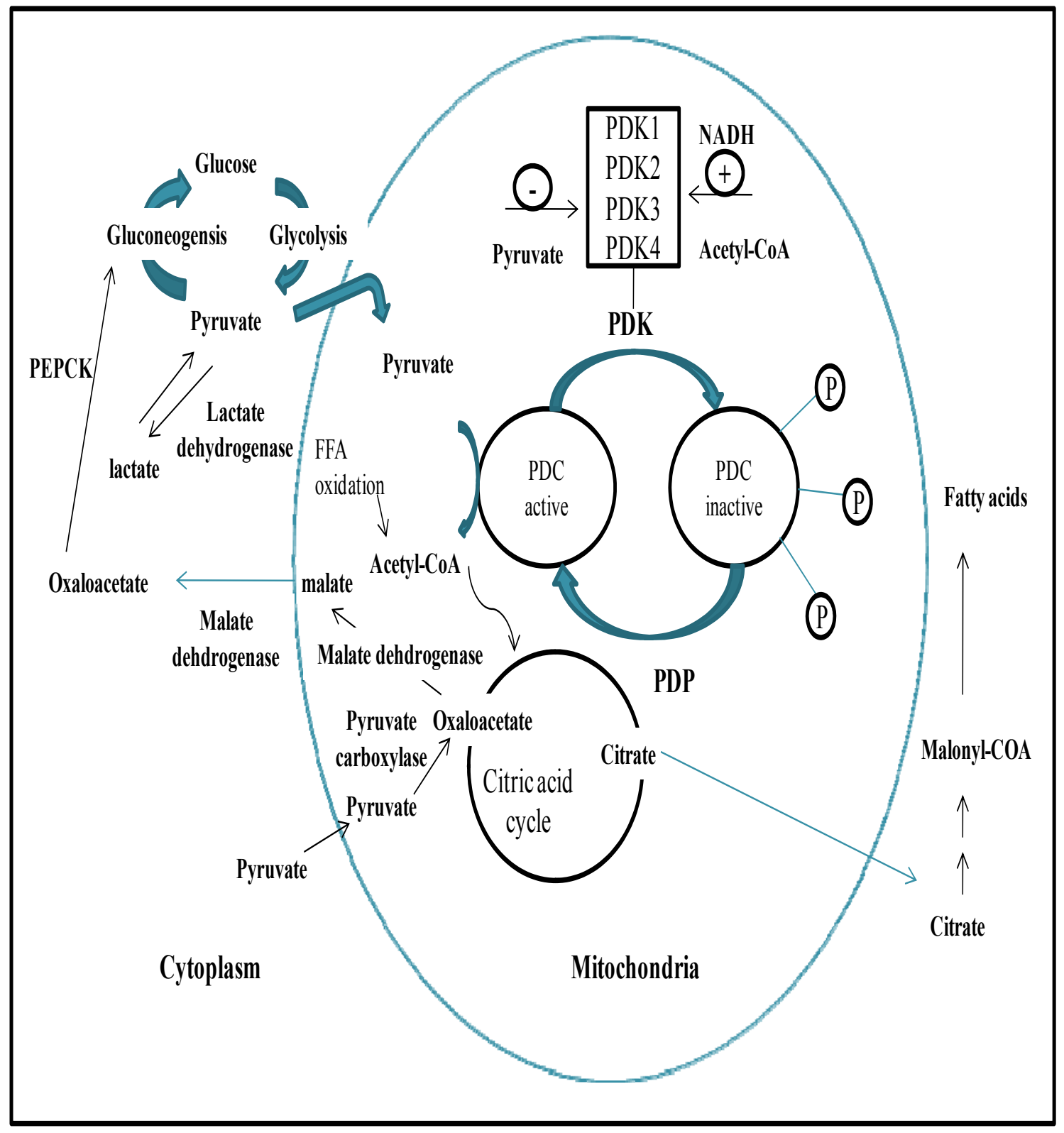

Figure 1.3: The role of the PDK and PDP in the regulation process of the PDC and the related metabolic processes.

PDC catalyzes the irreversible oxidative decarboxylation of pyruvate into acetyl-CoA. The PDC is regulated by the reversible phosphorylation reaction. Pyruvate dehydrogenase kinase (PDK) inactivates PDC by phosphorylation and pyruvate dehydrogenase phosphatase (PDP) activates PDC by dephosphorylation. The regulation of the PDC links with the glucose and fatty acid metabolism. NADH, nicotinamide adenine dinucleotide hydride; FFA, free fatty acids; PDP, pyruvate dehydrogenase; PEPCK; phosphoenolpyruvate carboxykinase. 
Although PDC activity is directly inhibited by the acetyl-CoA and NADH, the two byproducts of fatty acid and pyruvate oxidation, covalent modification of the PDC at the serine residues appears to be more important for regulating the PDC activity (Harris et al., 2002). Two regulatory enzymes are involved in this covalent modification, the PDK which inactivates the PDC through phosphorylation and the PDP which activate the PDC through dephosphorylation. Four PDK isoenzymes (PDK1, PDK2, PDK3 and PDK4) and two PDP isoenzymes (PDP1 and PDP2) are expressed in mammals (BowkerKinley et al., 1998; Huang et al., 1998). The phosphorylation and the dephosphorylation occur at three serine residues number 203, 264 and 271 on the $\alpha$-subunit of the E1 element of the PDC (Harris et al., 2002; Sugden \& Holness, 2003).

\subsubsection{PDK gene expression}

PDK consists of two subunits, the catalytically active $\alpha$-subunit and the regulatory $\beta$-subunit. Four isoenzymes of PDK have been identified in mammalian tissues (PDK1, PDK2, PDK3 and PDK4) (Bowker-Kinley et al., 1998; Kwon \& Harris, 2004; Rowles et al., 1996). The primary structure of PDK was determined for the first time by isolating a cDNA encoding a 48-kDa form of PDK, later termed PDK from a rat heart cDNA library (Popov et al., 1993). Based on analysis of the deduced amino acid sequences and crystal structures studies, it had been suggested that PDK does not belong to the eukaryotic serine/threonine protein kinases but rather it resembles the prokaryotic histidine protein kinases. Therefore, it had been assigned to the ATPase/kinase superfamily (composed of bacterial histidine protein kinases, DNA gyrases, and molecular chaperone Hsp90) (Bowker-Kinley et al., 1998; Popov et al., 1993; Steussy et al., 2001).

There is $66-74 \%$ homology in the primary structures between the four PDK isoenzymes: PDK3 and PDK4 are the most distinct and PDK1 and PDK2 the most conserved (Popov et al., 1994). Each PDK isoform is extremely similar in sequence between species, and PDK1 and PDK2 are $>95 \%$ identical between rat and human (Sugden \& Holness, 2003). The PDK2, PDK3, and PDK4 share the same molecular weight which corresponds to a 45-kDa, while only PDK1 has molecular weight of 48 KDa (Sugden \& Holness, 2003).

The mammalian PDK isoenzymes exhibit tissue-specific expression patterns (Bowker-Kinley et al., 1998). PDK1 expression has been detected in heart (Sugden et al., 2000b; Wu et al., 1998), the pancreatic islet (Sugden et al., 2001a) and skeletal muscle (Peters et al., 2001). PDK2 is expressed ubiquitously with particularly high expression in heart, liver, and kidney (Bowker-Kinley et al., 1998), while PDK3 is expressed in testis, kidney and brain (Huang et al., 1998). Finally, PDK4 is highly expressed in several tissues, including heart (Sugden et al., 2000b; Wu et al., 1998), skeletal muscle (Holness et al., 2002; Holness et al., 2000; Peters et al., 2001), liver (Holness et al., 2003; Sugden et al., 2002), kidney (Bowker-Kinley et al., 1998; Sugden et al., 2001b) and the pancreatic islet (Sugden et al., 2001a). 
PDK isoenzymes show different kinetic parameters for phosphorylation site specificity in the regulation of PDC activity. As I mentioned before, the phosphorylation of $\alpha$-subunit of the E1 element of the PDC, occurs at three specific serine residues, serine-264 (designated phosphorylation site 1), serine-271 (phosphorylation site 2) and serine-203 (phosphorylation site 3) (Harris et al., 2002; Holness \& Sugden, 2003; Sugden \& Holness, 2003). PDC can be inactivated by phosphorylation of each site alone, although phosphorylation of site 1 is most rapid and site 3 phosphorylation least rapid. All four PDKs exhibit higher activity towards site 1 of free E1 compared with sites 2 and 3. PDK2 exhibits the highest activity and PDK3 the lowest activity towards site 1 . Hence, PDK2 activity may account for much of the short-term inhibition of PDC observed on the transition from the fed to the fasted state through phosphorylation of site 1. PDK4 exhibits a much higher activity towards site 2 compared with PDK1, PDK2 and PDK3 (Korotchkina \& Patel, 2001). All four PDKs can phosphorylate sites 1 and 2, but site 3 can be phosphorylated only by PDK1, this was demonstrated using recombinant mutant proteins of the E1 element of the PDC with a single functional phosphorylation site (Kolobova et al., 2001; Korotchkina \& Patel, 2001).

\subsubsection{The role of the PDK4 gene in metabolic processes}

PDK4 is expressed in heart, skeletal muscle, liver, kidney and in the pancreatic islets. PDK4 is involved in the regulation of different metabolic processes within these tissues. In heart for example, Harris et al reported marked increase in the abundance of the PDK4 mRNA and protein in the hearts of rats that had been starved or rendered diabetic with streptozotocin ( $\mathrm{Wu}$ et al., 1998). Re-feeding of starved rats and insulin treatment of diabetic rats very effectively reversed the increase in PDK4 protein, mRNA levels and restored PDK enzyme activity to levels of chow-fed control rats. On the other hand, little or no change in the amounts of PDK1 and PDK2 protein and the abundance of their messages occurred in response to starvation and diabetes, indicating that control of the amount of PDK4 is important in long-term regulation of the activity of the pyruvate dehydrogenase complex in rat heart (Wu et al., 1998). Also, Mary Sugden reported that hyperthyroidism and high fat feeding induced the expression of the PDK4 in hearts of rats (Sugden et al., 2000b), while in liver high-fat feeding increased hepatic PDK2, but not PDK4, protein expression whereas hyperthyroidism increased both hepatic PDK2 and PDK4 protein expression (Holness et al., 2003). However, Huang et al reported that free fatty acids are effective inducers of PDK4 expression in $7800 \mathrm{C} 1$ hepatoma cells (Huang et al., 2002). Finally, high fat diets also induced the mRNA levels of the PDK4 gene in skeletal muscle (Sparks et al., 2006). In addition, starvation induced the PDK4 gene expression on both the RNA and protein levels not only in heart but in different mammalian tissues including liver and kidney (Wu et al., 2000). All these facts suggest that PDK4 may be the most important means of regulation of PDC activity during starvation and in diet-induced obesity.

Therefore, PDK4 is involved in the regulation of glucose synthesis and fatty acid oxidation as PDK4 upregulation during starvation may participate in directing available pyruvate toward oxaloacetate formation in liver and kidney or to the lactate output rather 
than oxidation in case of skeltelatl muscle, with subsequent use for glucose synthesis for entry into the gluconeogenic pathway and glucose synthesis (Sparks et al., 2006; Sugden \& Holness, 2002, 2003; Sugden et al., 2000a). Indeed, blood concentrations of glucose, lactate, pyruvate, and alanine are low in PDK4-knockout $\left(\mathrm{PDK}^{-1}\right)$ mice in the starved state (Jeoung et al., 2006), consistent with an important role for PDK4 in maintaining glucose levels during starvation. In addition, a recent PDK $4^{-/-}$mice model showed lower fasting blood glucose levels, a slightly improved glucose tolerance, and slightly greater insulin sensitivity compared with wild-type mice (Jeoung \& Harris, 2008). In the same time, these PDK $4^{--}$mice have elevated levels of nonesterified fatty acids, ketone bodies, and branched-chain amino acids, consistent with slower rates of fatty acid oxidation.

Several transcription factors and coactivators have been implicated in the regulation of the PDK4 gene expression and its downstream metabolic processes. Activation of PPAR $\alpha$ in vivo enhances hepatic and renal PDK4 protein expression in the fed state promoting fatty acid oxidation (Huang et al., 2002; Sugden et al., 2001c). Furthermore, the upregulation of hepatic and renal PDK4 protein expression normally evoked in response to prolonged starvation is attenuated in PPAR $\alpha$-deficient mice (Sugden et al., 2001b; Sugden et al., 2002). In contrast, skeletal muscle PDK4 gene expression is suppressed by treatment of insulin-resistant rats with PPAR agonists, promoting lipid entrapment in adipose tissue (Way et al., 2001). Interestingly, the transcriptional coactivator PGC-1 $\alpha$ that is in the core of this dissertation coactivates PDK4 gene expression via the orphan nuclear receptor ERR $\alpha$, exerting reciprocal inhibitory influences on glucose catabolism while increasing alternate mitochondrial oxidative pathways in skeletal muscle (Wende et al., 2005). In addition, recent studies have also shown that the forkhead transcription factor FOXO1 and the glucocorticoid receptor (GR), two additional potential PGC-1 $\alpha$ partners, directly regulate PDK4 expression through consensus binding sites in the PDK4 gene promoter (Furuyama et al., 2003; Kwon et al., 2004). 


\section{CHAPTER 2: RESEARCH OBJECTIVES AND SPECIFIC AIMS}

\subsection{Research objectives}

\subsubsection{Characterize the regulation of PDK4 gene by thyroid hormone}

Thyroid hormone (T3) is a key regulator of several processes including development, differentiation and metabolic balance. Among its cellular metabolic effects is the stimulation of fatty acid oxidation which is accompanied by a reduction in glucose utilization. This particular effect can be explained, in part, by the ability of T3 to induce the hepatic pyruvate dehydrogenase kinase (PDK4) gene expression. PDK4 suppresses glucose oxidation by its inhibitory effect on the pyruvate dehydrogenase complex (PDC) leading to an increase in fatty acid oxidation. T3 mediates its effect on gene expression of other genes through binding to a thyroid hormone receptor which is a nuclear receptor bound to the thyroid hormone response elements (TRE), frequently found in the promoters of these target genes. Upon T3 binding to the thyroid hormone receptor, the receptor undergoes a conformational change and recruits transcriptional coregulators which facilitate the regulation of transcription by T3. Peroxisome proliferator-activated receptor gamma coactivator-1 (PGC-1) and the CCAAT/enhancer binding protein $(\mathrm{C} / \mathrm{EBP})$ are among these transcription coregulators. Previous studies in our lab have demonstrated that PGC- $1 \alpha$ and $\mathrm{C} / \mathrm{EBP} \beta$ are coactivators for the T3 induction of CPT-1a and PEPCK, respectively. In addition, the forkhead transcription factor (FOXO1) and the estrogen related receptor $\alpha(E R R \alpha)$ are involved in the transcription regulation of PDK4 and other metabolic genes.

The induction of PDK4 gene by T3 was already documented; however, the mechanism of this activation has not been investigated. Both, the TRE site in the promoter of the PDK4 gene, and the transcription coregulators or the accessory factors that are involved in this activation, have not been identified. Therefore, the first hypothesis is that T3 activates PDK4 gene expression directly through a TRE site or indirectly through the recruitment of transcription factors and accessory proteins or through both mechanisms. To address this hypothesis, I characterized the PDK4 gene promoter to locate a TRE site, and I also tested whether PGC- $1 \alpha$ and C/EBP $\beta$ participate in the T3 induction of the PDK4 gene. Also, the role of accessory factors as the ERR $\alpha$ and the FOXO1 in this induction was examined.

\subsubsection{Study the network of the transcription factors involved in the early response of hepatic metabolic genes to thyroid hormone}

Thyroid hormone regulates the expression of key metabolic genes including phosphoenolpyruvate carboxykinase (PEPCK), carnitine palmitoyltransferase 1a (CPT1a), apolipoprotein B (ApoB) and uncoupling protein 3 (UCP3). However, the detailed regulation of these genes is not fully understood. Moreover, previous studies 
demonstrated that T3 elevates the abundance of many transcription factors and coactivators associated with mitochondrial biogenesis and lipid metabolism, such as PGC-1 $\alpha$, ERR $\alpha$ and lipins. Therefore, the second hypothesis is that T3 stimulates metabolism in part by increasing a network of transcription factors that induce metabolic genes which may not contain a TRE site within their promoters. To address this hypothesis, I have examined the effect of treating primary hepatocytes with T3 for 24 hours on 90 transcription factors and metabolic genes using superarray ${ }^{\circledR}$ real time PCR technology.

\subsection{Specific aims}

The following are the specific aims for this dissertation:

- SPECIFIC AIM 1: To characterize regulation of PDK4 gene by thyroid hormone.

- SPECIFIC AIM 2: To determine if T3 elevates expression of transcription factors involved in the regulation of metabolic genes. 


\section{CHAPTER 3: RESULTS AND EXPERIMENTAL PROCEDURES}

\subsection{Results}

\subsubsection{Identifying thyroid response elements (TREs) sites within the rPDK4 gene promoter}

Transcription of the PDK4 gene in the liver is induced by T3 in hyperthyroid rats (Sugden et al., 1996). However, the position of the TRE within the rPDK4 gene had not been determined. Therefore, the initial experiments were designed to localize and confirm the region in the rPDK4 promoter required for inducing rPDK4 transcription by T3. To localize a TRE in the PDK4 gene, I cotransfected HepG2 cells with rPDK4luciferase reporter constructs and an expression vector for TRß. First, I tested serial deletions of the PDK4 promoter driving the luciferase reporter. Deletion of the 283 nucleotides between -1256 to -973 of the rPDK4 promoter abolished T3 responsiveness from $5.1 \pm 0.4$ fold induction of the $-1256 /+78$ rPDK4 luciferase vector to $0.8 \pm 0.1$ with the $-973 /+78$ rPDK4 luciferase vector (Figure 3.1A). The results are expressed as the relative induction by $\mathrm{T} 3 \pm \mathrm{S}$.E. by comparing the $\mathrm{T} 3$ induction of vectors in the $\mathrm{T} 3$ treated cells to the non-treated ones. These data suggested that there was a TRE in this region of the PDK4 promoter. I identified two potential TREs sites within this region of the rPDK4 promoter. These TREs resemble the well established putative consensus hexamer half-site sequence $[(\mathrm{G} / \mathrm{A}) \mathrm{GGT}(\mathrm{C} / \mathrm{G}) \mathrm{A}]$ arranged as a direct repeat separated by four nucleotides (DR4) which is the optimal binding site for TR/RXR. The putative TREs are shown in Figure 3.1B together with a model of the rat PDK4 promoter identifying the binding sites for ERR $\alpha$, FOXO1 and PGC-1 $\alpha$.

I used site-directed mutagenesis of the PDK4 promoter to determine if either of these potential TREs was important for the T3 induction. I disrupted the TRE1 by changing the (GGT) in the second hexamer half site sequence into (AAC), and for the TRE2 I changed the (GG) in its second hexamer half site into (AA). Primers used to establish these mutations are listed in the experimental procedures section. To determine the effect of these mutations on the T3 responsiveness, I transfected HepG2 cells with the TRE1 mutant $-1256 /+78$, TRE2 mutant $-1256 /+78$ or the wild type $-1256 /+78$ and tested for T3 responsiveness by luciferase assays. TRE1 mutation caused a very significant reduction in the $\mathrm{T} 3$ responsiveness $(1.5 \pm 0.2$ fold, $60 \%$ less than the wild type $3.8 \pm 0.4$ fold, $\mathrm{p}=0.0019)$. On the other hand, the TRE2 mutation did not alter the T3 responsiveness $(4.4 \pm 1.4, \mathrm{p}=0.299)$ (Figure 3.1C).

To further confirm the role of TRE1 in the T3 induction of the rPDK4 gene promoter, we preformed an in vivo transfection into the livers of hyperthyroid rats (Figure 3.1D). This experiment was conducted in collaboration with Dr. Gene Ness lab in University of South Florida, and was performed by his graduate student Lindsey Boone. The $-1256 /+78$ rPDK4 luciferase vector wild type and the TRE1 mutant were transfected by electroporation into different spots of the same rat liver. 
Figure 3.1: Localization and identification of the $T 3$ responsive regions within the rPDK4 promoter that enhance $\mathrm{T} 3$ responsiveness.

A. HepG2 cells were transiently transfected with $2 \mu \mathrm{g}$ of different rPDK4 luciferase reporters, $1 \mu \mathrm{g}$ of RSV-TR $\beta$, and $0.1 \mu \mathrm{g}$ of TK-renilla. For hormone treatment, cells were incubated either in serum-free DMEM or DMEM containing $100 \mathrm{nM}$ T3 for $24 \mathrm{~h}$. All transfections were performed in duplicate and repeated three to six times. Luciferase and renilla assays were performed in the same tube. Luciferase activity was corrected for both protein content and renilla activity which served as a transfection control. Results are expressed as the relative induction by $\mathrm{T} 3 \pm \mathrm{S}$.E. by comparing the $\mathrm{T} 3$ induction of vectors in the treated cells to the non-treated ones. The significance is calculated in relative to the shortest construct of the rPDK4-luciferase $(-578 /+78)(* *=p$ value 0.001 to $0.01, * * *=$ $\mathrm{p}$ value $<0.001)$. B. A model of the rat PDK4 promoter is shown that contains the sites for the binding of the ERR $\alpha, \mathrm{FOXO} 1$ and PGC-1 $\alpha$, also the sequence of the region between -1256 to -973 for the rPDK4 promoter with underlined potential TREs. C. HepG2 cells were transiently transfected with $2 \mu \mathrm{g}$ of various $-1256 /+78$ rPDK4 constructs, $1 \mu \mathrm{g}$ of RSV-TR $\beta$, and $0.1 \mu \mathrm{g}$ of TK-renilla. For hormone treatment, cells were incubated either in serum-free DMEM or DMEM containing $100 \mathrm{nM} \mathrm{T} 3$ for $24 \mathrm{~h}$. All transfections were performed in duplicate and repeated three to six times. Luciferase assays were performed as described above. Results are expressed as the relative induction by $\mathrm{T} 3 \pm \mathrm{S}$.E. by comparing the $\mathrm{T} 3$ induction of vectors in the treated cells to the nontreated ones. The significance is calculated in relative to the wild type rPDK4 -1256/+78luciferase $(* *=\mathrm{p}$ value 0.001 to 0.01$)$. D. Hypothyroid rats were transfected in vivo by electroporation of liver as outlined in the experimental procedures section. The transfection included the $-1256 /+78$ wild type rPDK4-luciferase or the TRE1 mut rPDK4- luciferase plasmids. TK-renilla was included as a control. The hypothyroid rats were exposed to T3 three days before electroporation, with an additional half dose injection prior to the day of electroporation. The values are the average of four hypothyroid untreated rats and four T3 treated rats. 
A.

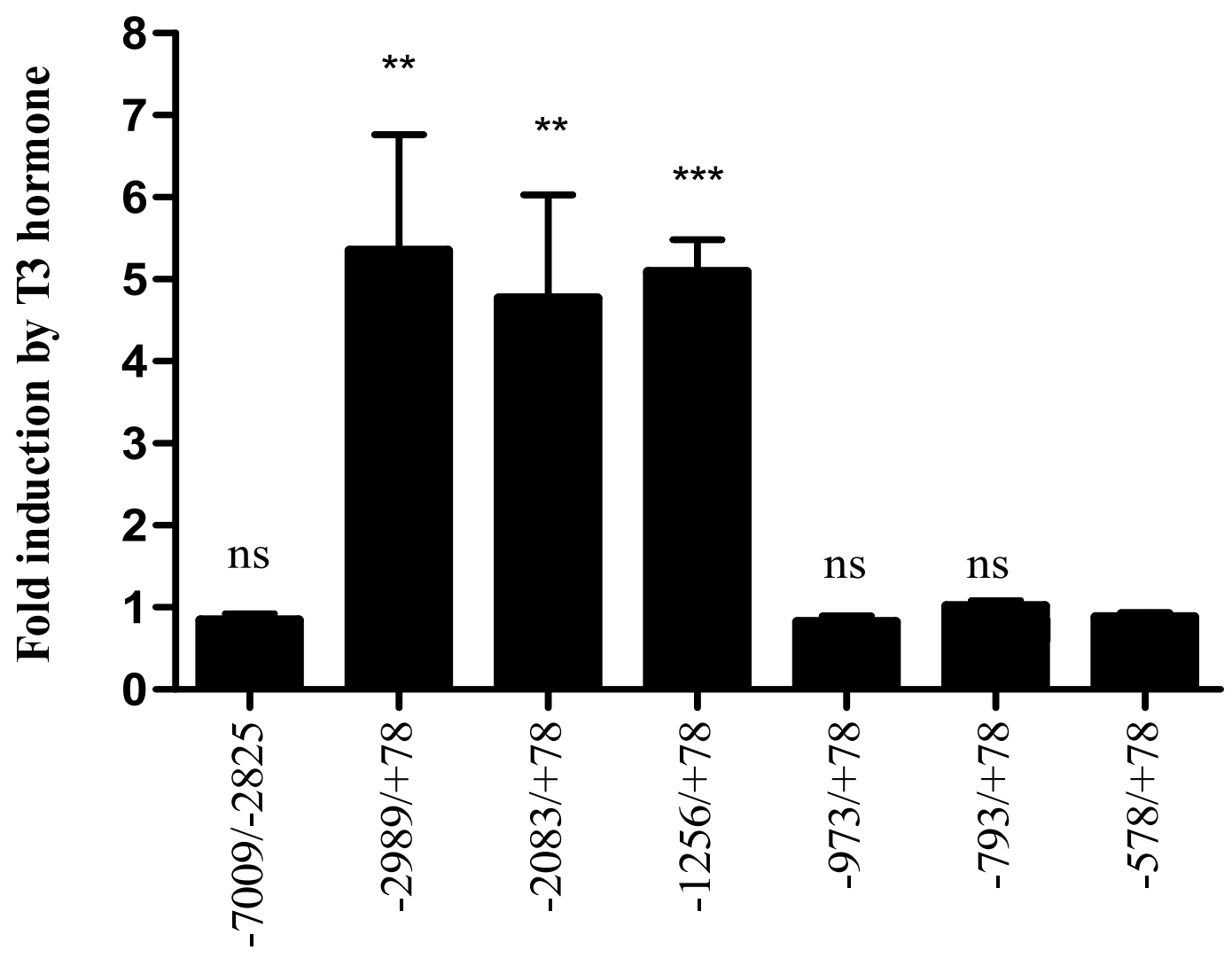

Different constructs of rat PDK4

B.

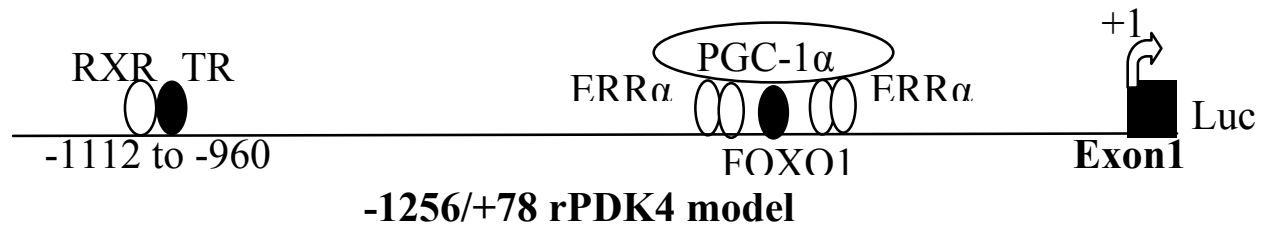

-1256 ggagcagagtttgcacgagagatagaaattagacatcagtcatgtgactaggttagctctcttaggggaa -1187

-1186 aaggcaaagtaagagtgcacctagggtcacccatgactttcatcacaccacatcctccttacatgcgagg -1117

TRE1 site

-1116 gctaagggcaccttgggtaacaaactgcctttgctgecttgttcccattccattccatttgcaaccgagtcgt -1044

TRE2 site

-1043 tatcattgtcccttatcaacagtccatttcgagtgaacagaagagcgagagaggttaggatgagagtttt $\quad-973$ 
C.

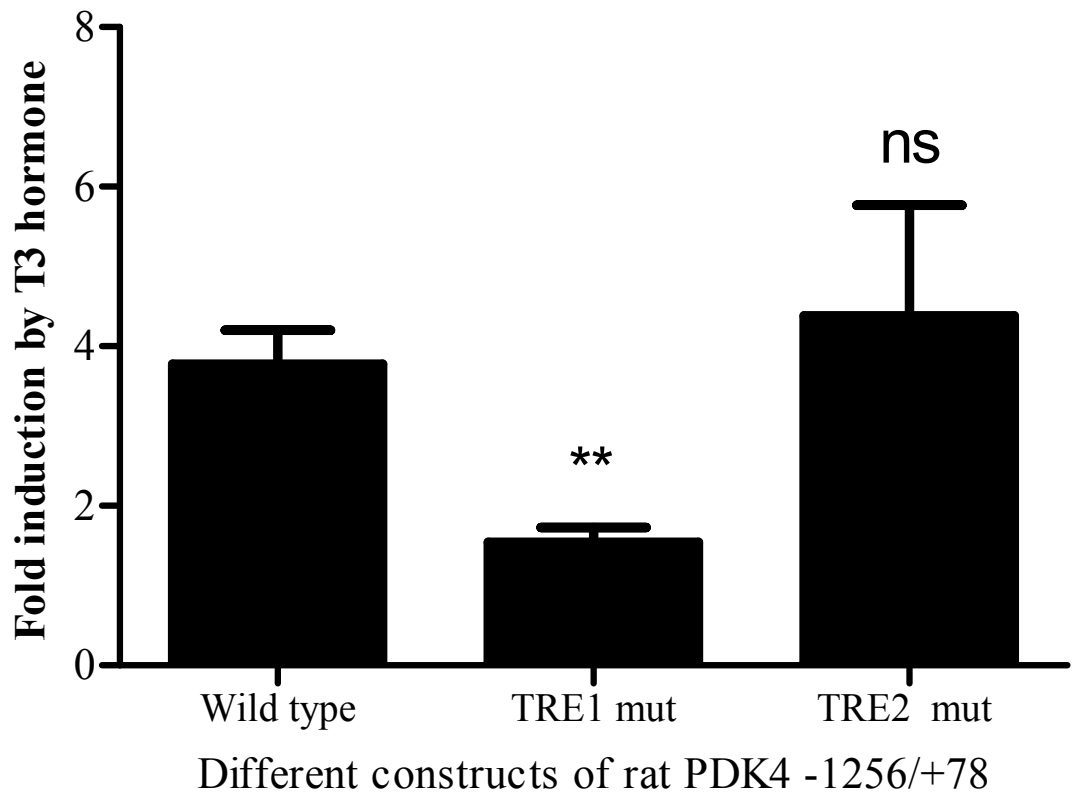

D.

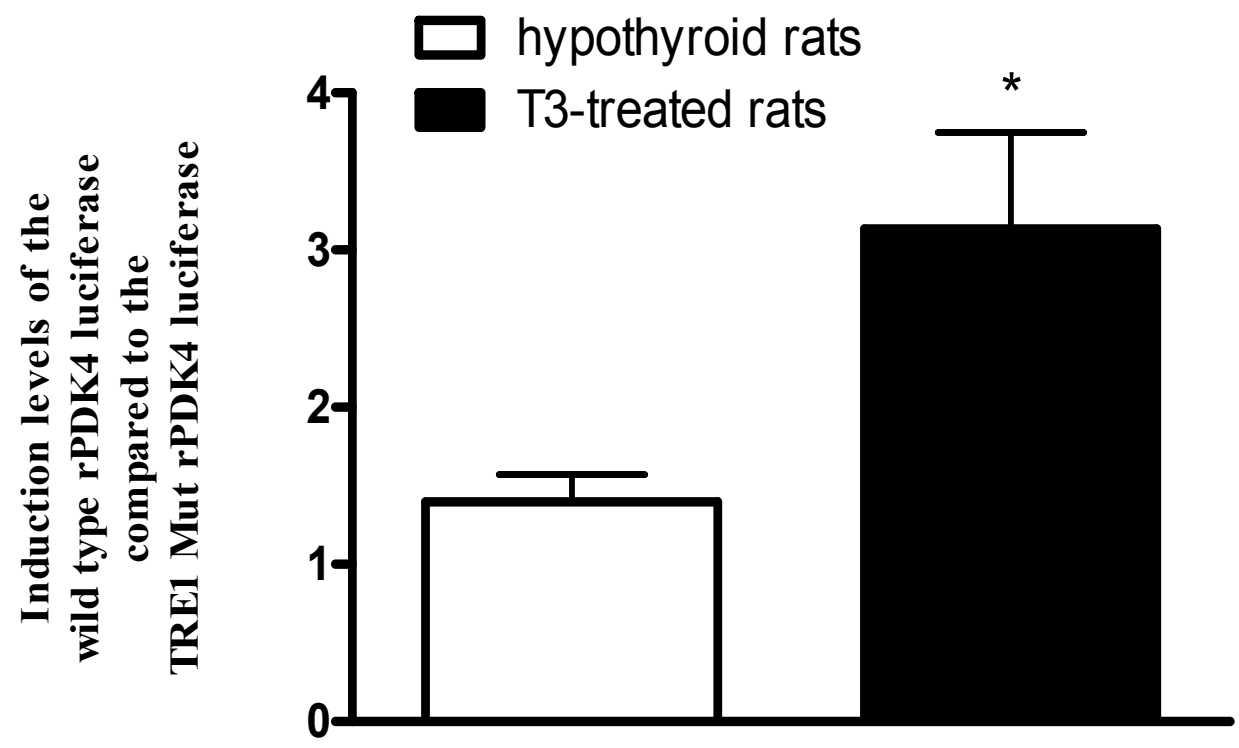

Figure 3.1: (continued). 
Four hypothyroid rats were treated with T3 for 3 days before electroporation; with an additional half dose injection the day prior to electroporation. Another hypothyroid four rats were left untreated. In rats with T3 treatment, the expression of the wild type $1256 /+78$ rPDK4 luciferase promoter increased significantly by $3.1 \pm 0.6$ fold $(p=0.01)$ in comparison to the mutant one, while in non-treated rats the induction of the wild type form was not significantly different than that of the mutant form being only $1.4 \pm 0.2$ fold (Figure 3.1D).

Finally, gel shift mobility assays were conducted with the wild type and the mutants oligomers for the TRE1 site to test the ability of the TR $\beta$ to bind this element in vitro. The results indicated that the TR $\beta$ can bind as a heterodimer with RXR to the wild type of the TRE1 site. However, TR $\beta$ did not bind the mutated TRE (Figure 3.2). The sequence of the oligomers used in this gel shift assays are indicated at the bottom of the panel.

These data prove that we had discovered a TRE site localized within the -1112 to -1096 region of the rPDK4 gene promoter, and that disruption of this site by site directed mutagenesis reduced the ability of the $\mathrm{T} 3$ to induce the rPDK4 gene.

\subsubsection{Association of the TR $\beta$, PGC-1 $\alpha$ and C/EBP $\beta$ with the PDK4 gene promoter in vivo}

Previous studies from our laboratory have implicated the involvement of both peroxisome proliferator activated receptor gamma coactivator-1 alpha (PGC-1 $\alpha$ ) and CCAAT/enhancer binding protein beta $(\mathrm{C} / \mathrm{EBP} \beta)$ in the activation of different metabolic genes including the CPT-1a and PEPCK (Park et al., 1999; Song et al., 2004; Zhang et al., 2004b). To determine whether TR $\beta$, PGC- $1 \alpha$ and C/EBP $\beta$ were associated with the PDK4 gene in vivo, we conducted ChIP assays (Figure 3.3). Rat primary hepatocytes were exposed to $100 \mathrm{nM} \mathrm{T3}$ for $24 \mathrm{~h}$ or left in serum-free media. We cross-linked the hepatocytes with $1 \%$ formaldehyde prior to conducting immunoprecipitations with the $\mathrm{TR} \beta$ or PGC- $1 \alpha$ or $\mathrm{C} / \mathrm{EBP} \beta$ antibodies. As a control, we used the immunoprecipitation with rabbit pre-immune serum. We created PCR primers sets for the proximal, the TRE region, and an upstream promoter region of the PDK4 gene, and they are listed in the experimental procedures section. The upstream region served as a negative control. The data from the ChIP assays indicated that prior to T3 treatment both TR $\beta$ and C/EBP $\beta$ are associated with the proximal and the promoter region of the PDK4 gene around the TRE site. However, they are not associated with the upstream region of the PDK4 gene and the addition of T3 to hepatocytes did not increase the association of TR $\beta$ and C/EBP $\beta$ with the proximal or the TRE region. On the other hand, the ChIP data show that prior to T3 treatment PGC-1 $\alpha$ can associate to the proximal region of the PDK4 gene promoter, and to a little extent to the TRE region of the promoter. Following treatment of hepatocytes with T3, the association of PGC- $1 \alpha$ with the proximal region of the PDK4 gene increased by $1.85 \pm 0.2$ fold but T3 did not increase its association with the TRE region of the promoter (Figure 3.3). The TR $\beta, \mathrm{C} / \mathrm{EBP} \beta$ and PGC- $1 \alpha$ were associated to different extents with both the proximal and the TRE regions of the PDK4 

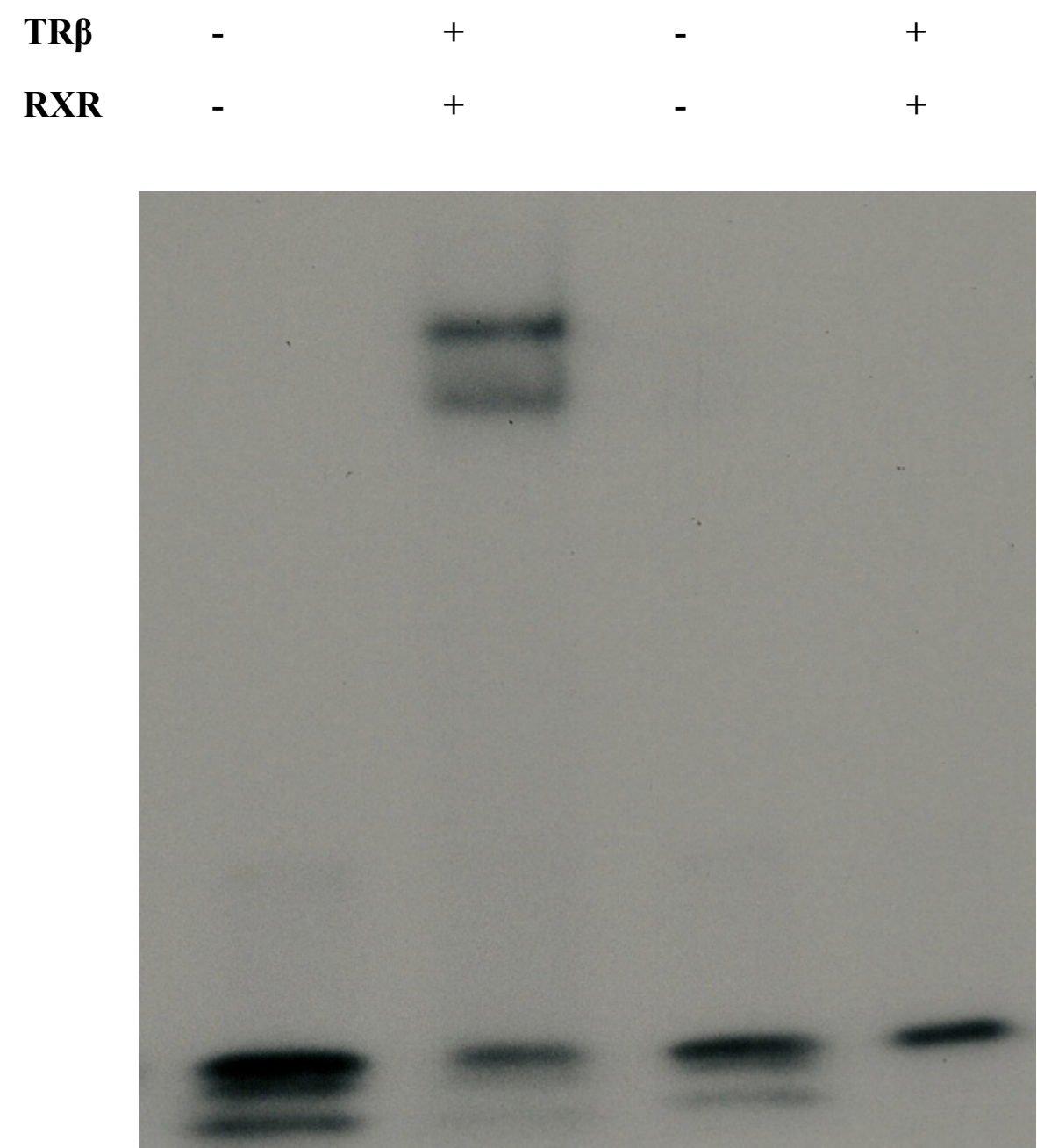

TRE1 Wild type

TRE1 Mutant

TRE1 WT top oligo TRE1 Mut top oligo
GGGCTAAGGGCACCTTGGGTAACAAA GGGCTAAGGGCACCTTGAACAACAAA

\section{Figure 3.2: TRß binding site in the rPDK4 promoter.}

A gel shift mobility assay was conducted as described in the experimental procedures section using the oligomers for the potential TRE1 site and its mutated version. The sequences for these oligomers are given below the gel shift with the mutated nucleotides shown in bold, and the sequence for the wild type TRE is underlined. 


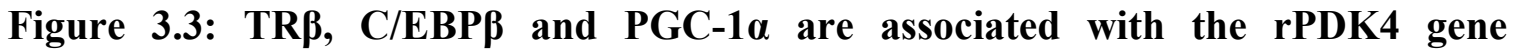
promoter in vivo.

A. Chromatin immunoprecipitation assays (ChIP) were conducted on primary rat hepatocytes. Hepatocytes were treated with 100nM thyroid hormone (T3) for 24 hours and then crossed linked with $1 \%$ formaldehyde as described in materials and methods. Antibodies to A. TR $\beta$, B. PGC- $1 \alpha$ and C. C/EBP $\beta$, or immunoglobin G (IgG) were used for immunoprecipitations. The amplified PCR products using primers for the proximal, The PDK4-TRE and upstream region of the rPDK4 gene were resolved on an agrose gel. D. The association of TR $\beta, \mathrm{C} / \mathrm{EBP} \beta$ and PGC- $1 \alpha$ with PDK4-TRE and proximal were quantified using quantity one software. These data are the average \pm SE of four independent ChIP assays ( $* *=p$ value 0.001 to 0.01 ). 


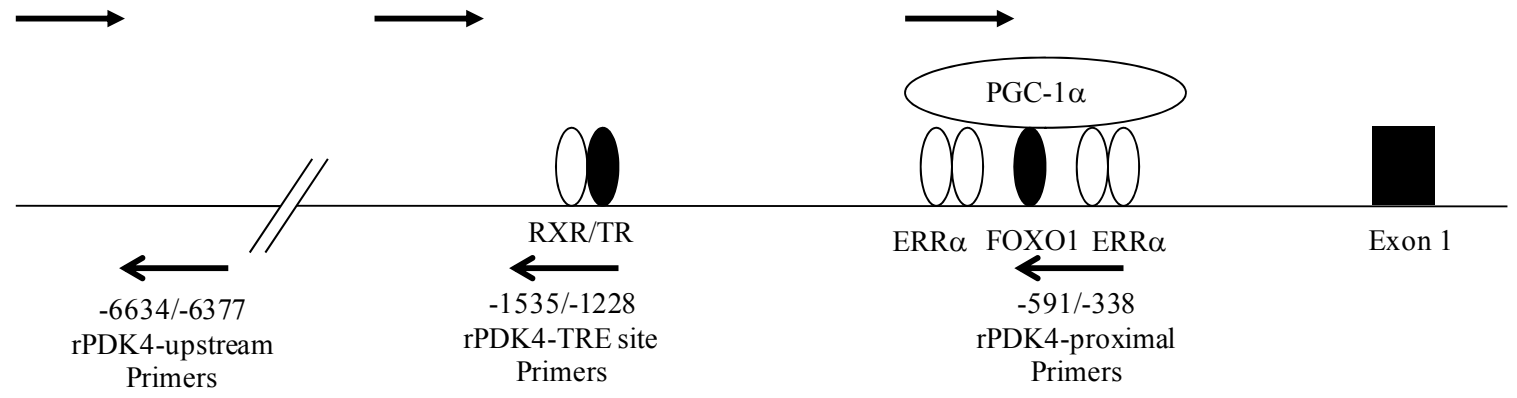

A.

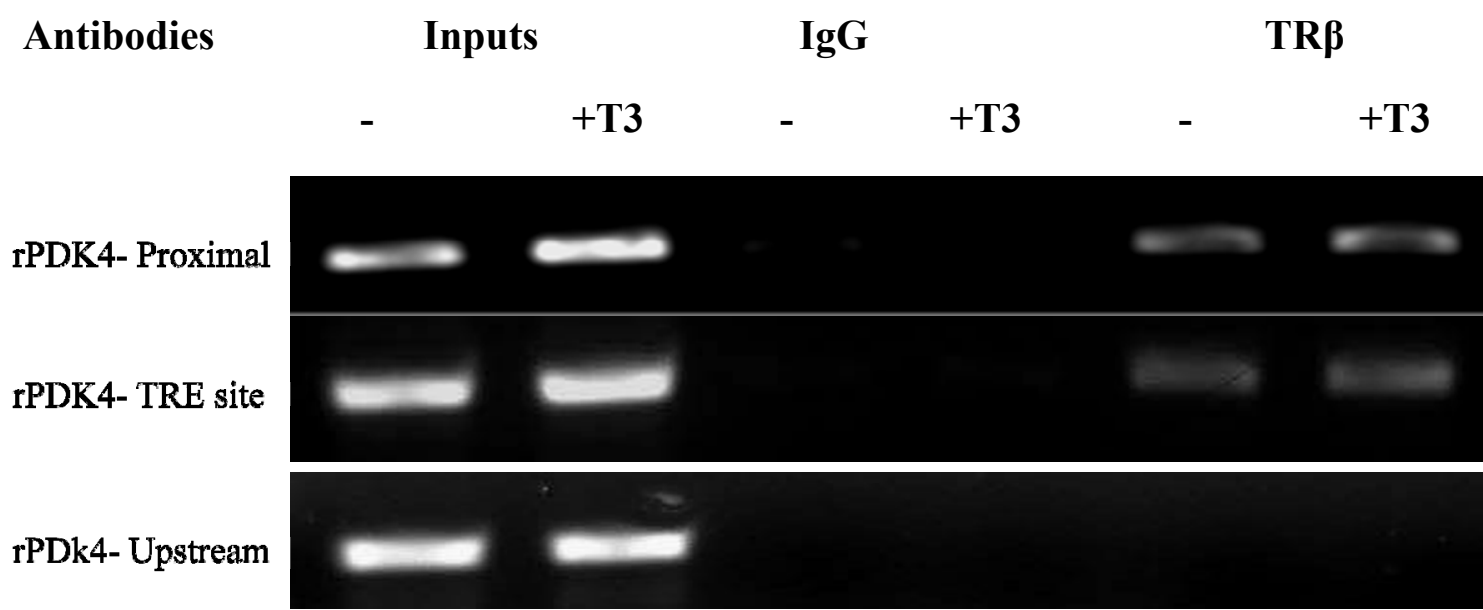

B.

Antibodies

Inputs

IgG

PGC-1 $\alpha$

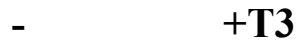

+T3

+T3

rPDK4- Proximal

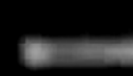

rPDK4- TRE site

rPDk4- Upstream

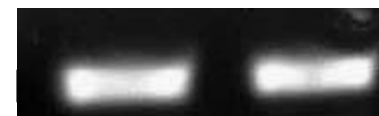


C.

Antibodies

Inputs

IgG

C/EBP及

$\begin{array}{lllll}+\mathrm{T} 3 & - & +\mathrm{T} 3 & - & +\mathrm{T} 3\end{array}$

rPDK4- Proximal

rPDK4- TRE site

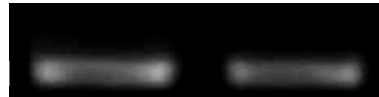

rPDk4- Upstream

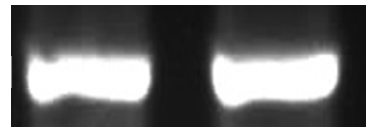

D.

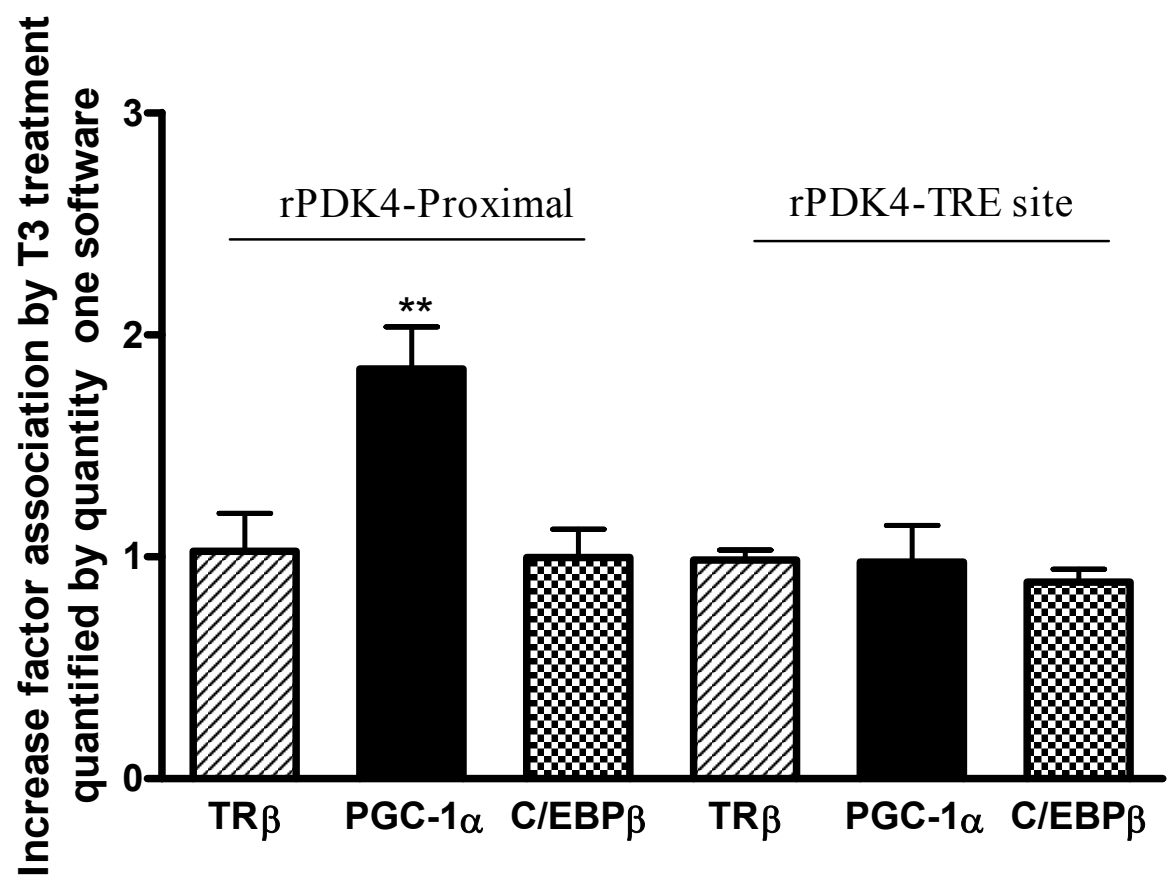

Figure 3.3: (continued). 
gene promoter but none of them were detected at the upstream control region of the PDK4 promoter. The data indicate that T3 through TR $\beta, \mathrm{C} / \mathrm{EBP} \beta$ and PGC-1 $\alpha$ can regulate the PDK4 transcription. This regulation may involve a looping of the proximal region of the promoter with its distal region that contains the TRE site.

\subsubsection{Thyroid hormone treatment increases the mRNA of both the PDK4 and PGC- $1 \alpha$ genes in primary rat hepatocytes.}

I examined the effect of thyroid hormone (T3) on the abundance of both PGC-1 $\alpha$ and PDK4 mRNA in primary rat hepatocytes. Primary rat hepatocytes were treated with $\mathrm{T} 3$ for $24 \mathrm{~h}$ and then RNA was isolated. The mRNA abundance was measured by real time PCR. Both the PGC- $1 \alpha$ and the PDK4 mRNA abundance were significantly increased $2.6 \pm 0.7$ fold and $2.2 \pm 0.3$ fold after T3 treatment in rat hepatocytes, respectively (Figure 3.4A). These data indicate that $\mathrm{T} 3$ can increase PGC- $1 \alpha$ mRNA abundance in the liver. However, previous studies from our laboratory showed that PGC$1 \alpha$ mRNA abundance did not change in heart after T3 treatment suggesting that T3 induces PGC-1 $\alpha$ in a tissue-specific manner (Zhang et al., 2004b). Next, I tested whether PGC-1 $\alpha$ and PDK4 protein abundance were increased in response to T3 administration in rat hepatocytes. Using Western analyses to assess PGC-1 $\alpha$ levels, we found that the PGC$1 \alpha$ and the PDK4 protein abundance were increased $2.2 \pm 0.2$ fold and $2 \pm 0.2$ fold in response to $\mathrm{T} 3$ treatment, respectively (Figure 3.4B). These experiments provide further confirmation that the PGC-1 $\alpha$ is a T3-responsive gene and supports our hypothesis that PGC- $1 \alpha$ is a coactivator in T3 action for the PDK4 gene.

\subsubsection{PGC-1 $\alpha$ enhances the thyroid hormone induction of the PDK4 gene and the role of the forkhead transcription factor (FOXO1) and the estrogen related receptor $\alpha(E R R \alpha)$ in this enhancement.}

In the next experiments I examined the ability of PGC- $1 \alpha$ to enhance the $\mathrm{T} 3$ induction of the PDK4 gene. I conducted co-transfections of pSV-PGC- $1 \alpha$ with the wild type $-1256 /+78$ rPDK4-luc or the forkhead transcription factor (FOXO1) mutant at position -347 or the estrogen related receptor $\alpha(E R R \alpha)$ mutants at positions -338 and 370 of the $-1256 /+78$ rPDK4-luc. Transfections were conducted in HepG2 hepatoma cells. Primers used to establish the mutations in the -1256/+78 rPDK4-luc are listed in the experimental procedures section. Addition of $100 \mathrm{nM}$ of $\mathrm{T} 3$ for 24 hours stimulated the wild type version of $-1256 /+78$ rPDK4-luc vector by $8.4 \pm 2$ fold. In these experiments, overexpression of PGC- $1 \alpha$ induced it by $4.3 \pm 0.7$ fold. When T3 was added in the presence of PGC-1 $\alpha$, I obtained a synergistic effect with $23.2 \pm 4$ fold induction. Also, when treating the -338 ERR $\alpha$ mutant, -370 ERR $\alpha$ mutant and -347 FOXO1 mutant versions of the rPDK4 -1256/+78 with T3 all of them showed luciferase induction by similar levels $7 \pm 1.2$ fold, $6.1 \pm 1.3$ fold and $7.1 \pm 0.7$ fold, respectively. However, the overexpression of PGC- $1 \alpha$ did not induce either of the ERR $\alpha$ mutants or induced the -347 FOXO1 mutant by $3.1 \pm 0.6$ fold only, which is still lower than the wild type $-1256 /+78$ induction. 
Figure 3.4: Thyroid hormone increases PDK4 and PGC-1 $\alpha$ mRNA and protein abundance in primary hepatocytes.

A. Primary rat hepatocytes were plated on collagen-coated plates for $16 \mathrm{~h}$. T3 was added at a concentration of $100 \mathrm{nM}$ to the hepatocytes for $24 \mathrm{~h}$. RNA was harvested, and the abundance of PDK 4 and PGC- $1 \alpha$ mRNA was determined by real time PCR. The data are presented as the fold induction of mRNA abundance by T3 (average \pm SE) from four independent hepatocytes preparations, and the control samples were assigned a relative value of 1 . B. The expression of the PDK4 and PGC- $1 \alpha$ proteins was monitored by Western blot analysis using specific antibodies (1: 1000, Santa Cruz). The data are presented as the fold induction of protein abundance by T3 (average \pm SE) from three independent hepatocytes preparations, and the control samples were assigned a relative value of $1(*=\mathrm{p}$ value 0.01 to $0.05, * *=\mathrm{p}$ value 0.001 to 0.01$)$. 
A.

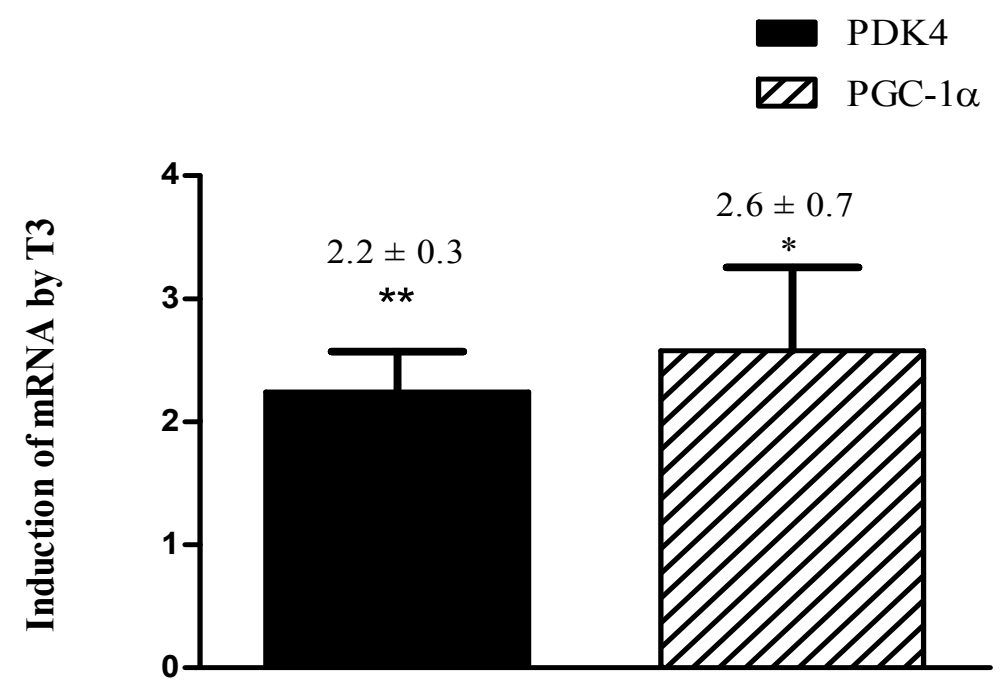

B.

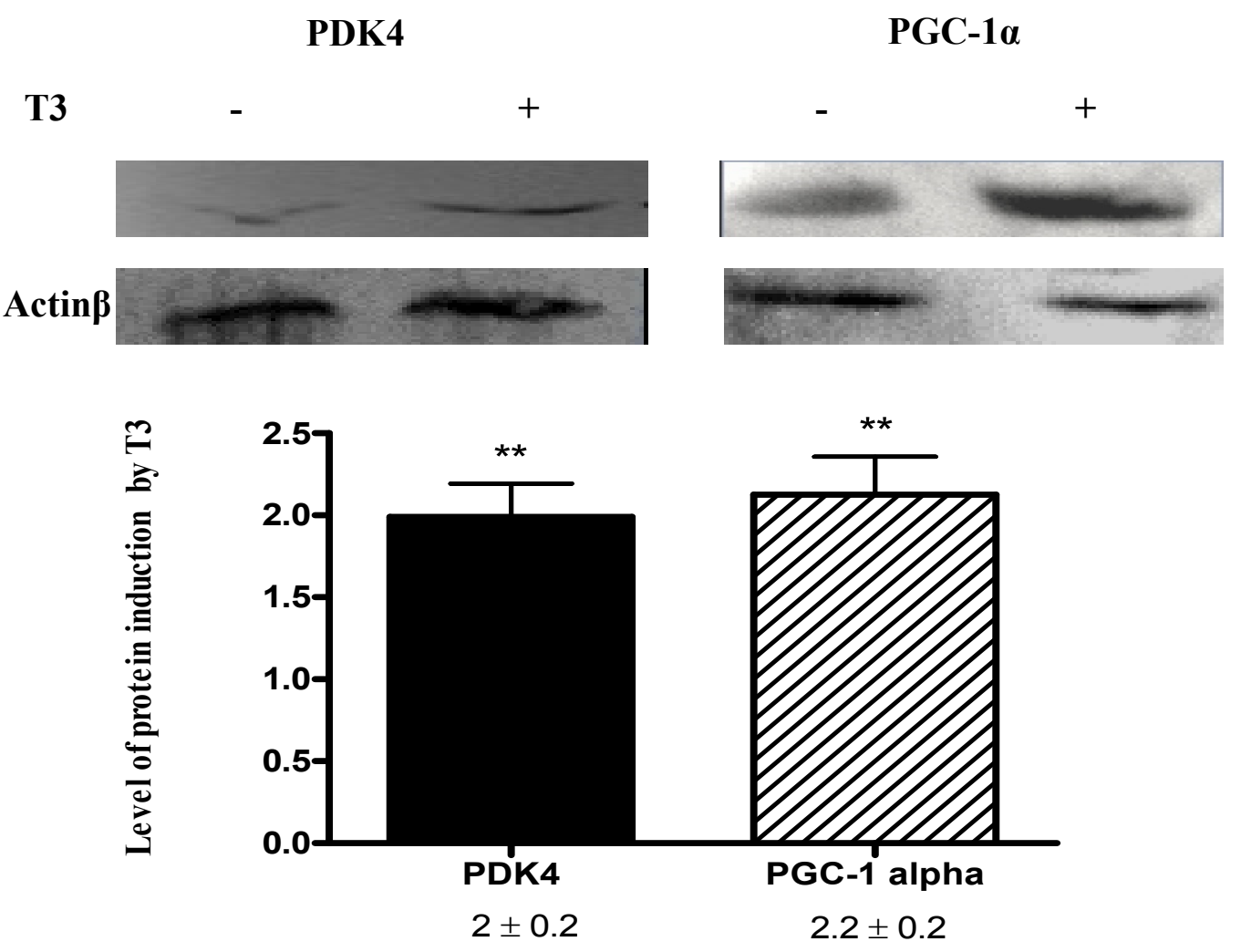


But astonishing, when T3 was added in the presence of PGC-1 $\alpha$, I still obtained a significant synergistic effect for all the mutants versions of the $-1256 /+78$ as follows: $15.5 \pm 3.5$ fold for the -338 ERR $\alpha$ mutant, $11.6 \pm 2$ fold for the -370 ERR $\alpha$ mutant and $20.1 \pm 4.4$ fold for the -347 FOXO1 mutant (Figure 3.5). These data indicate that PGC$1 \alpha$ stimulates PDK4 gene primarily through the -338 to -370 region of the rPDK4 promoter but, more importantly, that PGC- $1 \alpha$ can act as a coactivator for the T3 induction of the PDK4 gene either through binding to its elements in the -338 to -370 region or may be through interacting with the thyroid receptor itself. For this reason we still observed a significant synergistic effect with T3 addition even though I mutated both ERR $\alpha$ sites in the promoter and PGC-1 $\alpha$ alone by itself could not induce the PDK4 promoter. Supporting this concept are the ChIP data showing association of PGC-1 $\alpha$ with the rPDK4 TRE site Figure 3.3D. Moreover, previous studies had detected an interaction between the PGC- $1 \alpha$ and both the TR $\beta$ and RXR in vitro and in vivo (Delerive et al., 2002; Puigserver et al., 1998; Wu et al., 2002). To further confirm this possibility I used adenoviral delivery of shRNA specific for silencing the PGC-1 $\alpha$ in primary hepatocytes to see the effect of reduction in the PGC- $1 \alpha$ gene expression on the hepatic T3 induction of PDK4 gene as.

\subsubsection{Knocking down of the PGC-1 $\alpha$ in rat primary hepatocytes affects the ability of thyroid hormone to induce different metabolic genes.}

To test the role of the PGC-1 $\alpha$ in the T3 induction of hepatic metabolic gene expression, I infected rat primary hepatocytes with adenovirus encoding the shRNA to silence the PGC-1 $\alpha$ (Ad-siPGC-1 $\alpha$ ) for 16 hours prior to treatment of cells with T3 for additional 24 hours. Adenovirus encoding control shRNA that does not silence any rat genes was used as a control (Ad-NC). Ad-siPGC-1 $\alpha$ significantly knocked down the expression of PGC- $1 \alpha$ by $70 \%$ compared to the Ad-NC in hepatocytes non-treated with $\mathrm{T} 3(0.3 \pm 0.04$ fold relative to Ad-NC infected hepatocytes non treated with T3). In addition, the induction of PGC- $1 \alpha$ by $\mathrm{T} 3$ treatment was reduced in hepatocytes infected with Ad-siPGC- $1 \alpha(0.6 \pm 0.04$ fold relative to Ad-NC infected hepatocytes untreated with T3) in comparison to that infected with Ad-NC $(6.2 \pm 3$ relative to Ad-NC infected hepatocytes untreated with T3) (Figure 3.6A). The knock down of the PGC-1 $\alpha$ in primary hepatocytes was accompanied by inability of $\mathrm{T} 3$ to induced the expression of PDK4, CPT-1a, PEPCK and C/EBP $\beta$, while T3 had increased all these genes in hepatocytes infected with Ad-NC by $3.3 \pm 0.9$ fold, $3.9 \pm 1$ fold, $3.12 \pm 0.52$ fold, $1.7 \pm$ 0.35 fold, respectively (Figure 3.6B-E). This impairment of the T3 induction for these metabolic genes after PGC- $1 \alpha$ silencing indicates that PGC- $1 \alpha$ is an important coactivator in the $\mathrm{T} 3$ induction process of these genes in primary hepatocytes.

I have shown in this first part of the results chapter of this dissertation the ability of thyroid hormone to induce the PDK4 gene through a TRE and that PGC-1 $\alpha$ enhanced this induction. When PGC-1 $\alpha$ was completely silenced, thyroid hormone lost its ability to activate the PDK4 gene indicating that PGC- $1 \alpha$ is an important coactivator in this process. 


\section{Figure 3.5: PGC-1 $\alpha$ enhances the T3 induction of rPDK4 gene.}

HepG2 hepatoma cells were transiently transfected with $2 \mu \mathrm{g}$ of different rPDK4-Luc constructs, $1 \mu \mathrm{g}$ of pSV-PGC- $1 \alpha$ or pSV, $1.0 \mu \mathrm{g}$ of RSV-TR $\beta$, and $0.1 \mu \mathrm{g}$ of TK-Renilla. T3 was added at a concentration of $100 \mathrm{nM}$ for $24 \mathrm{~h}$. All transfections were performed in duplicate and repeated three to six times. Luciferase and renilla assays were performed in the same tube. Luciferase activity was corrected for both protein content and renilla activity which served as a transfection control. Results are expressed as fold induction by PGC- $1 \alpha$ or T3 compared to the untreated cells in each data set $(*=p$ value 0.01 to 0.05 , $* *=\mathrm{p}$ value 0.001 to $0.01, * * *=\mathrm{p}$ value $<0.001)$. 


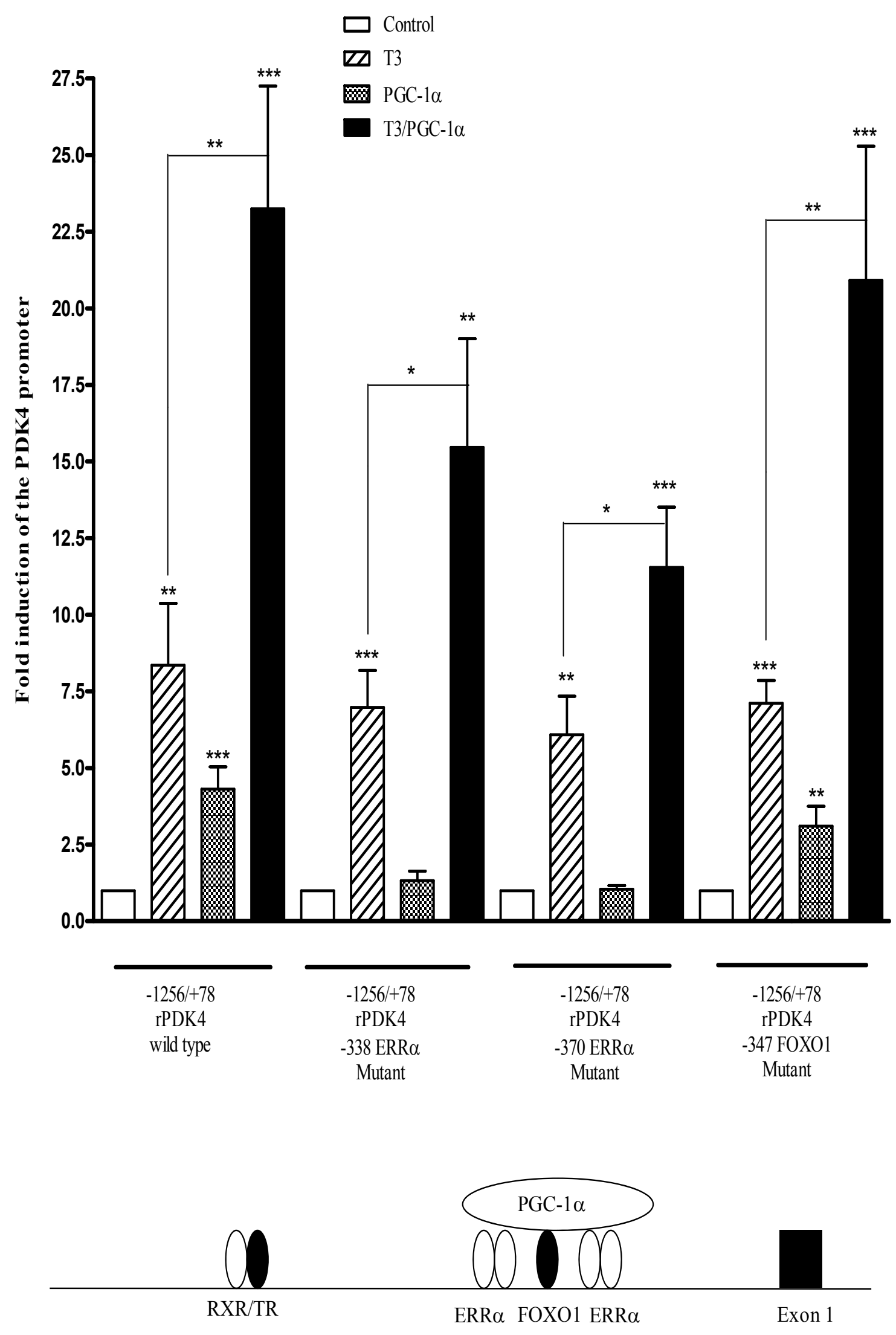


Figure 3.6: The effect of knocking down the PGC-1a on the induction gene expression of the PDK4, CPT-1a, PEPCK and C/EBP $\beta$ by T3.

Rat primary hepatocytes were infected with adenoviral vectors expressing shRNA for PGC-1 $\alpha$ (Ad-siPGC-1 $\alpha$ ), or expressing control-shRNA (Ad-NC). After $24 \mathrm{~h}$, hepatocytes were treated with $\mathrm{T} 3$ at a concentration of $100 \mathrm{nM}$ for another 24 hours. RNA was isolated from the cells, and the mRNA abundance of the indicated genes was measured by real time PCR. 18S rRNA was used as the control. The infections were repeated three times on independent plates of cells. A. fold induction of the PGC- $1 \alpha$ gene expression in hepatocytes in comparison to hepatocytes infected with Ad-NC and non-tretaed with T3. B. PDK4, C. CPT-1a, D. PEPCK and E. C/EBP $\beta$ mRNAs abundance were also measured in the same time with measuring the PGC- $1 \alpha$ gene expression. The data are expressed as the mean of the fold induction \pm S.E. of mRNA abundance relative to cells non-treated with $\mathrm{T} 3(*=\mathrm{p}$ value 0.01 to $0.05, * *=\mathrm{p}$ value 0.001 to 0.01$)$. 
A.

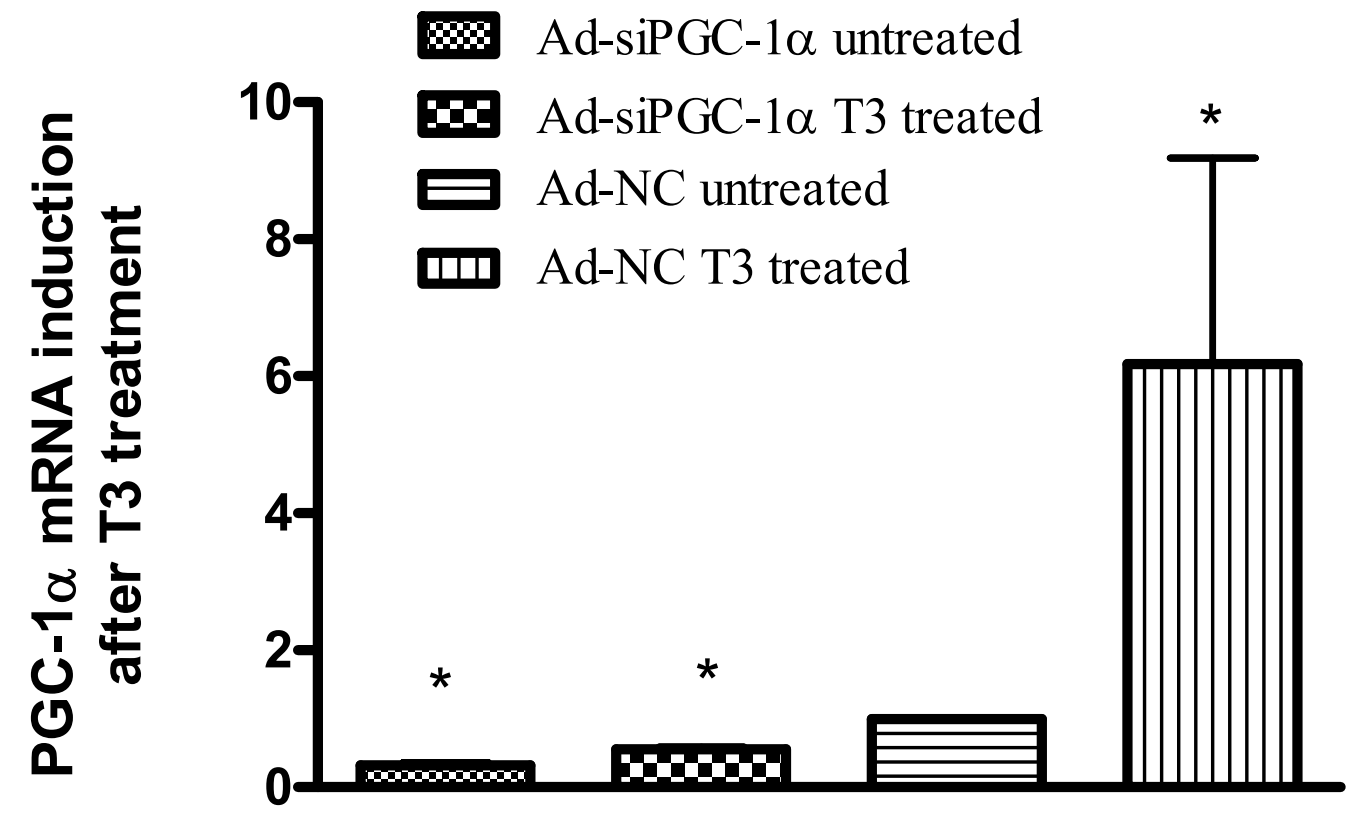

B.

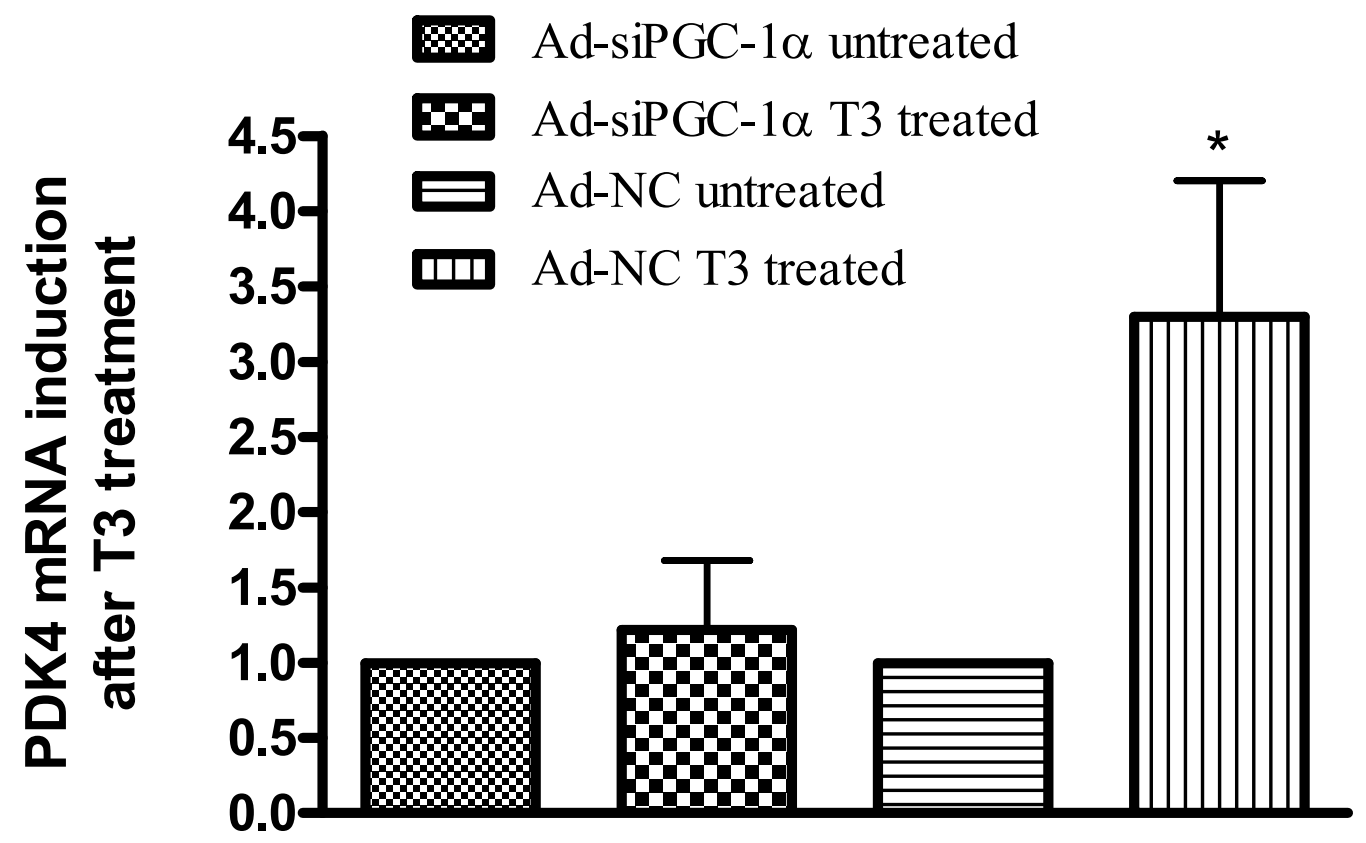


C.

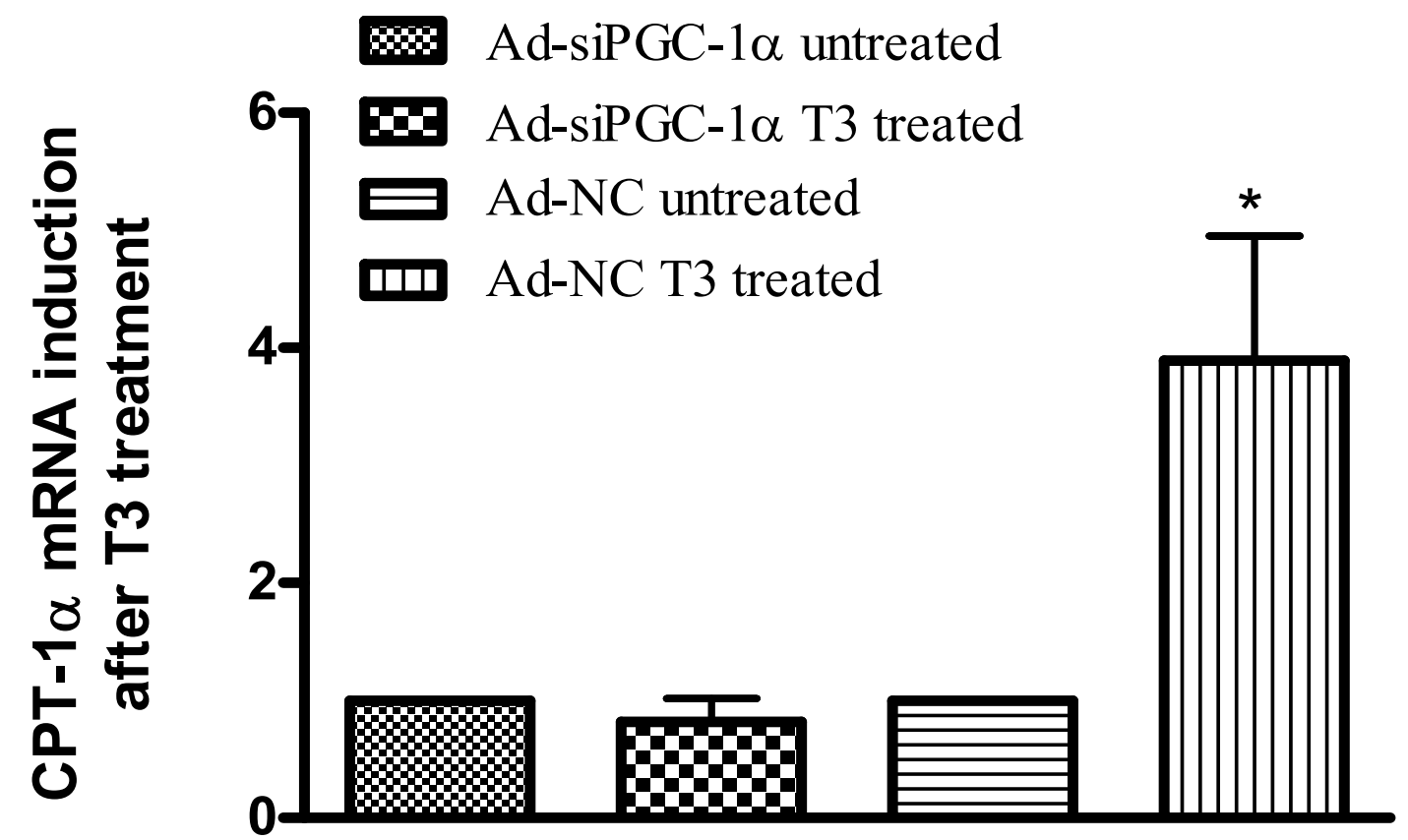

D.

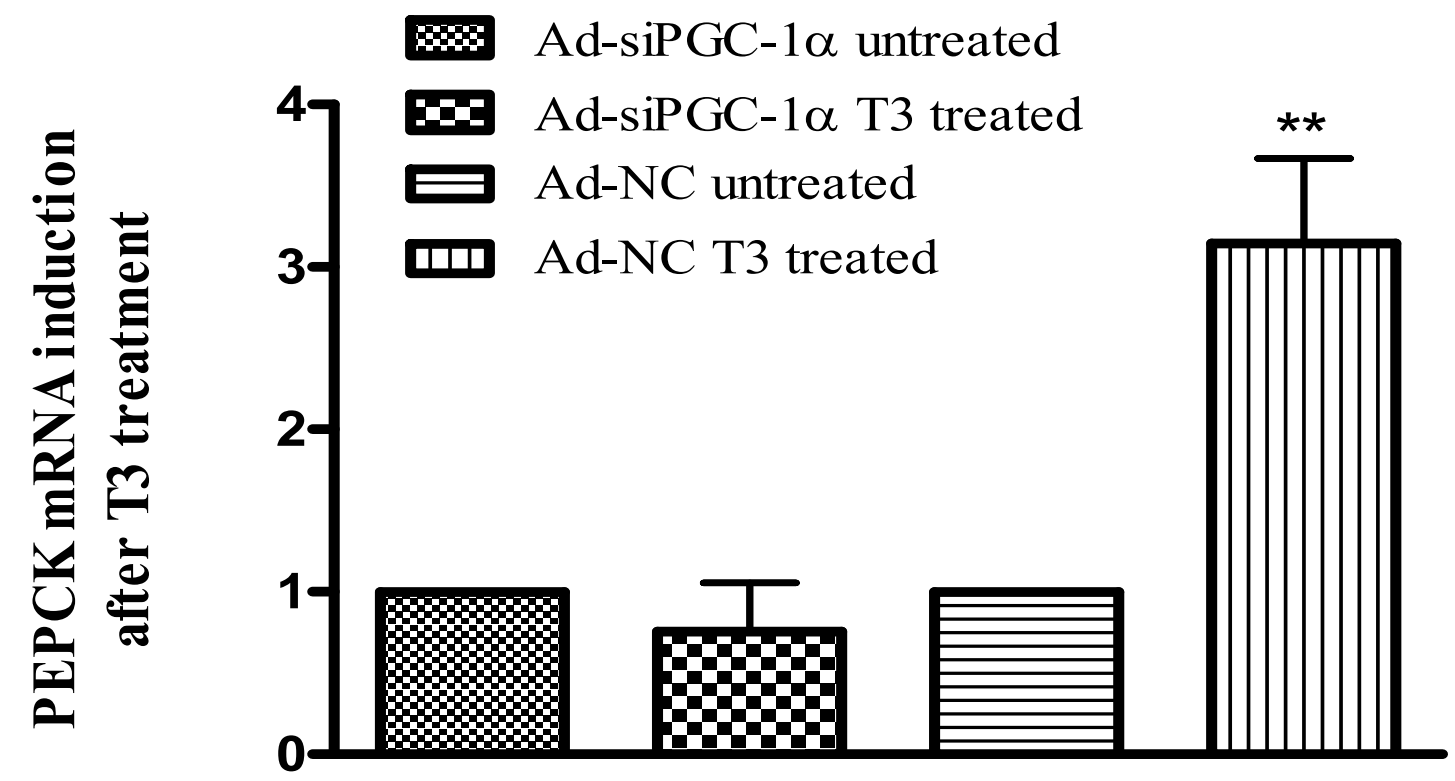

Figure 3.6: (continued). 
E.

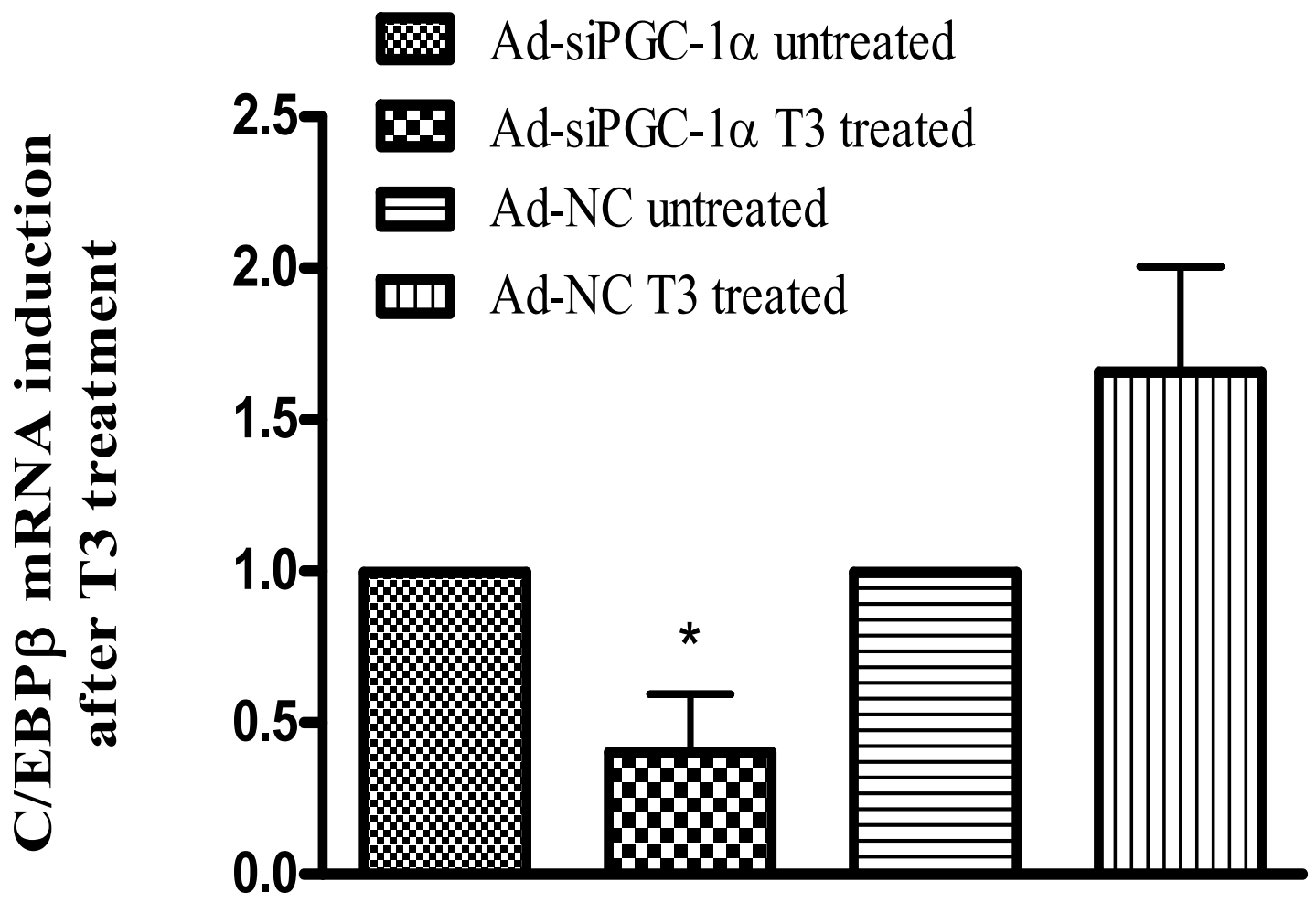

Figure 3.6: (continued). 
To further investigate the mechanism of PDK4 induction by thyroid hormone, I tested the role of another coregulator, $\mathrm{C} / \mathrm{EBP} \beta$, that was associated with the PDK4 gene promoter by ChIP technique in the induction of PDK4 by thyroid hormone (refer to Figure 3.3C).

\subsubsection{Overexpression of $\mathrm{C} / \mathrm{EBP} \beta$ induces the $\mathrm{PPDK} 4$ gene luciferase promoter.}

Previous studies from our laboratory had shown that C/EBP $\beta$ is implicated in the T3 induction of the PEPCK gene (Park et al., 1999). Therefore, in the following part of this dissertation I investigated the role of the C/EBP $\beta$ as a coregulator in the induction of the PDK4 gene by T3. In the first experiment, I tested the ability of the C/EBP $\beta$ to induce the PDK4 gene promoter in the absence of T3. I conducted co-transfections of different serial deletions constructs of the rPDK4 promoter driving a luciferase reporter and MSV$\mathrm{C} / \mathrm{EBP} \beta$ in HepG2 hepatoma cells and measured the level of induction for these luciferase constructs. Luciferase assays showed that deletion of the 210 nucleotides between -788 to -578 of the rPDK4 promoter significantly reduced C/EBP $\beta$ responsiveness from $7.6 \pm 0.7$ fold to $3.3 \pm 0.5$ fold $(\mathrm{p}=0.001)$, and also the deletion of the 255 nucleotides between -325 to -70 of the rPDK4 promoter significantly reduced $\mathrm{C} / \mathrm{EBP} \beta$ responsiveness from $4.4 \pm 0.8$ fold to $1.00 \pm 0.3$ fold $(\mathrm{p}=0.005)$ (Figure 3.7). These data indicate that $\mathrm{C} / \mathrm{EBP} \beta$ can induce PDK4 gene expression and that at least two sites in the PDK4 gene promoter between nucleotides -788 to -578 and -325 to -70 are essential for its action. These data are consistent with the ChIP data (Figure 3.3C) where C/EBP $\beta$ was associated with both the proximal and the TRE site of rPDK4 gene promoter.

\subsubsection{Thyroid hormone treatment increases the C/EBP $\beta$ protein abundance in primary hepatocytes.}

The next question investigated whether $\mathrm{C} / \mathrm{EBP} \beta$ was regulated by $\mathrm{T} 3$. I treated primary rat hepatocytes with $100 \mathrm{nM} \mathrm{T} 3$ for $24 \mathrm{~h}$ and extracted proteins. Using Western analyses to assess C/EBP $\beta$ protein level, I found that the C/EBP $\beta$ protein abundance was significantly increased by $2.1 \pm 0.4$ fold in response to $\mathrm{T} 3$ treatment (Figure 3.8). This experiment demonstrated that $\mathrm{C} / \mathrm{EBP} \beta$ abundance is modulated by $\mathrm{T} 3$ and raised the possibility that it may be a coregulator in T3 action for the PDK4 gene.

\subsubsection{C/EBP $\beta$ enhances the thyroid hormone induction of rPDK4 gene.}

In the next experiment, I examined the ability of the C/EBP $\beta$ to enhance the T3 induction of the PDK4 gene. I conducted co-transfections of the wild type -1256/+78 rPDK4-luc and MSV-C/EBP $\beta$ in HepG2 hepatoma cells with and without T3 addition. Addition of $100 \mathrm{nM}$ of T3 for 24 hours stimulated the wild type version of $-1256 /+78$ rPDK4-luc vector by $5.3 \pm 1.1$ fold. In these experiments, overexpression of $\mathrm{C} / \mathrm{EBP} \beta$ induced the PDK4-luc vector $4.7 \pm 1.3$ fold. 


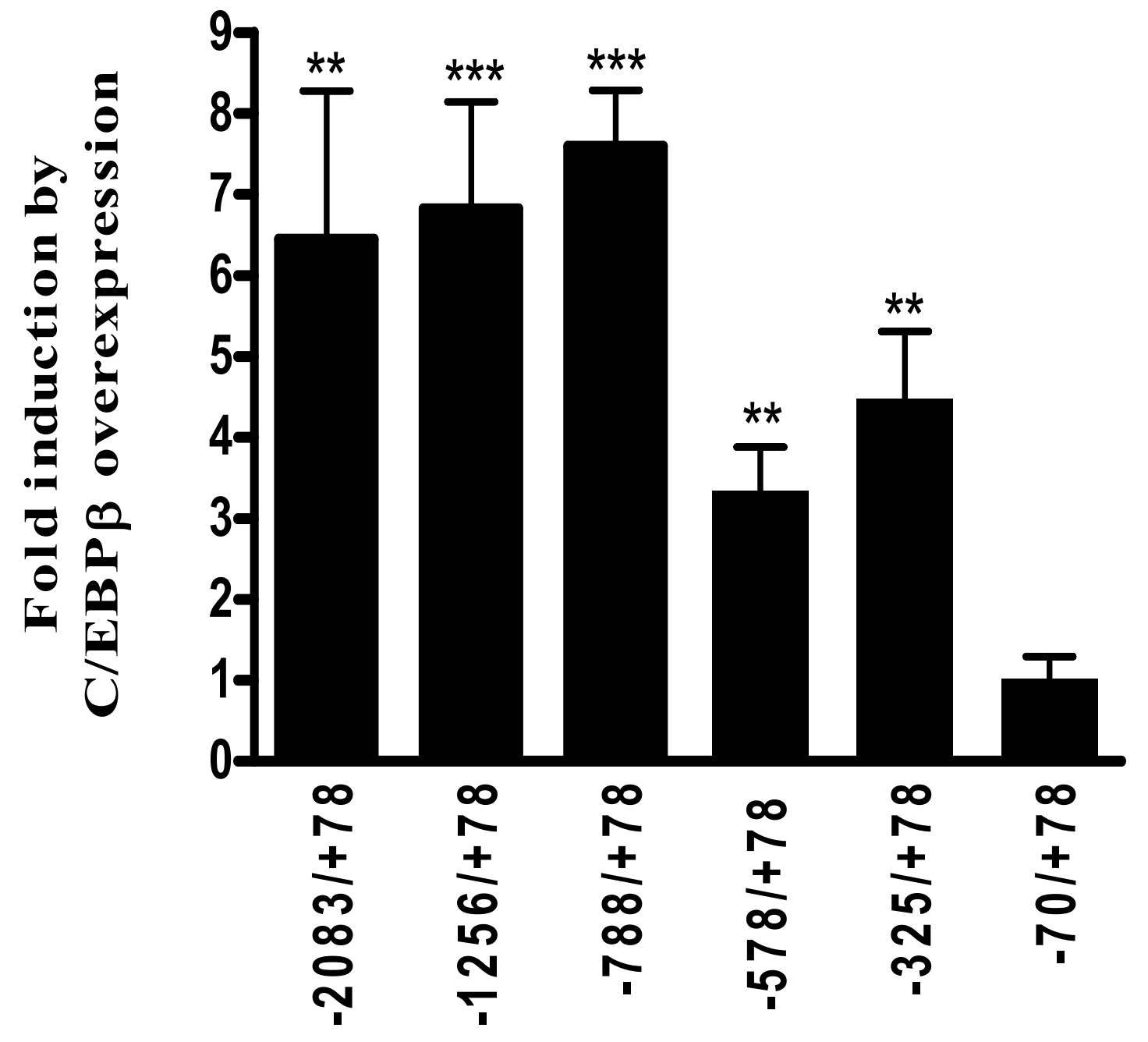

Figure 3.7: Overexpression of C/EBP $\beta$ induces the rPDK4 promoter.

HepG 2 cells were transiently transfected with $2 \mu \mathrm{g}$ of different rPDK 4 constructs, $1 \mu \mathrm{g}$ of $\mathrm{MSV}-\mathrm{C} / \mathrm{EBP} \beta$, and $0.1 \mu \mathrm{g}$ of TK-renilla. All transfections were performed in duplicate and repeated three at least three times. Luciferase and renilla assays were performed in the same tube. Luciferase activity was corrected for both protein content and renilla activity which served as a transfection control. Results are expressed as the relative induction by $\mathrm{T} 3 \pm \mathrm{S}$.E by comparing the $\mathrm{T} 3$ induction of vectors in the treated cells to the non-treated ones. The significance is calculated in relative to the shortest version of the rPDK4-luciferase $(-70 /+78)(* *=p$ value 0.001 to $0.01, * * *=p$ value $<0.001)$. 


\section{T3}

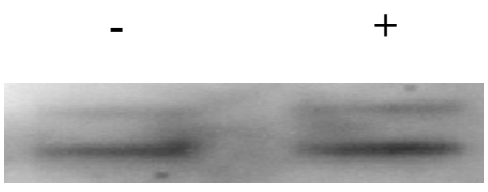

C/EBPß

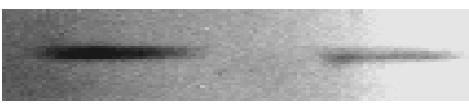

\section{$\operatorname{Actin} \beta$}

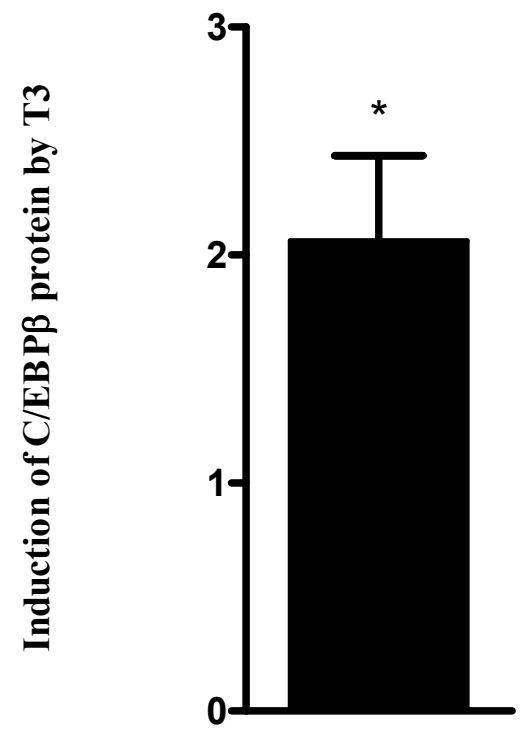

$2.1 \pm 0.4$

Figure 3.8: Thyroid hormone increases the C/EBPß protein abundance in primary hepatocytes.

The expression of the $\mathrm{C} / \mathrm{EBP} \beta$ proteins was monitored by Western blot analysis using specific antibodies (1: 1000, Santa Cruz). The data are presented as the fold induction of protein abundance by T3 (average \pm SE) from three independent hepatocytes preparations, and the control samples were assigned a relative value of $1\left(^{*}=\mathrm{p}\right.$ value 0.01 to 0.05$)$. 
When T3 was added in the presence of C/EBP $\beta$, I obtained a significant synergistic effect with a $16.9 \pm 5$ fold induction (Figure 3.9). These data indicate that $\mathrm{C} / \mathrm{EBP} \beta$ can activate the PDK4 gene promoter and can act synergistically with the T3 to amplify its effect on the PDK4 gene promoter.

To further demonstrate and confirm the role of the $\mathrm{C} / \mathrm{EBP} \beta$ protein in the induction of PDK4 transcription, I tested a set of specific dominant negative vectors. Hep4-C/EBP is a dominant negative C/EBP vector, which has the C/EBP leucine zipper attached to an acidic amphipathic helix containing 4 heptads repeats (Krylov et al., 1995). The amphipathic helix interacts with the basic region of $\mathrm{C} / \mathrm{EBP}$ proteins to form a strong non-DNA binding heterodimer and inhibits all C/EBP proteins including both alpha and beta isoforms (Krylov et al., 1995). For controls, I used the hep4-CREB which is a dominant negative CREB protein with a CREB leucine zipper and an amphipathic helix (Ahn et al., 1998) and the hep4-Fos which is a dominant negative Jun vector with the Fos leucine zipper and an amphipathic helix (Olive et al., 1997). To examine the effect of these dominant negative proteins on the basal induction of the PDK4 gene, the $-1256 /+78$ PDK4-luc vector was cotransfected with three dominant negative vectors into HepG2 cells and after 48 hours from the transfection, proteins were extracted from the cells and tested for the luciferase level induction. The dominant negative C/EBP reduced the basal levels of the PDK4 gene significantly by $32 \%(p=0.02)$, while the dominant negative FOS did not have any effect on the basal level of the PDK4 gene and the dominant negative CREB even significantly doubled its basal level $(p=0.0007)$ (Figure 3.10A). The reason for the induction of the PDK4 gene basal level by hep4-CREB is not known.

To confirm the role of the C/EBP proteins in the induction of the PDK4 gene by T3, I cotransfected the $-1256 /+78$ PDK4-luc vector with three dominant negative vectors into HepG2 cells and treated them with $100 \mathrm{nM}$ T3. Proteins were extracted from the cells and tested for the luciferase activity. Cotransfection with hep4-C/EBP inhibited the $4.5 \pm$ 1.3 fold induction of $\mathrm{T}_{3}$. Both the dominant negative CREB and FOS did not affect at all the induction by $\mathrm{T}_{3}$ (Figure 3.10B).

These data indicate that $\mathrm{C} / \mathrm{EBP} \beta$ induces the expression of the PDK4 gene and enhances the $\mathrm{T} 3$ induction of this gene. Inhibition of the $\mathrm{C} / \mathrm{EBP}$ isoforms by dominant negative vectors abolishes the ability of T3 to induce PDK4 gene. However, the dominant negative vectors cannot differentiate between the two isoforms of the C/EBP and therefore, to pinpoint which isoform this involved in the T3 induction of the PDK4 gene, I used adenoviral shRNA delivery to specifically inhibit the C/EBP $\beta$ isoform in the primary rat hepatocytes.

\subsubsection{Knocking down C/EBPß reduces the ability of thyroid hormone to induce PDK4 gene expression in primary rat hepatocytes.}

To test the role of the $\mathrm{C} / \mathrm{EBP} \beta$ in the $\mathrm{T} 3$ induction of PDK4 gene expression, I infected rat primary hepatocytes with adenovirus encoding the shRNA to silence specifically the $\mathrm{C} / \mathrm{EBP} \beta$ (Ad-siC/EBP $\beta$ ). 


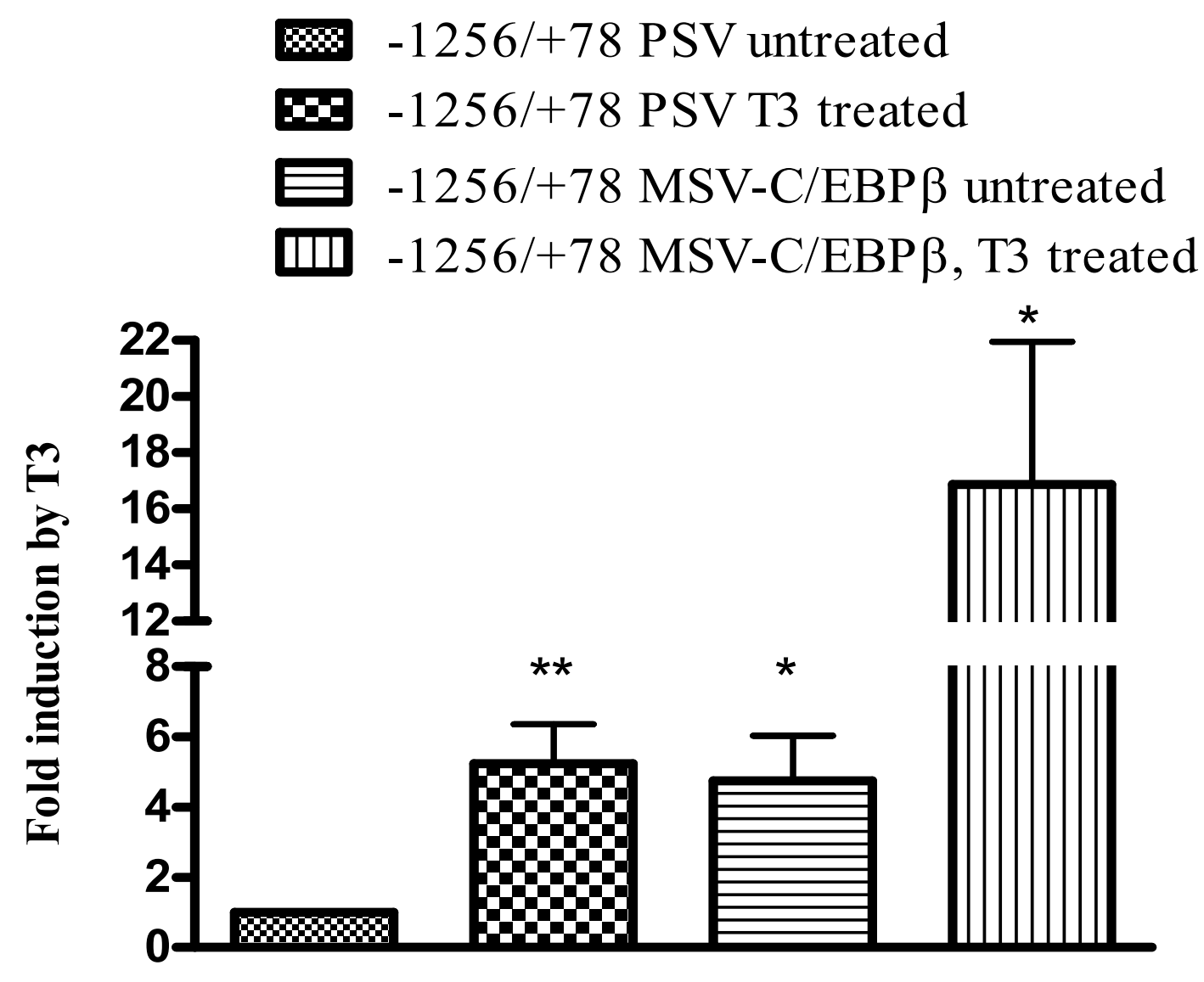

Figure 3.9: C/EBPß enhances the T3 induction of the rPDK4 gene.

HepG2 hepatoma cells were transiently transfected with $2 \mu \mathrm{g}$ of $-1256 /+78$ rPDK4-Luc constructs, $1 \mu \mathrm{g}$ of MSV-C/EBP $\beta$ or MSV, $1.0 \mu \mathrm{g}$ of RSV-TR $\beta$, and $0.1 \mu \mathrm{g}$ of TKRenilla. T3 was added at a concentration of $100 \mathrm{nM}$ for $24 \mathrm{~h}$. All transfections were performed in duplicate and repeated three times. Luciferase assays were performed as described in Figure 3.8. Results are expressed as fold induction by PGC-1 $\alpha$ or T3 versus the untreated cells in each data set $(*=\mathrm{p}$ value 0.01 to $0.05, * *=\mathrm{p}$ value 0.001 to 0.01$)$. 
Figure 3.10: The effect of inhibiting the C/EBP, FOS and CREB on the induction of rPDK4 by T3.

A. The effect of inhibiting the C/EBP, FOS and CREB on the basal expression of the 1256/+78 rPDK4 luc. HepG2 hepatoma cells were transiently transfected with $2 \mu \mathrm{g}$ of 1256/+78 rPDK4-Luc constructs, $1 \mu \mathrm{g}$ of PSV-40, hep4-C/EBP, hep4-FOS or hep4CREB, $1.0 \mu \mathrm{g}$ of RSV-TR $\beta$, and $0.1 \mu \mathrm{g}$ of TK-Renilla. Fourty-eight hours after the transfection, cells were collected. All transfections were performed in duplicate and repeated three times. Luciferase and renilla assays were performed in the same tube. Luciferase activity was corrected for both protein content and renilla activity which served as a transfection control. Results are expressed as fold induction by PGC-1 $\alpha$ or T3 versus the untreated cells in each data set $\left(^{*}=\mathrm{p}\right.$ value 0.01 to $0.05, * * *=p$ value $<0.001)$. B. The effect of inhibiting the C/EBP, FOS and CREB on the induction of the 1256/+78 rPDK4 luc by T3. HepG2 hepatoma cells were transiently transfected with 2 $\mu \mathrm{g}$ of -1256/+78 rPDK4-Luc constructs, $1 \mu \mathrm{g}$ of PSV-40, hep4-C/EBP, hep4-FOS or hep4-CREB, $1.0 \mu \mathrm{g}$ of RSV-TR $\beta$, and $0.1 \mu \mathrm{g}$ of TK-Renilla. T3 was added at a concentration of $100 \mathrm{nM}$ for $24 \mathrm{~h}$. All transfections were performed in duplicate and repeated three times. Luciferase assays were performed as described above. Results are expressed as fold induction by PGC- $1 \alpha$ or T3 versus the untreated cells in each data set (* $=\mathrm{p}$ value 0.01 to $0.05, * *=\mathrm{p}$ value 0.001 to 0.01 ) 
A.

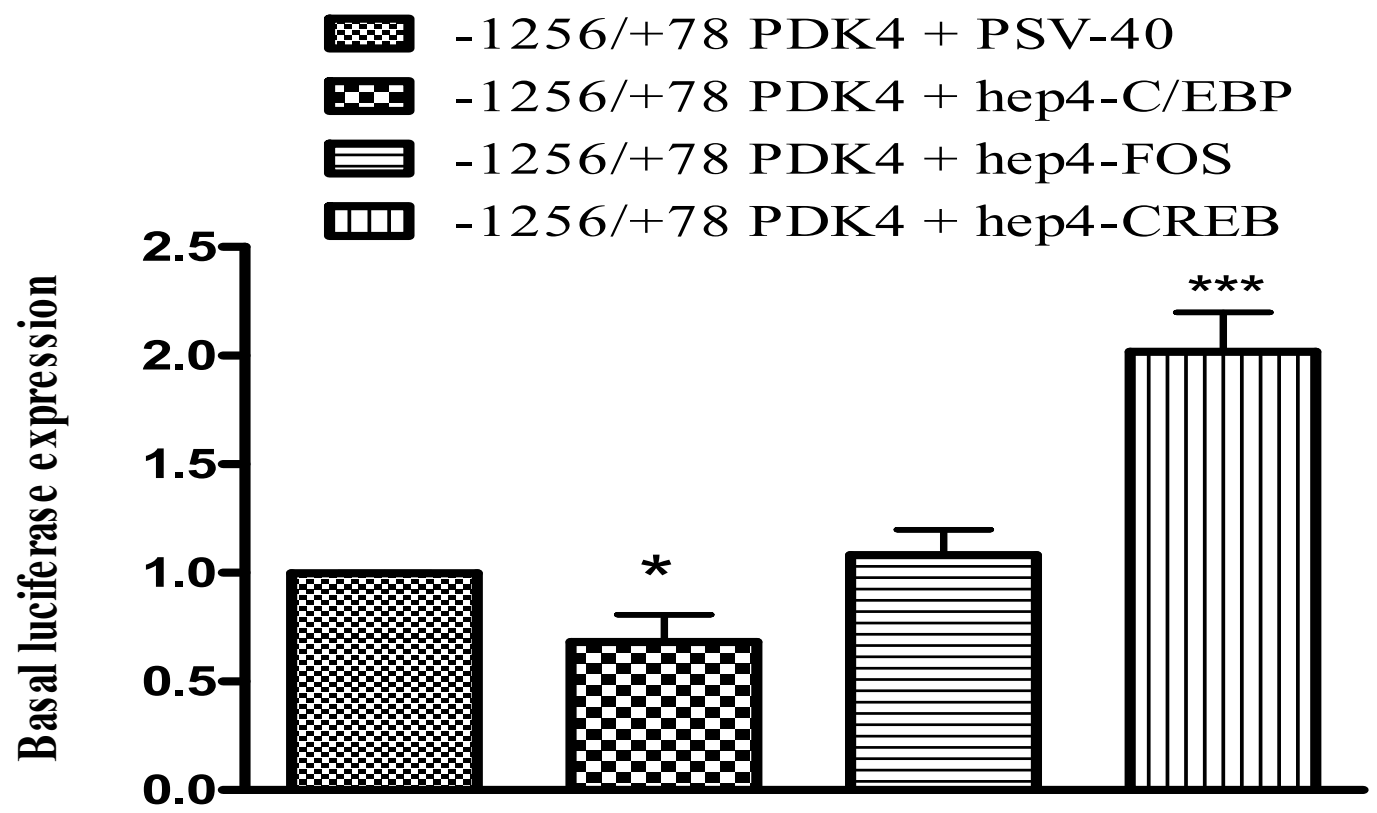

B.

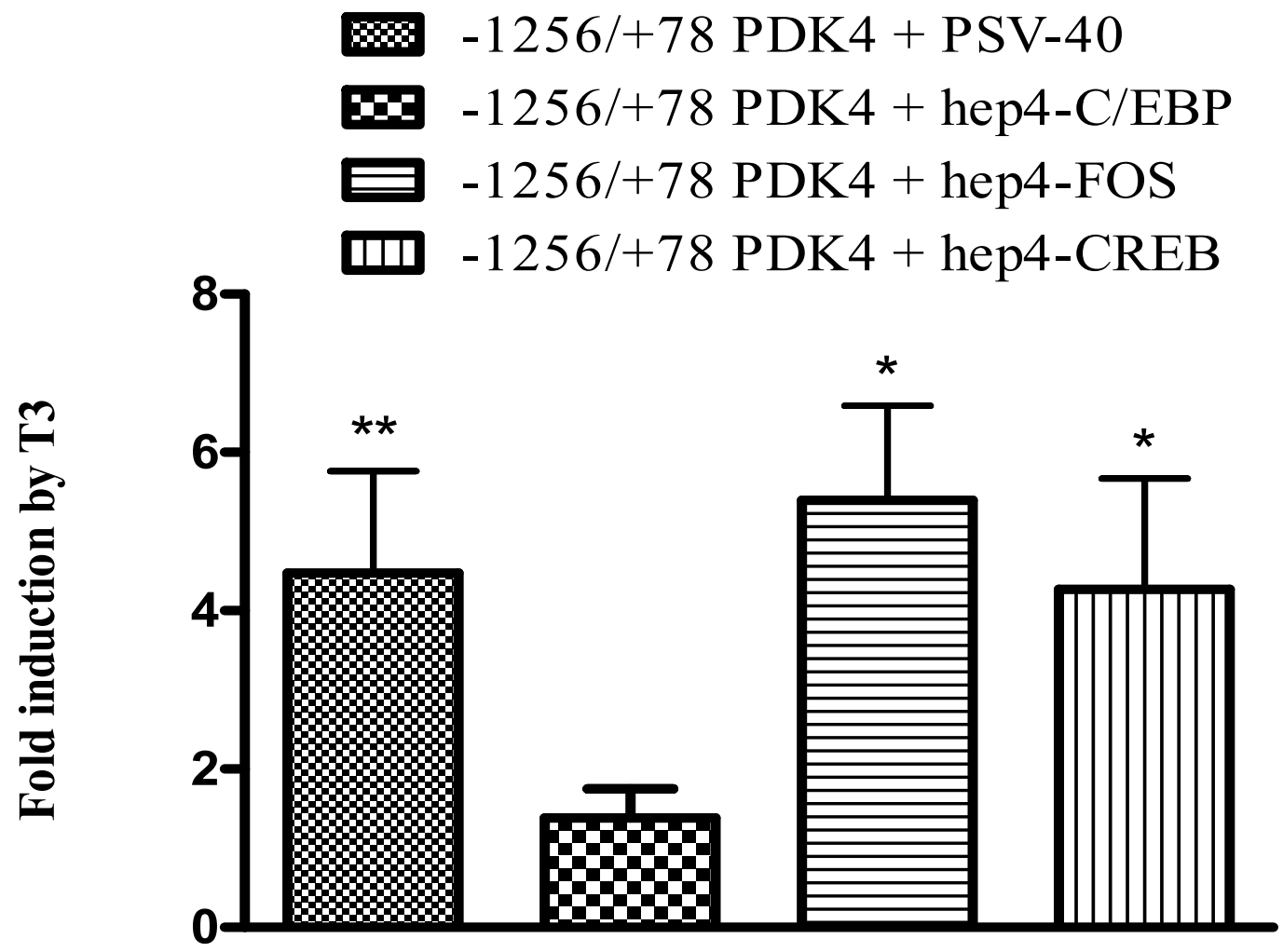


Hepatocytes were transduced with the adenoviruses for 16 hours prior to treatment of cells with T3 for another 24 hours. Adenovirus encoding control shRNA that does not silence any rat genes was used as a control (Ad-control). I obtained these adenoviruses from Dr. Jacob E. Friedman from University of Colorado at Denver (Schroeder-Gloeckler et al., 2007). Ad-siC/EBP $\beta$ significantly knocked down the expression of $\mathrm{C} / \mathrm{EBP} \beta$ by $65 \%$ compared to the Ad-NC in hepatocytes untreated with $\mathrm{T} 3$ (0.4 \pm 0.02 fold relative to Ad-control infected hepatocytes untreated with T3). In addition, the induction of $\mathrm{C} / \mathrm{EBP} \beta$ by $\mathrm{T} 3$ was reduced in hepatocytes infected with AdsiC/EBP $\beta(0.4 \pm 0.04$ fold relative to Ad-control infected hepatocytes untreated with T3) in comparison to that infected with Ad-control $(1.8 \pm 0.3$ relative to Ad-control infected hepatocytes untreated with T3) (Figure 3.11A). The knock down of the C/EBP $\beta$ in primary hepatocytes was accompanied by a significant reduction in the T3 induction of PDK4, as T3 induced PDK4 only by $1.55 \pm 0.24$ fold while T3 had increased PDK4 in hepatocytes infected with Ad-control by $2.3 \pm 0.2$ fold (Figure 3.11B). This reduction of the T3 induction for the PDK4 gene expression after C/EBP $\beta$ silencing indicates that $\mathrm{C} / \mathrm{EBP} \beta$ is an important coregulator in the T3 induction process of the PDK4 gene expression in primary hepatocytes.

From the previous experiments, I have confirmed the induction of PDK4 gene by T3 treatment. I also showed that both the PGC- $1 \alpha$ and C/EBP $\beta$ are important coregulators for this induction. However, previous studies had shown that thyroid hormone induces a number of metabolic genes. This implies a large network of genes and transcription factors that are involved in the T3 cellular and genomic actions (Weitzel et al., 2001; Yen et al., 2006). Therefore, I designed the next experiment to identify the early response network of transcription factors and metabolic genes that are regulated following 24 hours of T3 treatment involved in the thyroid hormone metabolic action.

\subsubsection{Thyroid hormone treatment induces a network of transcription factors and different metabolic genes in primary rat hepatocytes.}

Thyroid hormone regulates the expression of key metabolic genes including phosphoenolpyruvate carboxykinase (PEPCK), carnitine palmitoyltransferase 1a (CPT1a), apolipoprotein B (ApoB) and uncoupling protein 3 (UCP3) (Boss et al., 2000; Jackson-Hayes et al., 2003; Mukhopadhyay et al., 2003; Park et al., 1997; Yen et al., 2006). Also, previous studies demonstrated that T3 elevates the abundance of many transcription factors and coactivators associated with mitochondrial biogenesis and lipid metabolism, such as PGC-1 $\alpha$ and ERR $\alpha$ (Xie et al., 1999; Zhang et al., 2004b). These facts indicate that T3 may stimulate metabolism in part by increasing a network of transcription factors that induce different metabolic genes which may or may not contain a TRE site within their promoters. To address this possibility, I treated primary rat heptocytes with 100nM T3 for 24 hours, and then RNA was isolated from these hepatocytes and from non-treated ones. RNA was assessed on a superarray, containing 90 real time PCR primers for genes of transcription factors and metabolic genes, according to the manufacturer procedures using the Roche Light cycler 480 machine. A complete list of these genes is provided in the experimental procedures section. 
Figure 3.11: The effect of knocking down the C/EBP $\beta$ on the induction gene expression of the PDK4 gene by T3.

Rat primary hepatocytes were infected with adenoviral vectors expressing shRNA for $\mathrm{C} / \mathrm{EBP} \beta$ (Ad-siC/EBP $\beta$ ) or expressing control-shRNA (Ad-control). After $24 \mathrm{~h}$, hepatocytes were treated with $\mathrm{T} 3$ at a concentration $100 \mathrm{nM}$ for another 24 hours. RNA was isolated from the cells, and the A. PDK4 and B. C/EBP $\beta$ mRNA abundance was measured by real time PCR. $18 \mathrm{~S}$ rRNA was used as the control. The infections were repeated four to seven times on independent plates of cells. The data are expressed as the mean of the fold induction \pm S.E. of mRNA abundance relative to cells non-treated with T3. 
A.

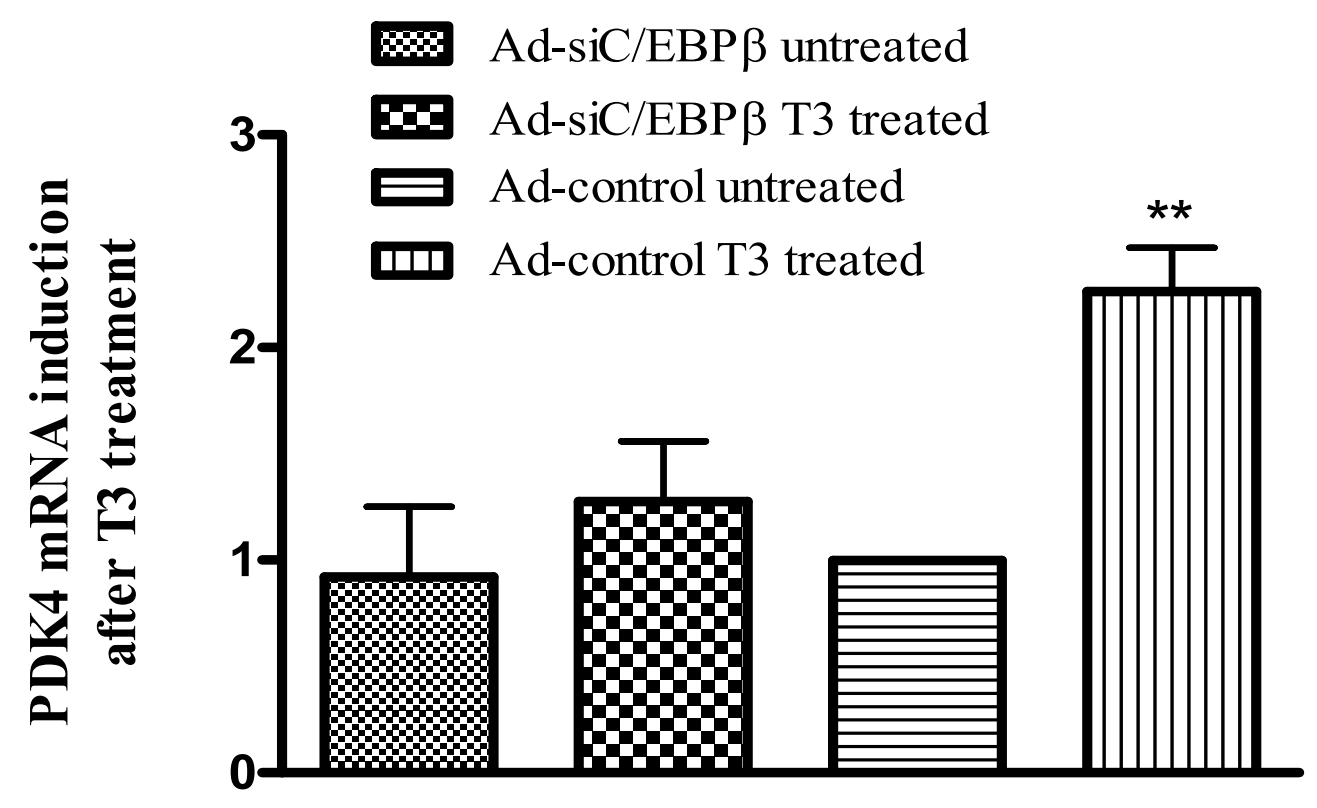

B.

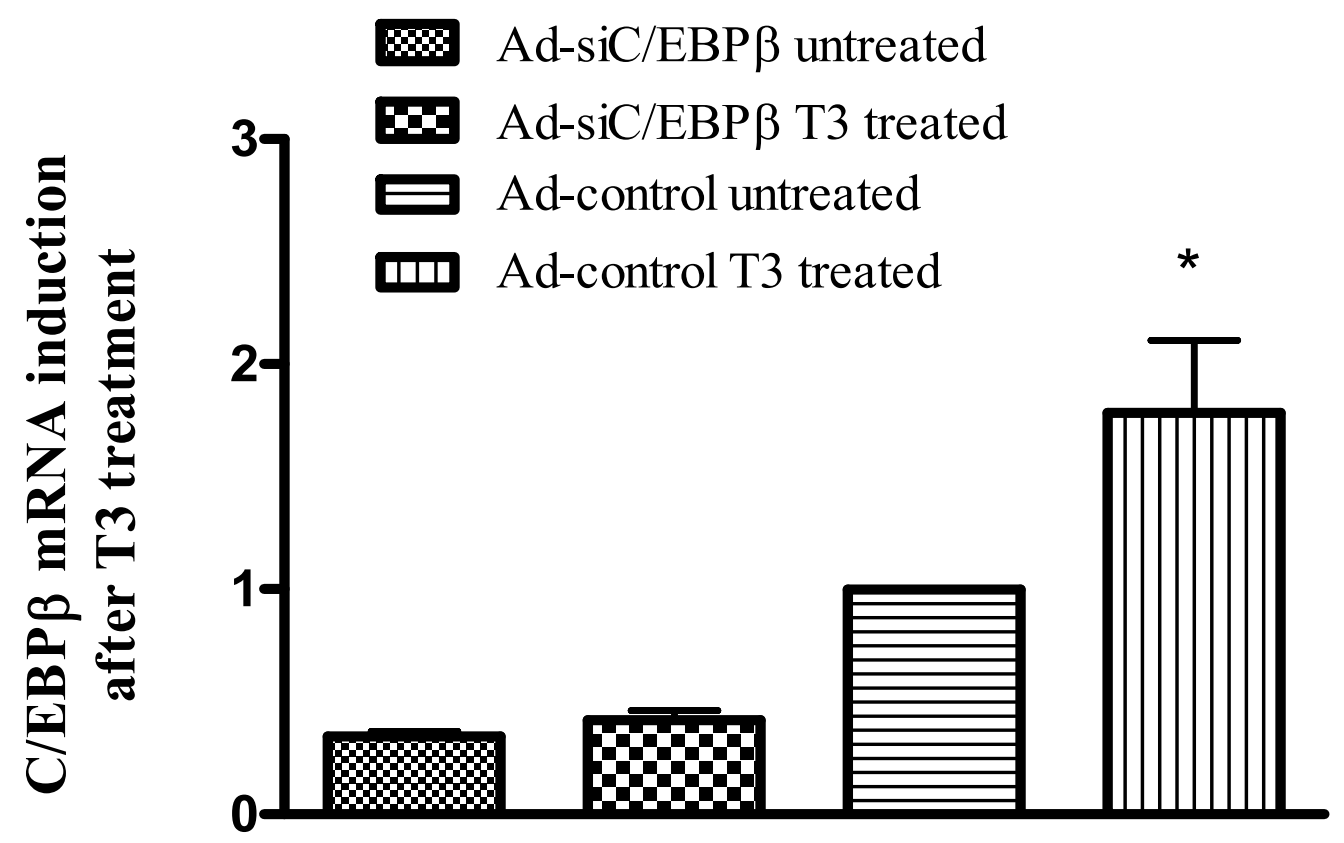


The results from four independent hepatocytes preparations showed up-regulation of 27 genes by more than 1.5 fold relative to non-treated cells (Figure 3.12). Thyroid treatment significantly induced genes involved in glucose homeostasis and gluconeogenesis such as, glucose-6-phosphatase (G6pase) by $1.7 \pm 0.2$ fold, phosphoenolpyruvate carboxykinase (PEPCK) by $3.7 \pm 1.1$ fold, solute carrier family 2 (facilitated glucose transporter), member 4 (Slc2a4) by $3.2 \pm 0.6$ fold, cytochrome P450 2E1 (Cyp2e1) by $2.2 \pm 0.7$ fold (Lieber, 1999). On the other hand, T3 treatment induced genes involved in fatty acid oxidation and metabolism such as, 3-ketoacyl-Coenzyme A thiolase alpha subunit (Hadha) by $2.5 \pm 0.05$ fold, fatty acid binding protein $3 /$ small heterodimer partner (Fabp3/SHP) by $2.5 \pm 0.8$ fold, solute carrier family 25 carnitine/acylcarnitine translocase member 20 (Slc25a20) by $2 \pm 0.5$ fold, fatty acid binding protein 1 (Fabp1) by $2.7 \pm 1$ fold, carnitine palmitoyltransferase 1a (CPT-1a) by $2 \pm 0.6$ fold, and acetyl-Coenzyme A carboxylase beta (Acacb) by $2.6 \pm 0.8$ fold. Interestingly T3 significantly induced genes involved in fatty acid and lipid synthesis including, solute carrier family 27 fatty acid transporter member 5 (Slc27a5) by $1.9 \pm 0.3$ fold, fatty acid synthase (FAS) by $2.3 \pm 0.3$ fold.

Also, T3 treatment induced number of transcription factors such as, GA binding protein transcription factor, beta subunit 1 (Gabpb1) by $1.9 \pm 0.4$ fold, peroxisome proliferative activated receptor, delta (Pparo) by $3.1 \pm 1$ fold, estrogen related receptor gamma (EsRR $\gamma)$ by $2.5 \pm 0.9$, CCAAT/enhancer binding protein beta (C/EBP $\beta)$ by $2 \pm$ 0.7 , sterol regulatory element-binding transcription factor 1 (Srebf1) by $3.5 \pm 0.6$ (Zhang et al., 2003), Sirtuin 1 (Sirt-1) which deacetylates proteins that contribute to cellular regulation (Frye, 1999), and the homeobox protein NK-2 homolog (Nkx2.5) that binds and activates the promoter of thyroid specific genes such as thyroglobulin, thyroperoxidase, and thyrotropin receptor (Civitareale et al., 1989; Dentice et al., 2006; Francis-Lang et al., 1992), it was increased by $2.8 \pm 0.7$ fold. In addition, T3 treatment showed induction of number of transcription coactivators such as, peroxisome proliferative activated receptor gamma coactivator-1 alpha (PGC-1 $\alpha$ ) by $2.3 \pm 0.9$ fold, peroxisome proliferative activated receptor gamma coactivator-1 beta (PGC-1 $\beta$ ) by $3 \pm$ 1.1 fold, also T3 induced both lipin gene isoforms, 1 and 2, by $2.1 \pm 0.7$ and $3.6 \pm 1.6$ fold, respectively.

Finally T3 treatment induced number of miscellaneous proteins involved in different metabolic processes including, deiodinase, iodothyronine, type II (Dio2) which is responsible for the activation of thyroid hormone by converting the prohormone thyroxine (T4) by outer ring deiodination (ORD) to bioactive triiodothyronine (T3) (Yen, 2001), it was increased by $3.7 \pm 1$ fold, pyruvate dehydrogenase kinase isoform 4 (PDK4) by $3 \pm 0.7$ fold and both isoforms of the uncoupling proteins, 2 and 3 (UCP2 and UCP3), involved in thermogensis, insulin secretion and fatty acid transportation anions (Fisler \& Warden, 2006), T3 induced UCP2 and UCP3 by $3.2 \pm 1.5$ fold and 3.5 \pm 1.6 , respectively. 
Figure 3.12: Effect of $\mathrm{T} 3$ on transcription factor and metabolic gene abundance in primary rat hepatocytes.

Primary rat hepatocytes were plated on collagen-coated plates for $16 \mathrm{~h}$. T3 was added at a concentration of $100 \mathrm{nM}$ to the hepatocytes for $24 \mathrm{~h}$. RNA was harvested using RNASTAT 60 and treated with Turbo DNase I to remove contaminating genomic DNA and further purified using the Qiagen RNeasy kit. The extracted total RNA was converted into cDNA using superarray $\mathrm{RT}^{2}$ First Strand Kit. The abundance of the transcription factors and metabolic genes mRNA was determined by superarray ${ }^{\circledR}$ real time PCR $\left(\mathrm{RT}^{2}\right.$ Profiler ${ }^{\mathrm{TM}}$ PCR Array System, SABiosciences cat \# CAPR-0529F). This superarray contains primers for 90 transcription factors/metabolic genes and 6 controls. The cDNA was assessed on the superarray according to the manufacturer protocol with a Roche light cycler 480 . The data are presented as the fold induction of mRNA abundance by T3 (average $\pm \mathrm{SE}$ ) from four independent hepatocytes preparations and the control samples were assigned a relative value of 1 . Only the genes that were induced by T3 treatment by more than 1.5 fold relative to non-treated cells are represented in this figure $(*=p$ value 0.01 to $0.05, * *=\mathrm{p}$ value 0.001 to $0.01, * * *=\mathrm{p}$ value $<0.001)$. 


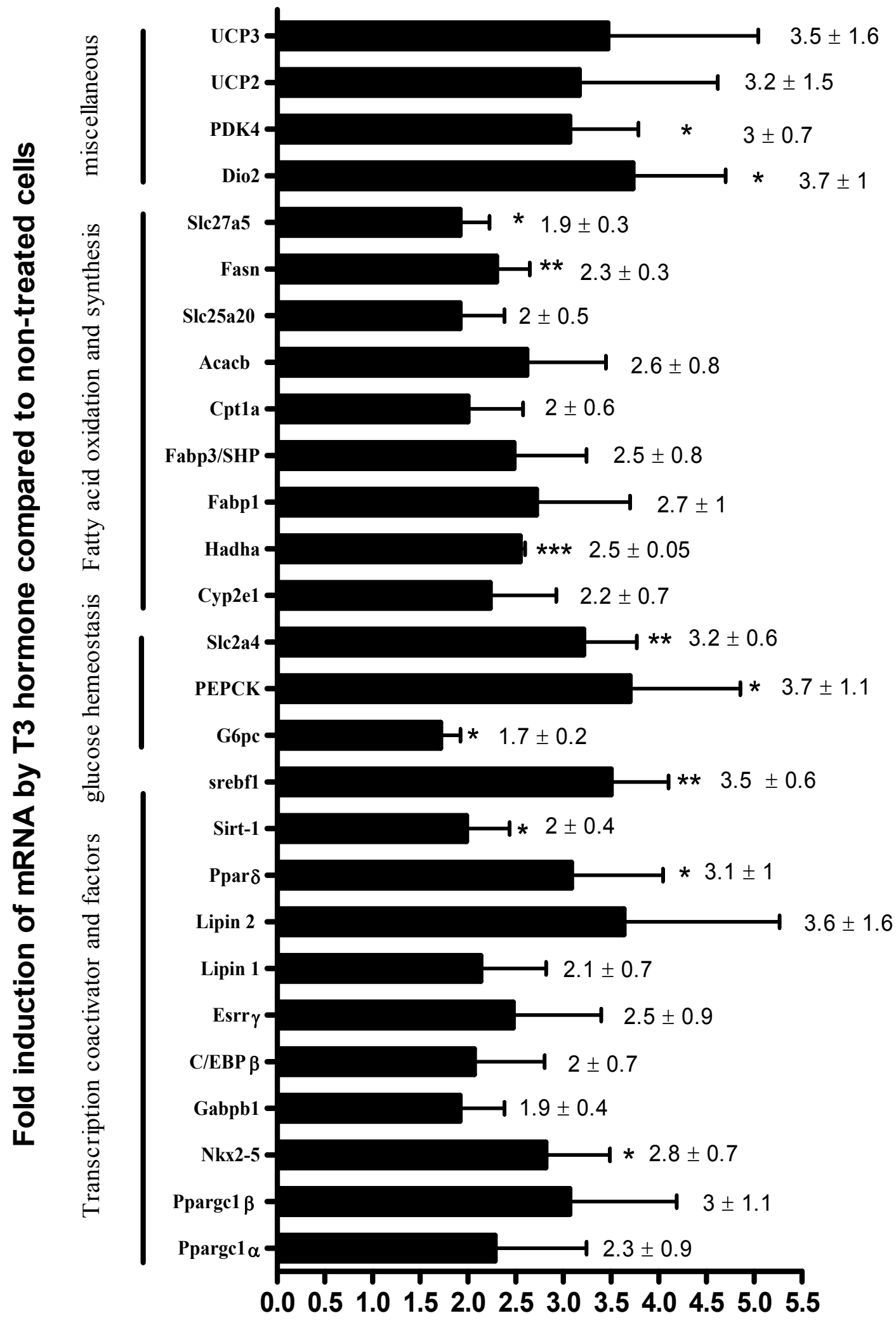




\subsection{Experimental procedures}

\subsubsection{Transient transfection of luciferase vectors}

PDK4-luciferase constructs (PDK4-luc) were transiently transfected into HepG2 cells by the calcium phosphate method as previously described (Zhang et al., 2004b). Transfections included $2 \mu \mathrm{g}$ of PDK4-luciferase along with SV40-thyroid hormone receptor $\beta$ (SV40-TR $\beta$ ), PSV-PGC-1 $\alpha$ and TK-Renilla. For experiments with C/EBP $\beta$; $\mathrm{MSV}-\mathrm{C} / \mathrm{EBP} \beta$ was included in the transfection. Dominant negative vectors for $\mathrm{C} / \mathrm{EBP}$ (hep4-CEBP), CREB (hep4-CREB) and FOS (hep4-FOS) were also transfected. Cells were transfected in Dulbecco's modified Eagle's medium containing 5\% calf serum, 5\% fetal calf serum and incubated overnight at $37^{\circ} \mathrm{C}$. Following two washes with phosphatebuffered saline, the medium was replaced by Dulbecco's modified Eagle's medium containing no serum. Cells were treated with $100 \mathrm{nM} \mathrm{T3}$ for $24 \mathrm{~h}$. After T3 treatment, cells were lysed in Passive Lysis Buffer (Promega). Both luciferase and Renilla activity were measured using Promega dual luciferase reporter kit (cat\# E1980). Protein content in each lysate was determined by Pierce BCA Protein assay kit (cat\# 23225). Luciferase activity was corrected for both protein content and Renilla activity to account for cell density and transfection efficiency, respectively.

\subsubsection{Site directed mutagenesis of the rPDK4 promoter}

Stratagene's Quick-change-XL site directed mutagenesis kit was used to carry out mutation in the potential TREs in the $-1256 /+78$ rPDK4-luciferase vector. TRE1 was disrupted by changing the (GGT) in its second hexamer half site sequence into (AAC), while the TRE2 was disrupted by changing only two nucleotides (GG) in its second hexamer half site into (AA). In addition, site directed mutagenesis technique was used to carry out mutations in the ERR $\alpha$ and FOXO1 binding sites in the $-1256 /+78$ rPDK4luciferase vector. Mutations of the ERR $\alpha$ binding site are named Mut338 and Mut370, while the mutation of the FOXO1 binding site is named Mut347. Primers used to establish all these mutations are listed in Table 3.1, mutated nucleotides are in bold.

\subsubsection{In vivo luciferase transfection}

In vivo transfection of the wild type and mutated TRE1 -1256/+78 was done by electroporation in hypothyroid (by hypophysectomy) rats livers. Four hypothyroid rats were used without thyroid treatment and another 4 rats were treated with T3 three days prior to electroporation, with an additional half-dose injection the day before electroporation. This experiement was done in Dr. Gene Ness lab in University of South Florida. Electroporation was performed as previously described (Lagor et al., 2007). Approximately $16 \mu \mathrm{g}$ of plasmid in $40 \mu \mathrm{l}$ of sterile saline was subcaspsular injected using a 30-gauge, 3/8-in length needle and it was visible below the capsular surface as a blanched out area after injection. A circular six-node electrode was placed on the liver 
Table 3.1: Sequences of the primers used for the site-directed mutagenesis of the rPDK4 promoter.

\begin{tabular}{|c|c|}
\hline TRE region & Primer sequence \\
\hline $\begin{array}{l}\text { MutTRE1 } \\
\text { Forward }\end{array}$ & 5'-GAGGGCTAAGGGCACCTTGAACAACAAACTGCCTTTGCTGC-3' \\
\hline $\begin{array}{l}\text { MutTRE1 } \\
\text { Reverse }\end{array}$ & 5'-CTCCCGATTCCCGTGGAACTTGTTGTTTGACGGAAACGACG-3' \\
\hline $\begin{array}{l}\text { MutTRE2 } \\
\text { Forward }\end{array}$ & 5'-GAGTGAACAGAAGAGCGAGAGAAATTAGGATGAGAGTTTTATGAC-3' \\
\hline $\begin{array}{l}\text { MutTRE2 } \\
\text { Reverse }\end{array}$ & 5'-CTCACTTGTCTTCTCGCTCTCTTTAATCCTACTCTCAAAATACTG-3' \\
\hline $\begin{array}{l}\text { Mut338 } \\
\text { Forward }\end{array}$ & 5'-AGATGGCTCCTGAGTTGTAAACAAAAACAAGTCTGGGCGGG-3' \\
\hline $\begin{array}{l}\text { Mut338 } \\
\text { Reverse }\end{array}$ & 5'-CCCGCCCAGACTTGTTTTTGTTTACAACTCAGGAGCCATCT-3' \\
\hline $\begin{array}{l}\text { Mut347 } \\
\text { forward }\end{array}$ & 5'-TGACATTGAGATGGCTCCTGAGTTTGCAACAAGGACAAGTCTGGGC-3' \\
\hline $\begin{array}{l}\text { Mut347 } \\
\text { Reverse }\end{array}$ & 5'-GCCCAGACTTGTCCTTGTTGCAAACTCAGGAGCCATCTCAATGTCA-3' \\
\hline $\begin{array}{l}\text { Mut370 } \\
\text { forward }\end{array}$ & 5'-CAGTTTCTGGCGAGGAATGCGTGTTCGTGAGATGGCTCCTGAGTTGTAA-3' \\
\hline $\begin{array}{l}\text { Mut370 } \\
\text { Reverse }\end{array}$ & 5'-TTACAACTCAGGAGCCATCTCACGAACACGCATTCCTCGCCAGAAACTG-3' \\
\hline
\end{tabular}


area where the plasmid was visible, so that each rat liver was electroportaed with both the wild type and the mutated version of the $-1256 /+78$ plasmid, in different spots of the liver. Electrodes were sunk to a controlled depth of $2 \mathrm{~mm}$ using a rubber spacer. $6 \times 150$ msec pulses at $100 \mathrm{~V} / \mathrm{cm}$, with a 150 -msec rest between pulses were used to perform the transfection for optimal gene delivery to the liver with minimal tissue damage. To control for transfection efficiency, a plasmid-encoding renilla luciferase was cotransfected. After electroporation, the liver was placed back in the abdomen, and the wound was closed with surgical staples. At the time of surgery, animals were given a single subcutaneous injection of ketoprofen $(5 \mathrm{mg} / \mathrm{kg})$ for analgesia.

The results are expressed as the mean of luciferase activity of the wild type 1256/+78 rPDK4-luciferase to that of the TRE1 mutated -1256/+78-luciferase for the hypothyroid rats or T3-treated rats.

\subsubsection{Electrophoretic mobility shift}

Electrophoretic mobility shift assays were conducted by labeling double-stranded oligonucleotides with Klenow enzyme and $\left[\alpha-{ }^{32} \mathrm{P}\right] \mathrm{dCTP}$. Oligonucleotides were designed that contain sequences for the TRE1. The mutated oligomers for each site (See Figure 3.2 for oligomer sequences) are identical to the mutations introduced into the PDK4-luc by site directed mutagenesis. His-tagged TR $\beta$ and RXR proteins were used to determine the ability of binding the TR $\beta$-RXR complex to bind to either the wild type or the muataed oligos (Bahouth et al., 1997; Park et al., 1997). The protein-DNA binding mixtures contained labeled probe $(30,000 \mathrm{cpm})$ and the purified protein in $80 \mathrm{mM} \mathrm{KCl}$, $25 \mathrm{mM}$ Tris- $\mathrm{HCl}$ ( $\mathrm{pH} 7.4$ ), $0.1 \mathrm{mM}$ EDTA, $1 \mathrm{mM}$ dithiothreitol, 10\% glycerol and poly deoxyinosine-deoxycytidine; which is a nonspecific competitor. The binding reactions was incubated at room temperature for $20 \mathrm{~min}$ and then resolved on 5\% non-denaturing acrylamide gels (80:1, acrylamide/bisacrylamide) in Tris-glycine running buffer $(22 \mathrm{mM}$ Tris and $190 \mathrm{mM}$ glycine). The electrophoresis was carried out at 180 volts for $80 \mathrm{~min}$ at $4{ }^{\circ} \mathrm{C}$.

\subsubsection{Chromatin immunoprecipitation (ChIP) assay}

The ChIP assays were performed as follows. Rat primary hepatocytes were prepared extracted from rat liver tissues by collagenase perfusion as previously described (Deng et al., 2002). Rat primary hepatocytes ( $3 \times 10^{6}$ in $60-\mathrm{mm}$ dishes) were maintained for $12 \mathrm{~h}$ in priming media of RPMI 1640 and $10 \%$ fetal bovine serum. Following two washes with phosphate-buffered saline, the medium was replaced by RPMI 1640 medium containing no serum. Then cells were treated with $100 \mathrm{nM}$ T3 for $24 \mathrm{~h}$. Cross-linking was performed with $1 \%$ formaldehyde for $15 \mathrm{~min}$ at room temperature and stopped by adding $125 \mathrm{mM}$ glycine to each plate for $5 \mathrm{~min}$. Cross-linked hepatocytes were washed twice with ice-cold phosphate-buffered saline. Cells were scraped from the plate and collected by centrifuging for $5 \mathrm{~min}$ at 2,000 rpm. ChIP assays were conducted with slight

modifications following the protocol given by the Millipore Magna 
ChIP kit (\#17-610). The cell pellets were resuspended in $200 \mu 1$ of cell lysis buffer, containing protease inhibitor mixtures (P8340, Sigma). Samples were incubated on ice for $15 \mathrm{~min}$ and vortexed once, followed by homogenization using a Dounce homogenizer. The homogenate was pelleted, resuspended in nuclear lysis buffer, and sonicated to 400-600bp $9 \times 30$ seconds in ice water, followed by centrifugation at 14,000 rpm for $10 \mathrm{~min}$. Chromatin preparations were diluted with dilution buffer and protease inhibitor cocktail and designated as input samples (no antibody), used for immunoprecipitation with the desired antibody, or with the control antibody rabbit $\operatorname{IgG}$ (Santa Cruz \# sc-2027). Antibodies used were anti-TR $\beta$ (sc-67122, Santa Cruz Biotechnology), anti-PGC-1 $\alpha$ (sc-13067, Santa Cruz Biotechnology.), or anti-C/EBP $\beta$ (sc-150, Santa Cruz Biotechnology). Samples were left rotating overnight at $4^{\circ}$ with the antibody and the A magnetic beads. The magnetic beads were pelleted and washed with a low-salt immune complex wash buffer, high-salt immune complex wash buffer, lithiumchloride immune complex wash buffer, and TE buffer. DNA was eluted using the ChIP elution buffer and treated with proteinase $\mathrm{K}$ for 4 hours at $65^{\circ} \mathrm{C}$ followed by 10 minutes at $95{ }^{\circ} \mathrm{C}$. DNA was purified using the Qiaquick PCR purification kit (Qiagen, \#28104).

A total of 3-6 $\mu 1$ of purified sample was used in 35 cycles of PCR. Primers for regions of the target genes are listed in Table 3.2. The PCR products were analyzed on 2\% Nusieve 3:1 agarose (Cambrex, 50094) and visualized with Multilmage Light Cabinet with Alpha Imager EP software. The relative intensity of the bands was determined using AlphaView version 1.2.0.1 (Alpha Innotech Corporation).

\subsubsection{Real-time PCR}

For real time PCR, cDNA was prepared using RNA isolated from primary rat hepatocytes. The RNA was isolated with RNA-Stat-60 (Tel-test) (Zhang et al., 2006). The RNA was then treated with DNase I (2 units) at $37^{\circ} \mathrm{C}$ for $1 \mathrm{~h}$ followed by addition of DNase Inactivation Reagent (Ambion). The concentration of each sample containing DNA free RNA was measured using Nano drop machine (Thermo scientific). Equal amounts of DNA-free RNA were used for first-strand cDNA synthesis. Two $\mu \mathrm{g}$ of DNA-free RNA extracted from different cells was converted to cDNA using Superscript reverse transcriptase III and random hexamers (Invitrogen). The parameters for real time PCR were as follows: $95^{\circ} \mathrm{C}$ for $10 \mathrm{~min}, 40$ cycles of $95^{\circ} \mathrm{C} 30 \mathrm{~s}$ and $60{ }^{\circ} \mathrm{C} 1 \mathrm{~min}$. The final concentration of primers in each well in the PCR plates was $0.1 \mu \mathrm{M}$. . Four $\mu \mathrm{l}$ of 1:5 of each cDNA was used as a template to assess target genes and the normalize control $18 \mathrm{~S}$ gene. The following forward (FP) and reverse primers (RP) were used for real time PCR to quanitate mRNA abundance: PDK4 forward primer, ggattactgaccgectctttagtt; PDK4 reverse primer, gcattccgtgaattgtccatc; PGC-1 $\alpha$ forward primer, atgaatgcagcggtcttagc; PGC-1 $\alpha$ reverse primer, aacaatggcagggtttgttc; CPT-1a forward primer, cggttcaagaatggcatcatc; CPT-1a reverse primer, tcacacccaccaccacgat; 18S forward primer, cggctaccacatccaaggaa; $18 \mathrm{~S}$ reverse primer, ttttcgtcactacctccccg. While the primers for both the C/EBP $\beta$ and the PEPCK were obtained from Qiagen (cat \# QT00366478 and QT01619975, respectively). 
Table 3.2: Sequences of the primers used in the ChIP assay to demonstrate interactions of TR $\beta$, PGC-1 $\alpha$ and C/EBP $\beta$ with the PDK4 gene.

$\begin{array}{lll}\text { Regions of PDK4 gene } & \text { Forward primer (FP) } & \text { Reverse primer (RP) }\end{array}$
amplified

rPDK4, -591/-338

(proximal)

rPDK4, $-1535 /-1228$

(TRE site)

rPDK4, -6634/-6377

(upstream)
TAAGGCTATTTAGGCAGTTT CCAGACTTGTCCTTGTTTAC

AGTGTCTCCACCAGATTGT

CTAAGAGAGCTAACCTAGT

TATGAGAAGTGCTGCAATAA CCAGACTTGTCCTTGTTTAC 
The results are relative quantification relates the PCR signal of the target transcript in treated cells to that of the untreated control cells using the delta delta CT method as described previously (Livak \& Schmittgen, 2001).

\subsubsection{Western blot}

Western analysis was performed on whole cell extracts from non-treated primary rat hepatocytes or treated with $100 \mathrm{nM}$ of T3 for 24 hours. Cells were lysed in RIPA buffer (20 mM Tris-Cl, pH 7.4, $150 \mathrm{mM} \mathrm{NaCl}, 0.5 \%$ deoxycholate, 5 mM EDTA pH 8.0, $0.1 \% \mathrm{SDS}$, and diluted protease inhibitor mixture). The cells were vortexed for 1 minute. The cell membranes was removed by centrifugation for $25 \mathrm{~min}$ at $4{ }^{\circ} \mathrm{C}$. An equal amount of protein was loaded onto a $12 \%$ SDS-PAGE gel and transferred to a $0.45-\mu \mathrm{m}$ pure nitrocellulose membrane (Bio-Rad). Blots were immunoblotted with primary antibodies (anti-PGC-1 $\alpha$, anti-C/EBP $\beta$ and anti-PDK4) in phosphate-buffered saline containing 5\% nonfat dry milk powder and were incubated with horseradish peroxidase-conjugated antirabbit secondary antibody. Immunoreactive proteins were identified using Super Signal West Femto Chemiluminescence Substrate (Pierce). The ChemiDoc ${ }^{\mathrm{TM}}$ XRS gel documentation system (Bio-Rad) was used to quantify the immunoreactive proteins. Actin was used as the loading control for each lane.

\subsubsection{Adenoviral infection}

Purified adenoviruses encoding shRNA specific for the PGC-1 $\alpha$ (Ad-siPGC-1 $\alpha$ ) and control adenoviruses encoding non-template shRNA (Ad-NC) were amplified by Viraquest incorporation. The purified adenoviruses encoding shRNA designed for $\mathrm{C} / \mathrm{EBP} \beta$ targeting its 3'-untranslated region (5'-CCGGGCCCTGAGTAATCAC-3') were obtained from Dr. Jacob E. Friedman from University of Colorado, together with its control adenoviruses encoding non-template shRNA (Ad-control). Primary rat hepatocytes were plated at a density of $3 \times 10^{6}$ in a 60-mm dish in RPMI 1640 media (3 plates for each condition). Five hours after plating the cells, media was aspirated and 2 $\mathrm{ml}$ of purified adenoviruses was added to the cells in the presence of $8 \mathrm{ug} / \mathrm{ml}$ polybrene. The media was changed 24 hours post transduction and the cells were treated with 100nM T3 for another 24 hours in serum free RPMI 1640. The hepatocytes were harvested and RNA was isolated using RNA Stat 60 and converted to cDNA after DNase treatment and real-time PCR was performed according to the instructions stated under the real-time PCR section (see section 3.2.6).

\subsubsection{Superarray ${ }^{\circledR}$ real time PCR}

To investigate the role of T3 in the expression of different transcription factors, superarray ${ }^{\circledR}$ real time PCR (SABioscience) was performed. The superarray is a custom designed real time plate, containing primers for 90 transcription factors and 6 controls, complete list of the genes is provided in Table 3.3. RNA was extracted from non-treated 
rat primary hepatocytes and hepatoctes treated with T3 100nM for 24 hours as mentioned in section 3.2.6 Real-time PCR. The extracted RNA was converted to cDNA using first strand synthesis kit from SABioscience, the produced cDNA was then assessed on the superarray according to the manufacturer procedures using the Roche Light cycler 480 machine. The parameters for real time PCR were as follows: $95^{\circ} \mathrm{C}$ for $10 \mathrm{~min}, 40$ cycles of $95^{\circ} \mathrm{C} 15 \mathrm{~s}$ and $60{ }^{\circ} \mathrm{C} 1 \mathrm{~min}$. 
Table 3.3: Complete list of the genes primers on the superarray real time plate.

\begin{tabular}{|c|c|c|}
\hline Gene name & Ref seq & Gene symbol \\
\hline $\begin{array}{l}\text { 1. Acyl-CoA synthetase long-chain family } \\
\text { member } 1\end{array}$ & NM_012820 & Acsl 1 \\
\hline 2. Carnitine palmitoyltransferase $1 \mathrm{a}$, liver & NM_031559 & Cpt1a \\
\hline 3. Carnitine palmitoyltransferase $1 \mathrm{~b}$, muscle & NM_013200 & Cpt1b \\
\hline 4. Carnitine palmitoyltransferase $1 \mathrm{c}$ & XM_001075677 & Cpt1c \\
\hline 5. Carnitine acetyltransferase & NM_001004085 & Crat \\
\hline $\begin{array}{l}\text { 6. Solute carrier family } 25 \text { (mitochondrial } \\
\text { carnitine/acylcarnitine translocase), member } \\
20\end{array}$ & NM_053965 & Slc25a20 \\
\hline 7. Carnitine palmitoyltransferase 2 & NM_012930 & Cpt2 \\
\hline $\begin{array}{l}\text { 8. Acyl-Coenzyme A dehydrogenase, very } \\
\text { long chain }\end{array}$ & NM_012891 & Acadvl \\
\hline $\begin{array}{l}\text { 9. Acetyl-coenzyme A dehydrogenase, } \\
\text { medium chain }\end{array}$ & NM_016986 & Acadm \\
\hline $\begin{array}{l}\text { 10. Cytochrome } \mathrm{P} 450 \text {, family } 2 \text {, subfamily e, } \\
\text { polypeptide } 1\end{array}$ & NM_031543 & Cyp2e1 \\
\hline 11. Malonyl-CoA decarboxylase & NM_053477 & Mlycd \\
\hline 12. Acetyl-Coenzyme A carboxylase beta & NM_053922 & Acacb \\
\hline $\begin{array}{l}\text { 13. Hydroxyacyl-Coenzyme A } \\
\text { dehydrogenase/3-ketoacyl-Coenzyme, alpha } \\
\text { subunit }\end{array}$ & NM_130826 & Hadha \\
\hline 14. $\mathrm{Cd} 36$ antigen & NM_031561 & $\mathrm{Cd} 36$ \\
\hline $\begin{array}{l}\text { 15. Solute carrier family } 27 \text { (fatty acid } \\
\text { transporter), member } 1\end{array}$ & NM_053580.2 & Slc27a1 \\
\hline $\begin{array}{l}\text { 16. Solute carrier family } 27 \text { (fatty acid } \\
\text { transporter), member } 2\end{array}$ & NM_031736.1 & Slc27a2 \\
\hline $\begin{array}{l}\text { 17. Solute carrier family } 27 \text { (fatty acid } \\
\text { transporter), member } 4\end{array}$ & XM_231115 & Slc27a4 \\
\hline $\begin{array}{l}\text { 18. Solute carrier family } 27 \text { (fatty acid } \\
\text { transporter), member } 5\end{array}$ & NM_024143 & Slc27a5 \\
\hline $\begin{array}{l}\text { 19. Solute carrier family } 2 \text { (facilitated glucose } \\
\text { transporter), member } 2\end{array}$ & NM_012879 & Slc2a2 \\
\hline $\begin{array}{l}\text { 20. Solute carrier family } 2 \text { (facilitated glucose } \\
\text { transporter), member } 4\end{array}$ & NM_012751 & Slc2a4 \\
\hline 21. Hexokinase 2 & NM_012735 & Hk2 \\
\hline 22. Phosphoenolpyruvate carboxykinase 1 & NM_198780 & Pck1 \\
\hline 23. Glucose-6-phosphatase, catalytic & NM 013098 & G6pc \\
\hline
\end{tabular}


Table 3.3: (continued).

\begin{tabular}{|c|c|c|}
\hline Gene name & Ref seq & Gene symbol \\
\hline $\begin{array}{l}\text { 24. Pyruvate dehydrogenase kinase, } \\
\text { isoenzyme } 2\end{array}$ & NM_030872 & Pdk2 \\
\hline $\begin{array}{l}\text { 25. Pyruvate dehydrogenase kinase, } \\
\text { isoenzyme } 4\end{array}$ & NM_053551 & Pdk4 \\
\hline 26. Acetyl-coenzyme A acetyltransferase 1 & NM_017075 & Acat1 \\
\hline $\begin{array}{l}\text { 27. 3-hydroxy-3-methylglutaryl-Coenzyme A } \\
\text { synthase } 2\end{array}$ & NM_173094 & Hmgcs 2 \\
\hline $\begin{array}{l}\text { 28. 3-hydroxy-3-methylglutaryl-Coenzyme A } \\
\text { lyase }\end{array}$ & NM_024386 & $\mathrm{Hmgcl}$ \\
\hline 29. 3-hydroxybutyrate dehydrogenase, type 1 & NM_053995 & Bdh1 \\
\hline $\begin{array}{l}\text { 30. 3-hydroxybutyrate dehydrogenase, type } 2 \\
\text { (predicted) }\end{array}$ & XM_215705 & Bdh2 \\
\hline 31. Stearoyl-Coenzyme A desaturase 1 & NM_139192 & Scd1 \\
\hline 32. Fatty acid desaturase 2 & NM_031344 & Fads2 \\
\hline 33. Acyl-Coenzyme A oxidase 1, palmitoyl & NM_017340 & Acox 1 \\
\hline 34. Acyl-Coenzyme A oxidase 3, pristanoyl & NM_053339 & Acox 3 \\
\hline 35. Hydroxysteroid (17-beta) dehydrogenase 4 & NM_024392 & Hsd17b4 \\
\hline 36. Acetyl-Coenzyme A acyltransferase 1 & NM_012489 & Acaa1 \\
\hline 37. Alpha-methylacyl-CoA racemase & NM_012816 & Amacr \\
\hline $\begin{array}{l}\text { 38. 2-4-dienoyl-Coenzyme A reductase 2, } \\
\text { peroxisomal }\end{array}$ & NM_171996 & Decr2 \\
\hline 39. Acyl-CoA thioesterase 8 & NM_130756 & $A \cot 8$ \\
\hline 40. Phytanoyl-CoA hydroxylase & NM_053674 & Phyh \\
\hline $\begin{array}{l}\text { 41. ATP-binding cassette, sub-family D (ALD), } \\
\text { member } 1 \text { (predicted) }\end{array}$ & XM_343840 & Abcd 1 \\
\hline 42. Carnitine O-octanoyltransferase & NM_031987 & Crot \\
\hline $\begin{array}{l}\text { 43. ATP-binding cassette, sub-family D (ALD), } \\
\text { member } 2\end{array}$ & NM_033352 & Abcd2 \\
\hline $\begin{array}{l}\text { 44. ATP-binding cassette, sub-family D (ALD), } \\
\text { member } 3\end{array}$ & NM_012804 & Abcd 3 \\
\hline $\begin{array}{l}\text { 45. Nuclear receptor subfamily } 0 \text {, group B, } \\
\text { member } 2\end{array}$ & NM_057133 & $\mathrm{Nr} 0 \mathrm{~b} 2$ \\
\hline 46. Apolipoprotein A-IV & NM_012737 & Apoa4 \\
\hline 47. Peroxisomal biogenesis factor $11 \mathrm{~A}$ & NM_053487 & Pex11a \\
\hline 48. Acyl-CoA thioesterase 12 & NM_130747 & $A \cot 12$ \\
\hline 49. Fatty acid synthase & NM_017332 & Fasn \\
\hline 50. Acetyl-coenzyme A carboxylase alpha & NM_022193 & Acaca \\
\hline
\end{tabular}


Table 3.3: (continued).

\begin{tabular}{|c|c|c|}
\hline Gene name & Ref seq & Gene symbol \\
\hline $\begin{array}{l}\text { 51. Protein phosphatase } 2 \mathrm{C} \text {, magnesium } \\
\text { dependent, catalytic subunit }\end{array}$ & NM_019372 & Ppm2c \\
\hline $\begin{array}{l}\text { 52. Pyruvate dehydrogenase phosphatase } \\
\text { isoenzyme } 2\end{array}$ & NM_145091 & Pdp2 \\
\hline 53. Fatty acid binding protein 1 , liver & NM_012556 & Fabp1 \\
\hline 54. Fatty acid binding protein 3 & NM_024162 & Fabp3/SHP \\
\hline 55. Insulin receptor substrate 2 & XM_573948 & Irs 2 \\
\hline 56. Thyroid hormone receptor alpha & NM_001017960 & Thra \\
\hline 57. Thyroid hormone receptor beta & NM_012672 & Thrb \\
\hline $\begin{array}{l}\text { 58. Peroxisome proliferator activated receptor } \\
\text { alpha }\end{array}$ & NM_013196 & Ppara \\
\hline $\begin{array}{l}\text { 59. Peroxisome proliferator activated receptor } \\
\text { delta }\end{array}$ & NM_013141 & Ppard \\
\hline $\begin{array}{l}\text { 60. Peroxisome proliferator activated receptor } \\
\text { gamma }\end{array}$ & NM_013124 & Pparg \\
\hline 61. Estrogen related receptor, alpha & NM_001008511 & Esrra \\
\hline 62. Estrogen-related receptor gamma & NM_203336 & Esrrg \\
\hline $\begin{array}{l}\text { 63. CCAAT/enhancer binding protein (C/EBP), } \\
\text { alpha }\end{array}$ & NM_012524 & Cebpa \\
\hline $\begin{array}{l}\text { 64. CCAAT/enhancer binding protein (C/EBP), } \\
\text { beta }\end{array}$ & NM_024125 & Cebpb \\
\hline $\begin{array}{l}\text { 65. CCAAT/enhancer binding protein (C/EBP), } \\
\text { beta }\end{array}$ & NM_024125 & Cebpd \\
\hline $\begin{array}{l}\text { 66. Sirtuin } 1 \text { (( silent mating type information } \\
\text { regulation } 2 \text {, homolog) } 1\end{array}$ & XM_228146 & Sirt1 \\
\hline $\begin{array}{l}\text { 67. Peroxisome proliferative activated receptor, } \\
\text { gamma, coactivator } 1 \text { alpha }\end{array}$ & NM_031347 & Ppargcla \\
\hline $\begin{array}{l}\text { 68. Peroxisome proliferative activated receptor, } \\
\text { gamma, coactivator } 1 \text { beta }\end{array}$ & NM_176075 & Ppargc1b \\
\hline 69. Forkhead box O1A & XM_342244 & Foxola \\
\hline 70. Forkhead box O3a (predicted) & XM_215421 & Foxo3a \\
\hline 71. Forkhead box A2 & NM_012743 & HNF3b/FoxA2 \\
\hline 72. Lipin 1 & NM_001012111 & Lpin 1 \\
\hline 73. Lipin 2 (predicted) & XM_237521 & Lpin2 \\
\hline 74. Sterol regulatory element binding factor 1 & XM_213329 & Srebfl \\
\hline 75. Nuclear respiratory factor 1 (predicted) & XM_231566 & Nrf1 \\
\hline 76. GA repeat binding protein, beta 1 & XM_344606 & Gabpb1 \\
\hline 77. Similar to myocyte enhancer factor $2 \mathrm{C}$ & NM_001014035 & LOC309957 \\
\hline
\end{tabular}


Table 3.3: (continued).

\begin{tabular}{|c|c|c|}
\hline Gene name & Ref seq & Gene symbol \\
\hline $\begin{array}{l}\text { 78. Nuclear receptor subfamily } 2 \text {, group } F \text {, } \\
\text { member } 2\end{array}$ & NM_080778 & $\mathrm{Nr} 2 \mathrm{f} 2$ \\
\hline $\begin{array}{l}\text { 79. Uncoupling protein } 2 \text { (mitochondrial, proton } \\
\text { carrier) }\end{array}$ & NM_019354 & Ucp2 \\
\hline $\begin{array}{l}\text { 80. Uncoupling protein } 3 \text { (mitochondrial, proton } \\
\text { carrier) }\end{array}$ & NM_013167 & Ucp3 \\
\hline 81. Diacylglycerol O-acyltransferase 1 & NM_053437 & Dgat1 \\
\hline $\begin{array}{l}\text { 82. Diacylglycerol O-acyltransferase homolog } 2 \\
\text { (mouse) }\end{array}$ & NM_001012345 & Dgat2 \\
\hline 83. Superoxide dismutase 1 & NM_017050 & Sod1 \\
\hline 84. Superoxide dismutase 2 , mitochondrial & NM_017051 & Sod2 \\
\hline $\begin{array}{l}\text { 85. Cytochrome c oxidase subunit IV } \\
\text { isoform } 1\end{array}$ & NM_017202 & Cox4i1 \\
\hline 86. Citrate synthase & NM_130755 & Cs \\
\hline 87. Deiodinase, iodothyronine, type II & NM_031720 & Dio2 \\
\hline $\begin{array}{l}\text { 88. NK2 transcription factor related, locus } 5 \\
\text { (Drosophila) }\end{array}$ & NM_053651 & Nkx2-5 \\
\hline 89. Actin, beta & NM_031144 & ActB \\
\hline 90. Ribosomal protein L13A & NM_173340 & RPL13A \\
\hline 91. Glyceraldehyde-3-phosphate dehydrogenase & NM_017008 & GAPDH \\
\hline \multicolumn{3}{|l|}{ 92. Genomic DNA Contamination control } \\
\hline \multicolumn{3}{|l|}{ 93. Reverse Transcriptase control } \\
\hline \multicolumn{3}{|l|}{ 94. Positive PCR control } \\
\hline 95. Positive PCR control & & \\
\hline
\end{tabular}




\section{CHAPTER 4: DISCUSSION}

Both thyroid hormone (T3) and the transcriptional coregulators (transcriptional factors \& coactivators) play an important role in regulating the transcription of genes involved in the glucose and fatty acid metabolism. In this study, I focused on the role of the thyroid hormone receptor beta (TR $\beta)$, proliferator-activated receptor gamma coactivator-1 alpha (PGC-1 $\alpha)$ and the CCAAT/enhancer binding protein beta (C/EBP $\beta)$ in the regulation of pyruvate dehydrogenase kinase 4 (PDK4) by thyroid hormone.

Pyruvate dehydrogenase kinases decrease the pyruvate dehydrogenase complex (PDC) activity by phosphorylation, thereby inhibiting the conversion of pyruvate to acetyl-CoA. Changes in PDC activity link glucose metabolism to fatty acid metabolism. PDKs facilitate gluconeogenesis by inhibiting PDC and preserving the three carbon compounds (pyruvate, lactate and alanine) as substrates for gluconeogenesis. At the same time, PDC inhibition (via PDKs) allows the oxidation of fatty acids to be the primary source of energy. Elevated gluconeogenesis and disturbance in fatty acid metabolism are observed in metabolic diseases as diabetes, obesity and hyperthyroidism (Basu et al., 2005; Baxter et al., 2004; Chevalier et al., 2006; Crunkhorn \& Patti, 2008; Kabir et al., 2005; Wensaas et al., 2009). My studies that focused on the mechanism by which thyroid hormone regulates the transcription of the PDK4 gene and the role of the transcriptional coregulators in this regulation, have shed light on the role of thyroid hormone in both the glucose and fatty acid metabolism. In addition, I have provided a broad picture of the network of transcription factors and coactivators involved in the hepatic regulation of T3 responsive metabolic genes.

\subsection{Regulation of the PDK4 gene expression}

\subsubsection{The role of the thyroid hormone in the PDK4 gene expression}

T3 is a prominent regulator of the PDK4 gene expression and activity in heart, liver and skeletal muscles (Holness et al., 2003; Sugden et al., 2000a; Sugden et al., $2000 \mathrm{~b}$ ). The transient transfection experiments done in this study showed that indeed T3 can induce PDK4 gene expression in vitro in hepatoma HepG2 cells and in vivo in hyperthyroid rats. This stimulation was mediated through a TRE site found in the PDK4 gene promoter designated as (agggcaccttgggtaa) which resembles the direct repeat separated by 4 nucleotides (DR4) type of TRE (Williams \& Brent, 1995). We were the first to identify a TRE site within the rPDK4 promoter indicating that T3 can activate the PDK4 gene expression directly and not through an intermediate factor. However, the identification of a TRE does not rule out a role of intermediate factors in the activation of the T3 induction. Therefore, I studied the role PGC- $1 \alpha$ and $\mathrm{C} / \mathrm{EBP} \beta$ as two potential intermediate factors in this induction. 


\subsubsection{The role of the PGC-1 $\alpha$ in the induction of the PDK4 by thyroid hormone}

Previous studies showed that there are links between the T3 metabolic actions and PGC-1 $\alpha$. First, PGC-1 $\alpha$ coactivated the thyroid receptors (Puigserver et al., 1998; Wu et al., 2002). PGC-1 $\alpha$ can also influence thyroid hormone action by altering RNA processing of $\mathrm{TR} \alpha$ transcripts, thus modulating the ratio of $\mathrm{TR} \alpha_{1}$ and $\mathrm{TR} \alpha_{2}$ isoforms which is accompanied by a decrease in 5'-deiodinase expression (Thijssen-Timmer et al., 2006). Second, Weitzel et al reported that the hepatic PGC- $1 \alpha$ mRNA expression is induced by T3 treatment (Weitzel et al., 2001). Third, the enhancement of the induction of carnitine palmitoyltransferase 1a (CPT-1a) by thyroid hormone in the presence of PGC-1 $\alpha$ was reported in previous studies (Zhang et al., 2004b). Finally, a recent review by Crunkhorn et al emphasized the potential linkage between PGC-1 coactivators and thyroid hormone action on the mitochondrial oxidation pathway (Crunkhorn \& Patti, 2008).

In agreement with the proposed role of the PGC-1 $\alpha$ in the $\mathrm{T} 3$ action, my experiments showed an association between the PGC- $1 \alpha$ and both the proximal and the TRE site in the PDK4 promoter in vivo indicated by ChIP technique. Previous studies had reported that PGC-1 $\alpha$ stimulated PDK4 (Wende et al., 2005). This association was increased significantly by thyroid hormone. Moreover, T3 treatment induced the mRNA and the protein level of both PDK4 and PGC-1 $\alpha$. In addition, overexpression of PGC-1 $\alpha$ showed significant synergistic effect on the T3 induction of PDK4 gene expression. However, this synergistic effect was not abolished by mutating either the ERR $\alpha$ or the FOXO1 binding sites, indicating that PGC- $1 \alpha$ is involved in the PDK4 regulation not only via the ERR $\alpha$ action but it can also exert its action through interacting with the TRs (Puigserver et al., 1998; Wu et al., 2002).

Adenoviral-mediated silencing of the PGC-1 $\alpha$ was utilized to investigate the role of the PGC-1 $\alpha$ in the induction of PDK4 and other metabolic genes by T3. This experiment showed that silencing PGC-1 $\alpha$ abolished the ability of T3 to induce PDK4, CPT-1a, PEPCK and C/EBP $\beta$ gene expression indicating that PGC- $1 \alpha$ is an important coactivator for the $\mathrm{T} 3$ induction of these genes in primary hepatocytes. This experiment contrasts with a recent study conducted by Wetizel's group, as they reported that silencing PGC-1 $\alpha$ had no effect on the induction of gene expression by T3 in rat pituitary (GC) cells (Wulf et al., 2007). In contrast with our studies, they measured the T3 effect on two other genes, glycerol-3-phosphate dehydrogenase (GPDH) and adenine nucleotide translocater 2 (ANT2). More importantly, they used GC pituitary cells, which are subclone of the rat $\mathrm{GH}_{3}$ pituitary tumor cell line and posses a different gene expression pattern than that of primary hepatocytes. The proliferation of GC cells are highly induced by T3 treatment (Barrera-Hernandez et al., 1999; Kitagawa et al., 1987; Laverriere et al., 1986; Miller et al., 2001; Nass et al., 2000). On the other hand, T3 has no effect on the proliferation of hepatocytes in vitro (Kariv et al., 2003). All these data suggest that the T3 regulation in pituitary GC cells is likely different than that for primary hepatocytes. It is also noteworthy that PGC- $1 \alpha$ is underexpressed in immortalized tumor cell lines as it was reported in human hepatoma cells (Martinez-Jimenez et al., 2006). In addition, The role of PGC- $1 \alpha$ in the T3 mediated gene expression in heart is still controversial. Two studies 
had indicated that PGC-1 is potentially involved in mediating myocardial-specific remodeling of mitochondria in response to thyroid hormone treatment (Goldenthal et al., 2004; McClure et al., 2005). However, two other studies had ruled out a role for the PGC-1 $\alpha$ in the cardiac mitochondrial adaptations by T3 (Athea et al., 2007; Irrcher et al., 2003), although, Irrcher et al stated that PGC-1 $\alpha$ is still involved in the mitochondrial adaptation by $\mathrm{T} 3$ treatment in liver and skeletal muscles indicating that PGC-1 $\alpha$ involvement in the T3 mediated gene expression is potentially tissue specific (Irrcher et al., 2003).

On the other hand, number of previous studies support the results from the adenoviral-mediated silencing of PGC-1 $\alpha$ experiment. One of these studies was conducted by the Spiegelman's group as they reported that C/EBP $\beta$ was abnormally activated in the fed state in the PGC-1 $\alpha$ null mice (Lin et al., 2004). Normally, fasting not feeding induced C/EBP $\beta$ in wild type mice (Lin et al., 2004). C/EBP $\delta$ was also induced in the fed liver lacking PGC-1 $\alpha$, while $\mathrm{C} / \mathrm{EBP} \alpha$ is expressed normally with respect to PGC-1 $\alpha$ genotypes indicating that silencing PGC- $1 \alpha$ alters expression of specific C/EBP isoforms. The aberrant induction of $\mathrm{C} / \mathrm{EBP} \beta$ and $\mathrm{C} / \mathrm{EBP} \delta$, however, is absent when PGC$1 \alpha$-deficient hepatocytes are grown in cell culture, suggesting that systemic signals are likely responsible for their increased expression (Lin et al., 2004). Although, this study had linked the PGC-1 $\alpha$ to the $\mathrm{C} / \mathrm{EBP} \beta$ gene induction by another physiological process which is feeding or fasting status and not $\mathrm{T} 3$ action, however, it supports our results that PGC- $1 \alpha$ is an important regulator of $\mathrm{C} / \mathrm{EBP} \beta$ gene expression. Also, as supportive evidence Crunkhorn and Patti had stated in their review, that their unpublished data indicate that siRNA targeting PGC- $1 \alpha$ or PGC- $1 \beta$ decreased the mRNA of TR $\alpha_{1}$ and mitochondrial genes in skeletal muscle (Crunkhorn \& Patti, 2008).

Based on the transient transfection, ChIP, and adenovirus mediating knockdown experiments done in this dissertation, we can model the mechanism by which PGC- $1 \alpha$ coactivate the induction of PDK4 gene expression by T3 (Figure 4.1). In this model, T3 increases the abundance of the PGC- $1 \alpha$ so that more PGC- $1 \alpha$ will be available to stimulate the PDK4 gene. PGC-1 $\alpha$ can induce the PDK4 gene expression through the interaction with the ERR $\alpha$ at the proximal part of the PDK4 promoter (Wende et al., 2005; Zhang et al., 2006). Also, PGC-1 $\alpha$ can synergistically coactivate the T3 induction of the PDK4 gene by interacting with the TR and RXR at the TRE site of the PDK4 promoter, even after disrupting the ERR $\alpha$ binding sites.

\subsubsection{The role of the C/EBPß in the induction of the PDK4 by thyroid hormone}

Although, our lab and others had reported that $\mathrm{C} / \mathrm{EBP} \alpha$ is involved in the T3 induction of number of genes (Jackson-Hayes et al., 2003; Jurado et al., 2002; Park et al., 1997; Y in et al., 2005), to our knowledge only two studies had linked the C/EBP $\beta$ to T3 action. The first study was done by Menendez-Hurtado, in which he reported that both $\mathrm{C} / \mathrm{EBP} \alpha$ and $\mathrm{C} / \mathrm{EBP} \beta$ gene expression decreased in liver of congenital hypothyroid rats during development (Menendez-Hurtado et al., 1997). Upon injection of those hypothyroid animals with thyroid hormone, there was an increase of hepatic $\mathrm{C} / \mathrm{EBP} \alpha$ and 


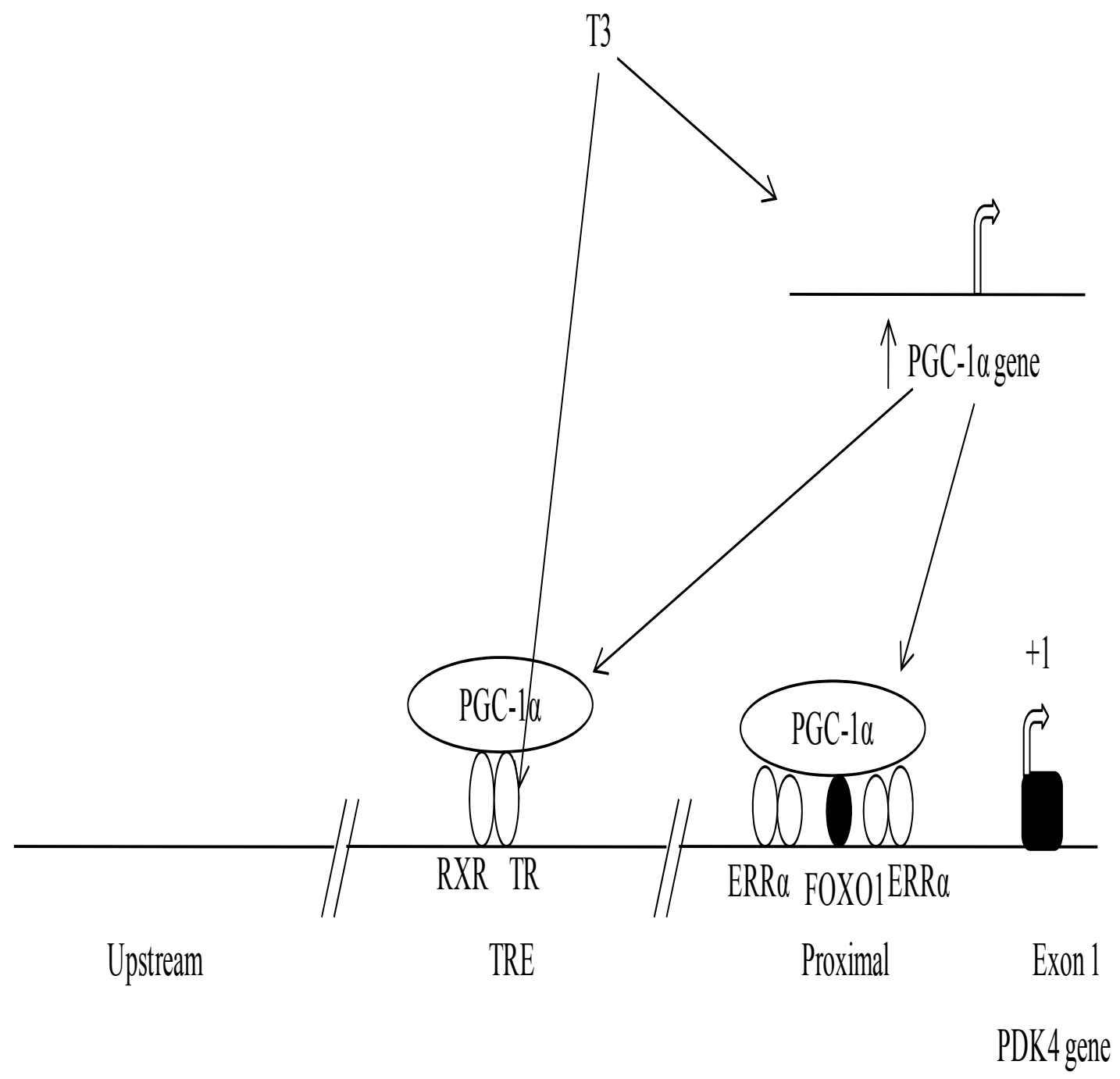

Figure 4.1: PGC-1a is a coactivator in the T3 induction of the PDK4 gene expression.

T3 activates the PDK4 gene expression directly through a TRE site and indirectly by stimulating the expression of the PGC- $1 \alpha$ gene expression. Also, T3 increases the association between PGC- $1 \alpha$ and the PDK4 promoter. 
C/EBP $\beta$ mRNA and protein levels (Menendez-Hurtado et al., 1997). The second study was carried out by our lab, and we reported that $\mathrm{C} / \mathrm{EBP} \beta$ overexpression enhanced the T3 induction of PEPCK (Park et al., 1999).

In this study we are the first to report that overexpression of the $\mathrm{C} / \mathrm{EBP} \beta$ in transient transfections induced the PDK4 promoter. In addition, C/EBP $\beta$ enhanced the T3 induction of PDK4 gene expression. Also, T3 treatment induced the C/EBP $\beta$ gene expression in primary hepatocytes. Moreover, adenoviral-mediated silencing of C/EBP $\beta$ experiments demonstrated that $\mathrm{C} / \mathrm{EBP} \beta$ is required for full induction of PDK4 mRNA by $\mathrm{T} 3$, as knocking down the $\mathrm{C} / \mathrm{EBP} \beta$ reduced the ability of T3 to induce PDK4 gene expression. The Ad-siC/EBP $\beta$ did not reduce significantly the basal levels of PDK4 mRNA levels. These results are similar to studies done by the Friedman's group, where they reported that $\mathrm{C} / \mathrm{EBP} \beta$ is not essential for maintenance of the basal PEPCK mRNA levels in C/EBP $\beta$ knockout mice (Arizmendi et al., 1999). However, C/EBP $\beta$ deletion limited the full induction of PEPCK and glucose 6-phosphatase genes in streptozotocin induced diabetic mice (Arizmendi et al., 1999). Although this study had linked C/EBP $\beta$ as essential factor for metabolic and gene regulatory responses to diabetes, it did not connect $\mathrm{C} / \mathrm{EBP} \beta$ to $\mathrm{T} 3$ action. However, $\mathrm{C} / \mathrm{EBP} \beta$ does modulate gluconeogenesis, a process regulated by both PDK4 gene and T3 (Fowden et al., 2001; Park et al., 1997; Sparks et al., 2006; Sugden \& Holness, 2002). It is also noteworthy that C/EBP $\beta$ participates in the regulation of the PEPCK gene in response to different stimulus like cAMP, glucocorticoids and insulin (Croniger et al., 2001; Duong et al., 2002; Yamada et al., 1999).

\subsection{Transcription factors and metabolic genes involved in the thyroid hormone network in primary hepatocytes}

Previous studies had showed that T3 regulates different aspects of both glucose and fatty acid metabolism. T3 simulates gluconeogenesis, cellular glucose uptake and glycogenolysis (Crunkhorn \& Patti, 2008; Fowden et al., 2001; Johnson, 2006; Park et al., 1997). In addition, T3 stimulates triglyceride production, lipogenesis, lipolysis and fatty acid oxidation (Feng et al., 2000; Moreno et al., 2008; Ness \& Zhao, 1994; Pykalisto et al., 1976; Ribeiro, 2008; Wahrenberg et al., 1994; Zhang et al., 2004b).

T3 exerts all these metabolic effects through inducing a network of transcription coregulators and metabolic genes (Weitzel et al., 2003a; Weitzel et al., 2003b; Weitzel et al., 2001). In this dissertation I used superarray ${ }^{\circledR}$ real time PCR arrays to identify selected metabolic genes and transcription coregulators that are regulated by 24 hours of T3 treatment in primary hepatocytes. Although, a similar experiment had been performed by the Weitzel's group, this experiment was done using a broad microarray technique unlike my experimental approach which focused on transcription coregulators and metabolic genes involved in glucose and fatty acid metabolism (Weitzel et al., 2003a). Also, microarray sensitivity is different than real-time PCR sensitivity (Kubista et al., 2006). Finally Wetizel's experiment was done using RNA extracted from T3-treated 
hypothyroid rats and outcomes from these rats can be different than that done using RNA extracted from cultured T3-treated primary hepatocytes from normal rats.

Indeed out of the 27 genes upregulated by T3 after 24 hours of treatment that I have reported in this study, only 4 genes, the two transcription coactivators PGC- $1 \alpha$ and PGC-1 $\beta$, Cytochrome P450 which is involved in both fatty acid oxidation and gluconeogenesis (Lieber, 1999), and fatty acid binding protein 1(Fabp1) involved in fatty acid metabolism (Kabir et al., 2005), are in common with that reported by Weitzel (Weitzel et al., 2003a). However, many of the genes detected in my study had been reported by previous studies to be stimulated by T3. In this study we reported the upregulation of some transcription factors like sterol regulatory element binding transcription factor (Srebf1), C/EBP $\beta$, peroxisomal proliferator activated receptor delta (PPAR $\delta$ ). These factors had been reported to be induced by $\mathrm{T} 3$ treatment by other studies (de Lange et al., 2007; Menendez-Hurtado et al., 1997; Zhang et al., 2003). On the other hand, to our knowledge we are the first to report the T3 induction of transcription factors lipin gene isoforms 1 and 2, ERR $\gamma$, GA binding protein transcription factor, beta subunit 1 (Gabpb1), Sirtuin 1 (Sirt-1) and transcription coactivator homeobox protein NK-2 (NKx2.5). It is important to mention in this aspect that lipin 1 was reported to be an amplifier of the PGC-1 $\alpha$ /PPAR $\alpha$-mediated control of hepatic lipid metabolism and it exerts its action by direct interacting with both PGC-1 $\alpha$ and PPAR $\alpha$ (Finck et al., 2006). Also, Sirt-1 had been involved in the activation of PGC-1 $\alpha$ by deacetylation (GerhartHines et al., 2007; Markus \& Morris, 2008). Thus, upregulation of lipin 1 and Sirt-1 by T3 may be another way to regulate the activity of PGC- $1 \alpha$.

Also, in this study we reported the T3 induction of genes involved in gluconeogenesis, PEPCK and G6pase and solute carrier family 2 (facilitated glucose transporter), member 4 (Slc2a4). All of them had been previously reported to be T3 responsive genes (Fowden et al., 2001; Park et al., 1997; Torrance et al., 1997). For genes involved in fatty acid oxidation and synthesis, we are the first to report the T3 induction of 3-ketoacyl-Coenzyme A thiolase alpha subunit (Hadha), fatty acid binding protein 3/small heterodimer partner (Fabp3/SHP), solute carrier family 25 carnitine/acylcarnitine translocase member 20 (Slc25a20), solute carrier family 27 fatty acid transporter member 5 (Slc27a5) and acetyl-Coenzyme A carboxylase beta (Acacb). In addition, we reported the upregulation of carnitine palmitoyltransferase 1a (CPT-1a) and fatty acid synthase (FAS) by T3 treatment, which had been previously documented (Xiong et al., 1998; Zhang et al., 2004b).

Finally, using this superarray technique we reported the T3 induction of miscellaneous genes. First, deiodinase type II (Dio2) which is responsible for generation of T3 from T4 predominantly in brain, pituitary, and brown adipose tissue in mammals (Yen, 2001) and we detected its hepatic upregulation in response to T3 treatment. It was recently reported that Dio2 mRNA was detectable by real time PCR in livers of cows and in the livers of liver X receptors null mice (Capuco et al., 2008; Kalaany et al., 2005). Second, we confirmed PDK4 (gene of interest of this dissertation) upregulation by T3 treatment. At last, uncoupling proteins 2 and 3 (UCP2 and UCP3) was also found to be $\mathrm{T} 3$ responsive genes. UCP3 was previously reported to be induced by T3 treatment (de 
Lange et al., 2007), however to our knowledge we are the first to report upregulationn of UCP2 by $\mathrm{T} 3$ treatment.

Thus, this part of the dissertation has pinpointed the network of transcription coregulators and metabolic genes involved in T3 hepatic action. Further studies using knockout mice or mice injected using virus mediating silencing of these genes can indicate its importance in the T3 mediated hepatic gene expression. 


\section{LIST OF REFERENCES}

Abel, E.D., Boers, M.E., Pazos-Moura, C., Moura, E., Kaulbach, H., Zakaria, M., Lowell, B., Radovick, S., Liberman, M.C., and Wondisford, F. (1999). Divergent roles for thyroid hormone receptor beta isoforms in the endocrine axis and auditory system. J Clin Invest 104, 291-300.

Agalioti, T., Lomvardas, S., Parekh, B., Yie, J., Maniatis, T., and Thanos, D. (2000). Ordered recruitment of chromatin modifying and general transcription factors to the IFNbeta promoter. Cell 103, 667-678.

Ahn, S., Olive, M., Aggarwal, S., Krylov, D., Ginty, D.D., and Vinson, C. (1998). A dominant-negative inhibitor of CREB reveals that it is a general mediator of stimulusdependent transcription of c-fos. Mol Cell Biol 18, 967-977.

Alam, T., An, M.R., and Papaconstantinou, J. (1992). Differential expression of three $\mathrm{C} / \mathrm{EBP}$ isoforms in multiple tissues during the acute phase response. J Biol Chem 267, 5021-5024.

Alaynick, W.A. (2008). Nuclear receptors, mitochondria and lipid metabolism. Mitochondrion 8, 329-337.

An, M.R., Hsieh, C.C., Reisner, P.D., Rabek, J.P., Scott, S.G., Kuninger, D.T., and Papaconstantinou, J. (1996). Evidence for posttranscriptional regulation of C/EBPalpha and $\mathrm{C} / \mathrm{EBPbeta}$ isoform expression during the lipopolysaccharide-mediated acute-phase response. Mol Cell Biol 16, 2295-2306.

Andersson, U., and Scarpulla, R.C. (2001). Pgc-1-related coactivator, a novel, seruminducible coactivator of nuclear respiratory factor 1-dependent transcription in mammalian cells. Mol Cell Biol 21, 3738-3749.

Aoyagi, S., Trotter, K.W., and Archer, T.K. (2005). ATP-dependent chromatin remodeling complexes and their role in nuclear receptor-dependent transcription in vivo. Vitam Horm 70, 281-307.

Arizmendi, C., Liu, S., Croniger, C., Poli, V., and Friedman, J.E. (1999). The transcription factor CCAAT/enhancer-binding protein beta regulates gluconeogenesis and phosphoenolpyruvate carboxykinase (GTP) gene transcription during diabetes. J Biol Chem 274, 13033-13040.

Athea, Y., Garnier, A., Fortin, D., Bahi, L., Veksler, V., and Ventura-Clapier, R. (2007). Mitochondrial and energetic cardiac phenotype in hypothyroid rat. Relevance to heart failure. Pflugers Arch 455, 431-442. 
Baar, K., Wende, A.R., Jones, T.E., Marison, M., Nolte, L.A., Chen, M., Kelly, D.P., and Holloszy, J.O. (2002). Adaptations of skeletal muscle to exercise: rapid increase in the transcriptional coactivator PGC-1. FASEB J 16, 1879-1886.

Bahouth, S.W., Cui, X., Beauchamp, M.J., and Park, E.A. (1997). Thyroid hormone induces beta1-adrenergic receptor gene transcription through a direct repeat separated by five nucleotides. J Mol Cell Cardiol 29, 3223-3237.

Baniahmad, A., Ha, I., Reinberg, D., Tsai, S., Tsai, M.J., and O'Malley, B.W. (1993). Interaction of human thyroid hormone receptor beta with transcription factor TFIIB may mediate target gene derepression and activation by thyroid hormone. Proc Natl Acad Sci U S A 90, 8832-8836.

Baniahmad, A., Kohne, A.C., and Renkawitz, R. (1992). A transferable silencing domain is present in the thyroid hormone receptor, in the v-erbA oncogene product and in the retinoic acid receptor. EMBO J 11, 1015-1023.

Barrera-Hernandez, G., Park, K.S., Dace, A., Zhan, Q., and Cheng, S.Y. (1999). Thyroid hormone-induced cell proliferation in GC cells is mediated by changes in G1 cyclin/cyclin-dependent kinase levels and activity. Endocrinology 140, 5267-5274.

Basu, R., Chandramouli, V., Dicke, B., Landau, B., and Rizza, R. (2005). Obesity and type 2 diabetes impair insulin-induced suppression of glycogenolysis as well as gluconeogenesis. Diabetes 54, 1942-1948.

Baxter, J.D., Webb, P., Grover, G., and Scanlan, T.S. (2004). Selective activation of thyroid hormone signaling pathways by GC-1: a new approach to controlling cholesterol and body weight. Trends Endocrinol Metab 15, 154-157.

Bernal-Mizrachi, C., Weng, S., Feng, C., Finck, B.N., Knutsen, R.H., Leone, T.C., Coleman, T., Mecham, R.P., Kelly, D.P., and Semenkovich, C.F. (2003). Dexamethasone induction of hypertension and diabetes is PPAR-alpha dependent in LDL receptor-null mice. Nat Med 9, 1069-1075.

Bezy, O., Vernochet, C., Gesta, S., Farmer, S.R., and Kahn, C.R. (2007). TRB3 blocks adipocyte differentiation through the inhibition of $\mathrm{C} / \mathrm{EBPbeta}$ transcriptional activity. Mol Cell Biol 27, 6818-6831.

Bhalla, S., Ozalp, C., Fang, S., Xiang, L., and Kemper, J.K. (2004). Ligand-activated pregnane $\mathrm{X}$ receptor interferes with HNF-4 signaling by targeting a common coactivator PGC-1alpha. Functional implications in hepatic cholesterol and glucose metabolism. J Biol Chem 279, 45139-45147.

Bianco, A.C., Salvatore, D., Gereben, B., Berry, M.J., and Larsen, P.R. (2002). Biochemistry, cellular and molecular biology, and physiological roles of the iodothyronine selenodeiodinases. Endocr Rev 23, 38-89. 
Boss, O., Hagen, T., and Lowell, B.B. (2000). Uncoupling proteins 2 and 3: potential regulators of mitochondrial energy metabolism. Diabetes 49, 143-156.

Bourguet, W., Germain, P., and Gronemeyer, H. (2000). Nuclear receptor ligand-binding domains: three-dimensional structures, molecular interactions and pharmacological implications. Trends Pharmacol Sci 21, 381-388.

Bowker-Kinley, M.M., Davis, W.I., Wu, P., Harris, R.A., and Popov, K.M. (1998). Evidence for existence of tissue-specific regulation of the mammalian pyruvate dehydrogenase complex. Biochem J 329 ( Pt 1), 191-196.

Bradley, D.J., Towle, H.C., and Young, W.S., 3rd (1992). Spatial and temporal expression of alpha- and beta-thyroid hormone receptor mRNAs, including the beta 2subtype, in the developing mammalian nervous system. J Neurosci 12, 2288-2302.

Braverman, L.E., Ingbar, S.H., and Sterling, K. (1970). Conversion of thyroxine (T4) to triiodothyronine (T3) in athyreotic human subjects. J Clin Invest 49, 855-864.

Brent, G.A., Dunn, M.K., Harney, J.W., Gulick, T., Larsen, P.R., and Moore, D.D. (1989). Thyroid hormone aporeceptor represses T3-inducible promoters and blocks activity of the retinoic acid receptor. New Biol 1, 329-336.

Cai, G., Huang, H., Shapiro, E., Zhou, H., Yeh, S., Melamed, J., Greco, M.A., and Lee, P. (2005). Expression of androgen receptor associated protein 55 (ARA55) in the developing human fetal prostate. J Urol 173, 2190-2193.

Cao, Z., Umek, R.M., and McKnight, S.L. (1991). Regulated expression of three C/EBP isoforms during adipose conversion of 3T3-L1 cells. Genes Dev 5, 1538-1552.

Capuco, A.V., Connor, E.E., and Wood, D.L. (2008). Regulation of mammary gland sensitivity to thyroid hormones during the transition from pregnancy to lactation. Exp Biol Med (Maywood) 233, 1309-1314.

Chakravarti, D., LaMorte, V.J., Nelson, M.C., Nakajima, T., Schulman, I.G., Juguilon, H., Montminy, M., and Evans, R.M. (1996). Role of CBP/P300 in nuclear receptor signalling. Nature 383, 99-103.

Chassande, O. (2003). Do unliganded thyroid hormone receptors have physiological functions? J Mol Endocrinol 31, 9-20.

Cheng, S.Y. (2000). Multiple mechanisms for regulation of the transcriptional activity of thyroid hormone receptors. Rev Endocr Metab Disord 1, 9-18.

Chevalier, S., Burgess, S.C., Malloy, C.R., Gougeon, R., Marliss, E.B., and Morais, J.A. (2006). The greater contribution of gluconeogenesis to glucose production in obesity is related to increased whole-body protein catabolism. Diabetes 55, 675-681. 
Christy, R.J., Yang, V.W., Ntambi, J.M., Geiman, D.E., Landschulz, W.H., Friedman, A.D., Nakabeppu, Y., Kelly, T.J., and Lane, M.D. (1989). Differentiation-induced gene expression in 3T3-L1 preadipocytes: CCAAT/enhancer binding protein interacts with and activates the promoters of two adipocyte-specific genes. Genes Dev 3, 1323-1335.

Chung, A.C., and Cooney, A.J. (2003). The varied roles of nuclear receptors during vertebrate embryonic development. Nucl Recept Signal 1, e007.

Civitareale, D., Lonigro, R., Sinclair, A.J., and Di Lauro, R. (1989). A thyroid-specific nuclear protein essential for tissue-specific expression of the thyroglobulin promoter. EMBO J 8, 2537-2542.

Croniger, C.M., Millward, C., Yang, J., Kawai, Y., Arinze, I.J., Liu, S., Harada-Shiba, M., Chakravarty, K., Friedman, J.E., Poli, V., et al. (2001). Mice with a deletion in the gene for CCAAT/enhancer-binding protein beta have an attenuated response to cAMP and impaired carbohydrate metabolism. J Biol Chem 276, 629-638.

Crunkhorn, S., and Patti, M.E. (2008). Links between thyroid hormone action, oxidative metabolism, and diabetes risk? Thyroid 18, 227-237.

de Lange, P., Feola, A., Ragni, M., Senese, R., Moreno, M., Lombardi, A., Silvestri, E., Amat, R., Villarroya, F., Goglia, F., et al. (2007). Differential 3,5,3'-triiodothyroninemediated regulation of uncoupling protein 3 transcription: role of Fatty acids. Endocrinology 148, 4064-4072.

Delerive, P., Wu, Y., Burris, T.P., Chin, W.W., and Suen, C.S. (2002). PGC-1 functions as a transcriptional coactivator for the retinoid X receptors. J Biol Chem 277, 3913-3917.

Deng, X., Cagen, L.M., Wilcox, H.G., Park, E.A., Raghow, R., and Elam, M.B. (2002). Regulation of the rat SREBP-1c promoter in primary rat hepatocytes. Biochem Biophys Res Commun 290, 256-262.

Dentice, M., Cordeddu, V., Rosica, A., Ferrara, A.M., Santarpia, L., Salvatore, D., Chiovato, L., Perri, A., Moschini, L., Fazzini, C., et al. (2006). Missense mutation in the transcription factor NKX2-5: a novel molecular event in the pathogenesis of thyroid dysgenesis. J Clin Endocrinol Metab 91, 1428-1433.

Dillmann, W.H., and Gloss, B.R. (2002). The role of thyroid hormone receptors in the heart. Methods Mol Biol 202, 55-70.

Duong, D.T., Waltner-Law, M.E., Sears, R., Sealy, L., and Granner, D.K. (2002). Insulin inhibits hepatocellular glucose production by utilizing liver-enriched transcriptional inhibitory protein to disrupt the association of CREB-binding protein and RNA polymerase II with the phosphoenolpyruvate carboxykinase gene promoter. J Biol Chem $277,32234-32242$. 
El Messaoudi, S., Fabbrizio, E., Rodriguez, C., Chuchana, P., Fauquier, L., Cheng, D., Theillet, C., Vandel, L., Bedford, M.T., and Sardet, C. (2006). Coactivator-associated arginine methyltransferase 1 (CARM1) is a positive regulator of the Cyclin E1 gene. Proc Natl Acad Sci U S A 103, 13351-13356.

Fan, M., Rhee, J., St-Pierre, J., Handschin, C., Puigserver, P., Lin, J., Jaeger, S., Erdjument-Bromage, H., Tempst, P., and Spiegelman, B.M. (2004). Suppression of mitochondrial respiration through recruitment of p160 myb binding protein to PGC1alpha: modulation by p38 MAPK. Genes Dev 18, 278-289.

Fawcett, T.W., Martindale, J.L., Guyton, K.Z., Hai, T., and Holbrook, N.J. (1999). Complexes containing activating transcription factor (ATF)/cAMP-responsive-elementbinding protein $(\mathrm{CREB})$ interact with the CCAAT/enhancer-binding protein $(\mathrm{C} / \mathrm{EBP})$ ATF composite site to regulate Gadd153 expression during the stress response. Biochem J 339 ( Pt 1), 135-141.

Feng, X., Jiang, Y., Meltzer, P., and Yen, P.M. (2000). Thyroid hormone regulation of hepatic genes in vivo detected by complementary DNA microarray. Mol Endocrinol 14, 947-955.

Finck, B.N., Gropler, M.C., Chen, Z., Leone, T.C., Croce, M.A., Harris, T.E., Lawrence, J.C., Jr., and Kelly, D.P. (2006). Lipin 1 is an inducible amplifier of the hepatic PGC1alpha/PPARalpha regulatory pathway. Cell Metab 4, 199-210.

Finck, B.N., and Kelly, D.P. (2006). PGC-1 coactivators: inducible regulators of energy metabolism in health and disease. J Clin Invest 116, 615-622.

Fisler, J.S., and Warden, C.H. (2006). Uncoupling proteins, dietary fat and the metabolic syndrome. Nutr Metab (Lond) 3, 38.

Fowden, A.L., Mapstone, J., and Forhead, A.J. (2001). Regulation of glucogenesis by thyroid hormones in fetal sheep during late gestation. J Endocrinol 170, 461-469.

Francis-Lang, H., Price, M., Polycarpou-Schwarz, M., and Di Lauro, R. (1992). Celltype-specific expression of the rat thyroperoxidase promoter indicates common mechanisms for thyroid-specific gene expression. Mol Cell Biol 12, 576-588.

Francis, G.A., Fayard, E., Picard, F., and Auwerx, J. (2003). Nuclear receptors and the control of metabolism. Annu Rev Physiol 65, 261-311.

Friedman, A.D., Landschulz, W.H., and McKnight, S.L. (1989). CCAAT/enhancer binding protein activates the promoter of the serum albumin gene in cultured hepatoma cells. Genes Dev 3, 1314-1322.

Frye, R.A. (1999). Characterization of five human cDNAs with homology to the yeast SIR2 gene: Sir2-like proteins (sirtuins) metabolize NAD and may have protein ADPribosyltransferase activity. Biochem Biophys Res Commun 260, 273-279. 
Furuyama, T., Kitayama, K., Yamashita, H., and Mori, N. (2003). Forkhead transcription factor FOXO1 (FKHR)-dependent induction of PDK4 gene expression in skeletal muscle during energy deprivation. Biochem J 375, 365-371.

Garlatti, M., Tchesnokov, V., Daheshia, M., Feilleux-Duche, S., Hanoune, J., Aggerbeck, M., and Barouki, R. (1993). CCAAT/enhancer-binding protein-related proteins bind to the unusual promoter of the aspartate aminotransferase housekeeping gene. J Biol Chem $268,6567-6574$.

Gerhart-Hines, Z., Rodgers, J.T., Bare, O., Lerin, C., Kim, S.H., Mostoslavsky, R., Alt, F.W., Wu, Z., and Puigserver, P. (2007). Metabolic control of muscle mitochondrial function and fatty acid oxidation through SIRT1/PGC-1alpha. EMBO J 26, 1913-1923.

Ghosh, A.K., Lacson, R., Liu, P., Cichy, S.B., Danilkovich, A., Guo, S., and Unterman, T.G. (2001). A nucleoprotein complex containing CCAAT/enhancer-binding protein beta interacts with an insulin response sequence in the insulin-like growth factor-binding protein-1 gene and contributes to insulin-regulated gene expression. J Biol Chem 276, 8507-8515.

Glass, C.K. (1994). Differential recognition of target genes by nuclear receptor monomers, dimers, and heterodimers. Endocr Rev 15, 391-407.

Glass, C.K., and Rosenfeld, M.G. (2000). The coregulator exchange in transcriptional functions of nuclear receptors. Genes Dev 14, 121-141.

Goldenthal, M.J., Weiss, H.R., and Marin-Garcia, J. (2004). Bioenergetic remodeling of heart mitochondria by thyroid hormone. Mol Cell Biochem 265, 97-106.

Gomberg-Maitland, M., and Frishman, W.H. (1998). Thyroid hormone and cardiovascular disease. Am Heart J 135, 187-196.

Grover, G.J., Egan, D.M., Sleph, P.G., Beehler, B.C., Chiellini, G., Nguyen, N.H., Baxter, J.D., and Scanlan, T.S. (2004). Effects of the thyroid hormone receptor agonist GC-1 on metabolic rate and cholesterol in rats and primates: selective actions relative to 3,5,3'-triiodo-L-thyronine. Endocrinology 145, 1656-1661.

Gullberg, H., Rudling, M., Forrest, D., Angelin, B., and Vennstrom, B. (2000). Thyroid hormone receptor beta-deficient mice show complete loss of the normal cholesterol 7alpha-hydroxylase (CYP7A) response to thyroid hormone but display enhanced resistance to dietary cholesterol. Mol Endocrinol 14, 1739-1749.

Hamm, J.K., Park, B.H., and Farmer, S.R. (2001). A role for C/EBPbeta in regulating peroxisome proliferator-activated receptor gamma activity during adipogenesis in 3T3-L1 preadipocytes. J Biol Chem 276, 18464-18471.

Handschin, C., and Spiegelman, B.M. (2006). Peroxisome proliferator-activated receptor gamma coactivator 1 coactivators, energy homeostasis, and metabolism. Endocr Rev 27, 728-735. 
Harris, R.A., Bowker-Kinley, M.M., Huang, B., and Wu, P. (2002). Regulation of the activity of the pyruvate dehydrogenase complex. Adv Enzyme Regul 42, 249-259.

Hashimoto, K., Cohen, R.N., Yamada, M., Markan, K.R., Monden, T., Satoh, T., Mori, M., and Wondisford, F.E. (2006). Cross-talk between thyroid hormone receptor and liver $\mathrm{X}$ receptor regulatory pathways is revealed in a thyroid hormone resistance mouse model. J Biol Chem 281, 295-302.

Hayashi, Y., Mangoura, D., and Refetoff, S. (1996). A mouse model of resistance to thyroid hormone produced by somatic gene transfer of a mutant thyroid hormone receptor. Mol Endocrinol 10, 100-106.

Heery, D.M., Kalkhoven, E., Hoare, S., and Parker, M.G. (1997). A signature motif in transcriptional co-activators mediates binding to nuclear receptors. Nature 387, 733-736.

Heinzel, T., Lavinsky, R.M., Mullen, T.M., Soderstrom, M., Laherty, C.D., Torchia, J., Yang, W.M., Brard, G., Ngo, S.D., Davie, J.R., et al. (1997). A complex containing NCoR, mSin3 and histone deacetylase mediates transcriptional repression. Nature 387, 4348.

Hodin, R.A., Lazar, M.A., and Chin, W.W. (1990). Differential and tissue-specific regulation of the multiple rat c-erbA messenger RNA species by thyroid hormone. J Clin Invest $85,101-105$.

Holness, M.J., Bulmer, K., Gibbons, G.F., and Sugden, M.C. (2002). Up-regulation of pyruvate dehydrogenase kinase isoform 4 (PDK4) protein expression in oxidative skeletal muscle does not require the obligatory participation of peroxisome-proliferator-activated receptor alpha (PPARalpha). Biochem J 366, 839-846.

Holness, M.J., Bulmer, K., Smith, N.D., and Sugden, M.C. (2003). Investigation of potential mechanisms regulating protein expression of hepatic pyruvate dehydrogenase kinase isoforms 2 and 4 by fatty acids and thyroid hormone. Biochem J 369, 687-695.

Holness, M.J., Kraus, A., Harris, R.A., and Sugden, M.C. (2000). Targeted upregulation of pyruvate dehydrogenase kinase (PDK)-4 in slow-twitch skeletal muscle underlies the stable modification of the regulatory characteristics of PDK induced by high-fat feeding. Diabetes 49, 775-781.

Holness, M.J., and Sugden, M.C. (2003). Regulation of pyruvate dehydrogenase complex activity by reversible phosphorylation. Biochem Soc Trans 31, 1143-1151.

Horlein, A.J., Naar, A.M., Heinzel, T., Torchia, J., Gloss, B., Kurokawa, R., Ryan, A., Kamei, Y., Soderstrom, M., Glass, C.K., et al. (1995). Ligand-independent repression by the thyroid hormone receptor mediated by a nuclear receptor co-repressor. Nature 377, 397-404. 
Huang, B., Gudi, R., Wu, P., Harris, R.A., Hamilton, J., and Popov, K.M. (1998). Isoenzymes of pyruvate dehydrogenase phosphatase. DNA-derived amino acid sequences, expression, and regulation. J Biol Chem 273, 17680-17688.

Huang, B., Wu, P., Bowker-Kinley, M.M., and Harris, R.A. (2002). Regulation of pyruvate dehydrogenase kinase expression by peroxisome proliferator-activated receptoralpha ligands, glucocorticoids, and insulin. Diabetes 51, 276-283.

Huss, J.M., and Kelly, D.P. (2004). Nuclear receptor signaling and cardiac energetics. Circ Res 95, 568-578.

Huss, J.M., Kopp, R.P., and Kelly, D.P. (2002). Peroxisome proliferator-activated receptor coactivator-1alpha (PGC-1alpha) coactivates the cardiac-enriched nuclear receptors estrogen-related receptor-alpha and -gamma. Identification of novel leucinerich interaction motif within PGC-1alpha. J Biol Chem 277, 40265-40274.

Irrcher, I., Adhihetty, P.J., Sheehan, T., Joseph, A.M., and Hood, D.A. (2003). PPARgamma coactivator-1alpha expression during thyroid hormone- and contractile activity-induced mitochondrial adaptations. Am J Physiol Cell Physiol 284, C1669-1677.

Jackson-Hayes, L., Song, S., Lavrentyev, E.N., Jansen, M.S., Hillgartner, F.B., Tian, L., Wood, P.A., Cook, G.A., and Park, E.A. (2003). A thyroid hormone response unit formed between the promoter and first intron of the carnitine palmitoyltransferase-Ialpha gene mediates the liver-specific induction by thyroid hormone. J Biol Chem 278, 7964-7972.

Jeoung, N.H., and Harris, R.A. (2008). Pyruvate dehydrogenase kinase-4 deficiency lowers blood glucose and improves glucose tolerance in diet-induced obese mice. Am J Physiol Endocrinol Metab 295, E46-54.

Jeoung, N.H., Wu, P., Joshi, M.A., Jaskiewicz, J., Bock, C.B., Depaoli-Roach, A.A., and Harris, R.A. (2006). Role of pyruvate dehydrogenase kinase isoenzyme 4 (PDHK4) in glucose homoeostasis during starvation. Biochem J 397, 417-425.

Johansson, C., Gothe, S., Forrest, D., Vennstrom, B., and Thoren, P. (1999). Cardiovascular phenotype and temperature control in mice lacking thyroid hormone receptor-beta or both alpha1 and beta. Am J Physiol 276, H2006-2012.

Johnson, J.L. (2006). Diabetes control in thyroid disease. Diabetes Spectrum 19, 148-153.

Jurado, L.A., Song, S., Roesler, W.J., and Park, E.A. (2002). Conserved amino acids within CCAAT enhancer-binding proteins (C/EBP(alpha) and beta) regulate phosphoenolpyruvate carboxykinase (PEPCK) gene expression. J Biol Chem 277, 2760627612.

Kabir, M., Catalano, K.J., Ananthnarayan, S., Kim, S.P., Van Citters, G.W., Dea, M.K., and Bergman, R.N. (2005). Molecular evidence supporting the portal theory: a causative link between visceral adiposity and hepatic insulin resistance. Am J Physiol Endocrinol Metab 288, E454-461. 
Kalaany, N.Y., Gauthier, K.C., Zavacki, A.M., Mammen, P.P., Kitazume, T., Peterson, J.A., Horton, J.D., Garry, D.J., Bianco, A.C., and Mangelsdorf, D.J. (2005). LXRs regulate the balance between fat storage and oxidation. Cell Metab 1, 231-244.

Kamei, Y., Xu, L., Heinzel, T., Torchia, J., Kurokawa, R., Gloss, B., Lin, S.C., Heyman, R.A., Rose, D.W., Glass, C.K., et al. (1996). A CBP integrator complex mediates transcriptional activation and AP-1 inhibition by nuclear receptors. Cell 85, 403-414.

Karin, M. (1990). Too many transcription factors: positive and negative interactions. New Biol 2, 126-131.

Kariv, R., Enden, A., Zvibel, I., Rosner, G., Brill, S., Shafritz, D.A., Halpern, Z., and Oren, R. (2003). Triiodothyronine and interleukin-6 (IL-6) induce expression of HGF in an immortalized rat hepatic stellate cell line. Liver Int 23, 187-193.

Kingston, R.E., and Narlikar, G.J. (1999). ATP-dependent remodeling and acetylation as regulators of chromatin fluidity. Genes Dev 13, 2339-2352.

Kitagawa, S., Obata, T., Willingham, M.C., and Cheng, S.Y. (1987). Thyroid hormone action: induction of morphological changes and stimulation of cell growth in rat pituitary tumor GH3 cells. Endocrinology 120, 2591-2596.

Klein, I., and Ojamaa, K. (2001). Thyroid hormone and the cardiovascular system. N Engl J Med 344, 501-509.

Knutti, D., Kaul, A., and Kralli, A. (2000). A tissue-specific coactivator of steroid receptors, identified in a functional genetic screen. Mol Cell Biol 20, 2411-2422.

Kohrle, J. (2000). The selenoenzyme family of deiodinase isozymes controls local thyroid hormone availability. Rev Endocr Metab Disord 1, 49-58.

Kolobova, E., Tuganova, A., Boulatnikov, I., and Popov, K.M. (2001). Regulation of pyruvate dehydrogenase activity through phosphorylation at multiple sites. Biochem $\mathrm{J}$ $358,69-77$.

Korotchkina, L.G., and Patel, M.S. (2001). Site specificity of four pyruvate dehydrogenase kinase isoenzymes toward the three phosphorylation sites of human pyruvate dehydrogenase. J Biol Chem 276, 37223-37229.

Kozlowska, L., and Rosolowska-Huszcz, D. (2004). Leptin, thyrotropin, and thyroid hormones in obese/overweight women before and after two levels of energy deficit. Endocrine 24, 147-153.

Krylov, D., Olive, M., and Vinson, C. (1995). Extending dimerization interfaces: the bZIP basic region can form a coiled coil. EMBO J 14, 5329-5337. 
Kubista, M., Andrade, J.M., Bengtsson, M., Forootan, A., Jonak, J., Lind, K., Sindelka, R., Sjoback, R., Sjogreen, B., Strombom, L., et al. (2006). The real-time polymerase chain reaction. Mol Aspects Med 27, 95-125.

Kuiper, G.G., Kester, M.H., Peeters, R.P., and Visser, T.J. (2005). Biochemical mechanisms of thyroid hormone deiodination. Thyroid 15, 787-798.

Kwon, H.S., and Harris, R.A. (2004). Mechanisms responsible for regulation of pyruvate dehydrogenase kinase 4 gene expression. Adv Enzyme Regul 44, 109-121.

Kwon, H.S., Huang, B., Unterman, T.G., and Harris, R.A. (2004). Protein kinase B-alpha inhibits human pyruvate dehydrogenase kinase-4 gene induction by dexamethasone through inactivation of FOXO transcription factors. Diabetes 53, 899-910.

Lagor, W.R., Heller, R., de Groh, E.D., and Ness, G.C. (2007). Functional analysis of the hepatic HMG-CoA reductase promoter by in vivo electroporation. Exp Biol Med (Maywood) 232, 353-361.

Landschulz, W.H., Johnson, P.F., Adashi, E.Y., Graves, B.J., and McKnight, S.L. (1988). Isolation of a recombinant copy of the gene encoding C/EBP. Genes Dev 2, 786-800.

Latchman, D.S. (1997). Transcription factors: an overview. Int J Biochem Cell Biol 29, 1305-1312.

Laudet, V. (1997). Evolution of the nuclear receptor superfamily: early diversification from an ancestral orphan receptor. J Mol Endocrinol 19, 207-226.

Laverriere, J.N., Muller, M., Buisson, N., Tougard, C., Tixier-Vidal, A., Martial, J.A., and Gourdji, D. (1986). Differential implication of deoxyribonucleic acid methylation in rat prolactin and rat growth hormone gene expressions: a comparison between rat pituitary cell strains. Endocrinology 118, 198-206.

Lazar, M.A. (1993). Thyroid hormone receptors: multiple forms, multiple possibilities. Endocr Rev 14, 184-193.

Lechan, R.M., Qi, Y., Jackson, I.M., and Mahdavi, V. (1994). Identification of thyroid hormone receptor isoforms in thyrotropin-releasing hormone neurons of the hypothalamic paraventricular nucleus. Endocrinology 135, 92-100.

Lee, J.W., Choi, H.S., Gyuris, J., Brent, R., and Moore, D.D. (1995). Two classes of proteins dependent on either the presence or absence of thyroid hormone for interaction with the thyroid hormone receptor. Mol Endocrinol 9, 243-254.

Lehman, J.J., Barger, P.M., Kovacs, A., Saffitz, J.E., Medeiros, D.M., and Kelly, D.P. (2000). Peroxisome proliferator-activated receptor gamma coactivator-1 promotes cardiac mitochondrial biogenesis. J Clin Invest 106, 847-856. 
Lekstrom-Himes, J., and Xanthopoulos, K.G. (1998). Biological role of the CCAAT/enhancer-binding protein family of transcription factors. J Biol Chem 273, 28545-28548.

Leone, T.C., Lehman, J.J., Finck, B.N., Schaeffer, P.J., Wende, A.R., Boudina, S., Courtois, M., Wozniak, D.F., Sambandam, N., Bernal-Mizrachi, C., et al. (2005). PGC1alpha deficiency causes multi-system energy metabolic derangements: muscle dysfunction, abnormal weight control and hepatic steatosis. PLoS Biol 3, e101.

Lieber, C.S. (1999). Microsomal ethanol-oxidizing system (MEOS): the first 30 years (1968-1998)--a review. Alcohol Clin Exp Res 23, 991-1007.

Lin, J., Handschin, C., and Spiegelman, B.M. (2005a). Metabolic control through the PGC-1 family of transcription coactivators. Cell Metab 1, 361-370.

Lin, J., Puigserver, P., Donovan, J., Tarr, P., and Spiegelman, B.M. (2002). Peroxisome proliferator-activated receptor gamma coactivator 1beta (PGC-1beta), a novel PGC-1related transcription coactivator associated with host cell factor. J Biol Chem 277, 16451648.

Lin, J., Tarr, P.T., Yang, R., Rhee, J., Puigserver, P., Newgard, C.B., and Spiegelman, B.M. (2003). PGC-1beta in the regulation of hepatic glucose and energy metabolism. J Biol Chem 278, 30843-30848.

Lin, J., Wu, P.H., Tarr, P.T., Lindenberg, K.S., St-Pierre, J., Zhang, C.Y., Mootha, V.K., Jager, S., Vianna, C.R., Reznick, R.M., et al. (2004). Defects in adaptive energy metabolism with CNS-linked hyperactivity in PGC-1alpha null mice. Cell 119, 121-135.

Lin, J., Yang, R., Tarr, P.T., Wu, P.H., Handschin, C., Li, S., Yang, W., Pei, L., Uldry, M., Tontonoz, P., et al. (2005b). Hyperlipidemic effects of dietary saturated fats mediated through PGC-1beta coactivation of SREBP. Cell 120, 261-273.

Livak, K.J., and Schmittgen, T.D. (2001). Analysis of relative gene expression data using real-time quantitative PCR and the 2(-Delta Delta C(T)) Method. Methods 25, 402-408.

Markus, M.A., and Morris, B.J. (2008). Resveratrol in prevention and treatment of common clinical conditions of aging. Clin Interv Aging 3, 331-339.

Martinez-Jimenez, C.P., Gomez-Lechon, M.J., Castell, J.V., and Jover, R. (2006). Underexpressed coactivators PGC1alpha and SRC1 impair hepatocyte nuclear factor 4 alpha function and promote dedifferentiation in human hepatoma cells. J Biol Chem 281, 29840-29849.

Matsuno, F., Chowdhury, S., Gotoh, T., Iwase, K., Matsuzaki, H., Takatsuki, K., Mori, M., and Takiguchi, M. (1996). Induction of the C/EBP beta gene by dexamethasone and glucagon in primary-cultured rat hepatocytes. J Biochem 119, 524-532. 
McClure, T.D., Young, M.E., Taegtmeyer, H., Ning, X.H., Buroker, N.E., Lopez-Guisa, J., and Portman, M.A. (2005). Thyroid hormone interacts with PPARalpha and PGC-1 during mitochondrial maturation in sheep heart. Am J Physiol Heart Circ Physiol 289, H2258-2264.

McKenna, N.J., Xu, J., Nawaz, Z., Tsai, S.Y., Tsai, M.J., and O'Malley, B.W. (1999). Nuclear receptor coactivators: multiple enzymes, multiple complexes, multiple functions. J Steroid Biochem Mol Biol 69, 3-12.

Menendez-Hurtado, A., Vega-Nunez, E., Santos, A., and Perez-Castillo, A. (1997). Regulation by thyroid hormone and retinoic acid of the CCAAT/enhancer binding protein alpha and beta genes during liver development. Biochem Biophys Res Commun 234, 605-610.

Michael, L.F., Wu, Z., Cheatham, R.B., Puigserver, P., Adelmant, G., Lehman, J.J., Kelly, D.P., and Spiegelman, B.M. (2001). Restoration of insulin-sensitive glucose transporter (GLUT4) gene expression in muscle cells by the transcriptional coactivator PGC-1. Proc Natl Acad Sci U S A 98, 3820-3825.

Miksicek, R.J., and Towle, H.C. (1982). Changes in the rates of synthesis and messenger RNA levels of hepatic glucose-6-phosphate and 6-phosphogluconate dehydrogenases following induction by diet or thyroid hormone. J Biol Chem 257, 11829-11835.

Miller, L.D., Park, K.S., Guo, Q.M., Alkharouf, N.W., Malek, R.L., Lee, N.H., Liu, E.T., and Cheng, S.Y. (2001). Silencing of Wnt signaling and activation of multiple metabolic pathways in response to thyroid hormone-stimulated cell proliferation. Mol Cell Biol 21, 6626-6639.

Moreno, M., de Lange, P., Lombardi, A., Silvestri, E., Lanni, A., and Goglia, F. (2008). Metabolic effects of thyroid hormone derivatives. Thyroid 18, 239-253.

Mukhopadhyay, D., Plateroti, M., Anant, S., Nassir, F., Samarut, J., and Davidson, N.O. (2003). Thyroid hormone regulates hepatic triglyceride mobilization and apolipoprotein B messenger ribonucleic Acid editing in a murine model of congenital hypothyroidism. Endocrinology 144, 711-719.

Munoz, A., Zenke, M., Gehring, U., Sap, J., Beug, H., and Vennstrom, B. (1988). Characterization of the hormone-binding domain of the chicken c-erbA/thyroid hormone receptor protein. EMBO J 7, 155-159.

Munroe, S.H., and Lazar, M.A. (1991). Inhibition of c-erbA mRNA splicing by a naturally occurring antisense RNA. J Biol Chem 266, 22083-22086.

Nagy, L., Kao, H.Y., Chakravarti, D., Lin, R.J., Hassig, C.A., Ayer, D.E., Schreiber, S.L., and Evans, R.M. (1997). Nuclear receptor repression mediated by a complex containing SMRT, mSin3A, and histone deacetylase. Cell 89, 373-380. 
Nagy, L., Kao, H.Y., Love, J.D., Li, C., Banayo, E., Gooch, J.T., Krishna, V., Chatterjee, K., Evans, R.M., and Schwabe, J.W. (1999). Mechanism of corepressor binding and release from nuclear hormone receptors. Genes Dev 13, 3209-3216.

Naslund, E. (2000). Associations of leptin, insulin resistance and thyroid function with long-term weight loss in dieting obese men. J Internal Med 248, 299-308.

Nass, R., Gilrain, J., Anderson, S., Gaylinn, B., Dalkin, A., Day, R., Peruggia, M., and Thorner, M.O. (2000). High plasma growth hormone (GH) levels inhibit expression of GH secretagogue receptor messenger ribonucleic acid levels in the rat pituitary. Endocrinology 141, 2084-2089.

Ness, G.C., and Zhao, Z. (1994). Thyroid hormone rapidly induces hepatic LDL receptor mRNA levels in hypophysectomized rats. Arch Biochem Biophys 315, 199-202.

Nowak, S.J., and Corces, V.G. (2004). Phosphorylation of histone H3: a balancing act between chromosome condensation and transcriptional activation. Trends Genet 20, 214220.

Ogryzko, V.V., Kotani, T., Zhang, X., Schiltz, R.L., Howard, T., Yang, X.J., Howard, B.H., Qin, J., and Nakatani, Y. (1998). Histone-like TAFs within the PCAF histone acetylase complex. Cell 94, 35-44.

Olive, M., Krylov, D., Echlin, D.R., Gardner, K., Taparowsky, E., and Vinson, C. (1997). A dominant negative to activation protein-1 (AP1) that abolishes DNA binding and inhibits oncogenesis. J Biol Chem 272, 18586-18594.

Onate, S.A., Tsai, S.Y., Tsai, M.J., and O'Malley, B.W. (1995). Sequence and characterization of a coactivator for the steroid hormone receptor superfamily. Science $270,1354-1357$.

Oppenheimer, J.H., Schwartz, H.L., Mariash, C.N., Kinlaw, W.B., Wong, N.C., and Freake, H.C. (1987). Advances in our understanding of thyroid hormone action at the cellular level. Endocr Rev 8, 288-308.

Park, E.A., Roesler, W.J., Liu, J., Klemm, D.J., Gurney, A.L., Thatcher, J.D., Shuman, J., Friedman, A., and Hanson, R.W. (1990). The role of the CCAAT/enhancer-binding protein in the transcriptional regulation of the gene for phosphoenolpyruvate carboxykinase (GTP). Mol Cell Biol 10, 6264-6272.

Park, E.A., Song, S., Olive, M., and Roesler, W.J. (1997). CCAAT-enhancer-binding protein alpha (C/EBP alpha) is required for the thyroid hormone but not the retinoic acid induction of phosphoenolpyruvate carboxykinase (PEPCK) gene transcription. Biochem J 322 ( Pt 1), 343-349.

Park, E.A., Song, S., Vinson, C., and Roesler, W.J. (1999). Role of CCAAT enhancerbinding protein beta in the thyroid hormone and cAMP induction of phosphoenolpyruvate carboxykinase gene transcription. J Biol Chem 274, 211-217. 
Patti, M.E., Butte, A.J., Crunkhorn, S., Cusi, K., Berria, R., Kashyap, S., Miyazaki, Y., Kohane, I., Costello, M., Saccone, R., et al. (2003). Coordinated reduction of genes of oxidative metabolism in humans with insulin resistance and diabetes: Potential role of PGC1 and NRF1. Proc Natl Acad Sci U S A 100, 8466-8471.

Perissi, V., Staszewski, L.M., McInerney, E.M., Kurokawa, R., Krones, A., Rose, D.W., Lambert, M.H., Milburn, M.V., Glass, C.K., and Rosenfeld, M.G. (1999). Molecular determinants of nuclear receptor-corepressor interaction. Genes Dev 13, 3198-3208.

Perra, A., Simbula, G., Simbula, M., Pibiri, M., Kowalik, M.A., Sulas, P., Cocco, M.T., Ledda-Columbano, G.M., and Columbano, A. (2008). Thyroid hormone (T3) and TRbeta agonist GC-1 inhibit/reverse nonalcoholic fatty liver in rats. FASEB J 22, 2981-2989.

Peters, S.J., Harris, R.A., Heigenhauser, G.J., and Spriet, L.L. (2001). Muscle fiber type comparison of PDH kinase activity and isoform expression in fed and fasted rats. Am J Physiol Regul Integr Comp Physiol 280, R661-668.

Popov, K.M., Kedishvili, N.Y., Zhao, Y., Gudi, R., and Harris, R.A. (1994). Molecular cloning of the p45 subunit of pyruvate dehydrogenase kinase. J Biol Chem 269, 2972029724.

Popov, K.M., Kedishvili, N.Y., Zhao, Y., Shimomura, Y., Crabb, D.W., and Harris, R.A. (1993). Primary structure of pyruvate dehydrogenase kinase establishes a new family of eukaryotic protein kinases. J Biol Chem 268, 26602-26606.

Puigserver, P., Rhee, J., Donovan, J., Walkey, C.J., Yoon, J.C., Oriente, F., Kitamura, Y., Altomonte, J., Dong, H., Accili, D., et al. (2003). Insulin-regulated hepatic gluconeogenesis through FOXO1-PGC-1alpha interaction. Nature 423, 550-555.

Puigserver, P., and Spiegelman, B.M. (2003). Peroxisome proliferator-activated receptorgamma coactivator 1 alpha (PGC-1 alpha): transcriptional coactivator and metabolic regulator. Endocr Rev 24, 78-90.

Puigserver, P., Wu, Z., Park, C.W., Graves, R., Wright, M., and Spiegelman, B.M. (1998). A cold-inducible coactivator of nuclear receptors linked to adaptive thermogenesis. Cell 92, 829-839.

Pykalisto, O., Goldberg, A.P., and Brunzell, J.D. (1976). Reversal of decreased human adipose tissue lipoprotein lipase and hypertriglyceridemia after treatment of hypothyroidism. J Clin Endocrinol Metab 43, 591-600.

Randle, P.J. (1986). Fuel selection in animals. Biochem Soc Trans 14, 799-806.

Rastinejad, F., Perlmann, T., Evans, R.M., and Sigler, P.B. (1995). Structural determinants of nuclear receptor assembly on DNA direct repeats. Nature 375, 203-211. 
Rhee, J., Inoue, Y., Yoon, J.C., Puigserver, P., Fan, M., Gonzalez, F.J., and Spiegelman, B.M. (2003). Regulation of hepatic fasting response by PPARgamma coactivator-1alpha (PGC-1): requirement for hepatocyte nuclear factor 4alpha in gluconeogenesis. Proc Natl Acad Sci U S A 100, 4012-4017.

Ribeiro, M.O. (2008). Effects of thyroid hormone analogs on lipid metabolism and thermogenesis. Thyroid 18, 197-203.

Ribeiro, R.C., Apriletti, J.W., Yen, P.M., Chin, W.W., and Baxter, J.D. (1994). Heterodimerization and deoxyribonucleic acid-binding properties of a retinoid $\mathrm{X}$ receptor-related factor. Endocrinology 135, 2076-2085.

Rosenfeld, M.G., Lunyak, V.V., and Glass, C.K. (2006). Sensors and signals: a coactivator/corepressor/epigenetic code for integrating signal-dependent programs of transcriptional response. Genes Dev 20, 1405-1428.

Rowles, J., Scherer, S.W., Xi, T., Majer, M., Nickle, D.C., Rommens, J.M., Popov, K.M., Harris, R.A., Riebow, N.L., Xia, J., et al. (1996). Cloning and characterization of PDK4 on 7q21.3 encoding a fourth pyruvate dehydrogenase kinase isoenzyme in human. J Biol Chem 271, 22376-22382.

Samuels, H.H., Forman, B.M., Horowitz, Z.D., and Ye, Z.S. (1988). Regulation of gene expression by thyroid hormone. J Clin Invest 81, 957-967.

Schaeffer, P.J., Wende, A.R., Magee, C.J., Neilson, J.R., Leone, T.C., Chen, F., and Kelly, D.P. (2004). Calcineurin and calcium/calmodulin-dependent protein kinase activate distinct metabolic gene regulatory programs in cardiac muscle. J Biol Chem 279, 39593-39603.

Schreiber, S.N., Knutti, D., Brogli, K., Uhlmann, T., and Kralli, A. (2003). The transcriptional coactivator PGC-1 regulates the expression and activity of the orphan nuclear receptor estrogen-related receptor alpha (ERRalpha). J Biol Chem 278, 90139018.

Schrem, H., Klempnauer, J., and Borlak, J. (2002). Liver-enriched transcription factors in liver function and development. Part I: the hepatocyte nuclear factor network and liverspecific gene expression. Pharmacol Rev 54, 129-158.

Schrem, H., Klempnauer, J., and Borlak, J. (2004). Liver-enriched transcription factors in liver function and development. Part II: the C/EBPs and D site-binding protein in cell cycle control, carcinogenesis, circadian gene regulation, liver regeneration, apoptosis, and liver-specific gene regulation. Pharmacol Rev 56, 291-330.

Schroeder-Gloeckler, J.M., Rahman, S.M., Janssen, R.C., Qiao, L., Shao, J., Roper, M., Fischer, S.J., Lowe, E., Orlicky, D.J., McManaman, J.L., et al. (2007). CCAAT/enhancer-binding protein beta deletion reduces adiposity, hepatic steatosis, and diabetes in Lepr(db/db) mice. J Biol Chem 282, 15717-15729. 
Schueler, P.A., Schwartz, H.L., Strait, K.A., Mariash, C.N., and Oppenheimer, J.H. (1990). Binding of 3,5,3'-triiodothyronine (T3) and its analogs to the in vitro translational products of c-erbA protooncogenes: differences in the affinity of the alpha- and betaforms for the acetic acid analog and failure of the human testis and kidney alpha-2 products to bind T3. Mol Endocrinol 4, 227-234.

Senger, K., Merika, M., Agalioti, T., Yie, J., Escalante, C.R., Chen, G., Aggarwal, A.K., and Thanos, D. (2000). Gene repression by coactivator repulsion. Mol Cell 6, 931-937.

Shuman, J.D., Cheong, J., and Coligan, J.E. (1997). ATF-2 and C/EBPalpha can form a heterodimeric DNA binding complex in vitro. Functional implications for transcriptional regulation. J Biol Chem 272, 12793-12800.

Song, S., Zhang, Y., Ma, K., Jackson-Hayes, L., Lavrentyev, E.N., Cook, G.A., Elam, M.B., and Park, E.A. (2004). Peroxisomal proliferator activated receptor gamma coactivator (PGC-1alpha) stimulates carnitine palmitoyltransferase I (CPT-Ialpha) through the first intron. Biochim Biophys Acta 1679, 164-173.

Sparks, L.M., Xie, H., Koza, R.A., Mynatt, R., Bray, G.A., and Smith, S.R. (2006). Highfat/low-carbohydrate diets regulate glucose metabolism via a long-term transcriptional loop. Metabolism 55, 1457-1463.

Stegmaier, P., Kel, A.E., and Wingender, E. (2004). Systematic DNA-binding domain classification of transcription factors. Genome Inform 15, 276-286.

Steussy, C.N., Popov, K.M., Bowker-Kinley, M.M., Sloan, R.B., Jr., Harris, R.A., and Hamilton, J.A. (2001). Structure of pyruvate dehydrogenase kinase. Novel folding pattern for a serine protein kinase. J Biol Chem 276, 37443-37450.

Stewart, M.D., Li, J., and Wong, J. (2005). Relationship between histone H3 lysine 9 methylation, transcription repression, and heterochromatin protein 1 recruitment. Mol Cell Biol 25, 2525-2538.

Sugden, M.C., Bulmer, K., Augustine, D., and Holness, M.J. (2001a). Selective modification of pyruvate dehydrogenase kinase isoform expression in rat pancreatic islets elicited by starvation and activation of peroxisome proliferator-activated receptor-alpha: implications for glucose-stimulated insulin secretion. Diabetes 50, 2729-2736.

Sugden, M.C., Bulmer, K., Gibbons, G.F., and Holness, M.J. (2001b). Role of peroxisome proliferator-activated receptor-alpha in the mechanism underlying changes in renal pyruvate dehydrogenase kinase isoform 4 protein expression in starvation and after refeeding. Arch Biochem Biophys 395, 246-252.

Sugden, M.C., Bulmer, K., Gibbons, G.F., Knight, B.L., and Holness, M.J. (2002). Peroxisome-proliferator-activated receptor-alpha (PPARalpha) deficiency leads to dysregulation of hepatic lipid and carbohydrate metabolism by fatty acids and insulin. Biochem J 364, 361-368. 
Sugden, M.C., Bulmer, K., and Holness, M.J. (2001c). Fuel-sensing mechanisms integrating lipid and carbohydrate utilization. Biochem Soc Trans 29, 272-278.

Sugden, M.C., Fryer, L.G., Priestman, D.A., Orfali, K.A., and Holness, M.J. (1996). Increased hepatic pyruvate dehydrogenase kinase activity in fed hyperthyroid rats: studies in vivo and with cultured hepatocytes. Mol Cell Endocrinol 119, 219-224.

Sugden, M.C., and Holness, M.J. (2002). Therapeutic potential of the mammalian pyruvate dehydrogenase kinases in the prevention of hyperglycaemia. Curr Drug Targets Immune Endocr Metabol Disord 2, 151-165.

Sugden, M.C., and Holness, M.J. (2003). Recent advances in mechanisms regulating glucose oxidation at the level of the pyruvate dehydrogenase complex by PDKs. Am J Physiol Endocrinol Metab 284, E855-862.

Sugden, M.C., Lall, H.S., Harris, R.A., and Holness, M.J. (2000a). Selective modification of the pyruvate dehydrogenase kinase isoform profile in skeletal muscle in hyperthyroidism: implications for the regulatory impact of glucose on fatty acid oxidation. J Endocrinol 167, 339-345.

Sugden, M.C., Langdown, M.L., Harris, R.A., and Holness, M.J. (2000b). Expression and regulation of pyruvate dehydrogenase kinase isoforms in the developing rat heart and in adulthood: role of thyroid hormone status and lipid supply. Biochem J 352 Pt 3, 731-738.

Tae, H.J., Luo, X., and Kim, K.H. (1994). Roles of CCAAT/enhancer-binding protein and its binding site on repression and derepression of acetyl-CoA carboxylase gene. $\mathrm{J}$ Biol Chem 269, 10475-10484.

Tata, J.R., Ernster, L., Lindberg, O., Arrhenius, E., Pedersen, S., and Hedman, R. (1963). The action of thyroid hormones at the cell level. Biochem J 86, 408-428.

Tata, J.R., and Widnell, C.C. (1966). Ribonucleic acid synthesis during the early action of thyroid hormones. Biochem J 98, 604-620.

Terada, S., Goto, M., Kato, M., Kawanaka, K., Shimokawa, T., and Tabata, I. (2002). Effects of low-intensity prolonged exercise on PGC-1 mRNA expression in rat epitrochlearis muscle. Biochem Biophys Res Commun 296, 350-354.

Thijssen-Timmer, D.C., Schiphorst, M.P., Kwakkel, J., Emter, R., Kralli, A., Wiersinga, W.M., and Bakker, O. (2006). PGC-1alpha regulates the isoform mRNA ratio of the alternatively spliced thyroid hormone receptor alpha transcript. J Mol Endocrinol 37, 251-257.

Tong, G.X., Tanen, M.R., and Bagchi, M.K. (1995). Ligand modulates the interaction of thyroid hormone receptor beta with the basal transcription machinery. J Biol Chem 270, 10601-10611. 
Torrance, C.J., Devente, J.E., Jones, J.P., and Dohm, G.L. (1997). Effects of thyroid hormone on GLUT4 glucose transporter gene expression and NIDDM in rats. Endocrinology 138, 1204-1214.

Trost, S.U., Swanson, E., Gloss, B., Wang-Iverson, D.B., Zhang, H., Volodarsky, T., Grover, G.J., Baxter, J.D., Chiellini, G., Scanlan, T.S., et al. (2000). The thyroid hormone receptor-beta-selective agonist GC-1 differentially affects plasma lipids and cardiac activity. Endocrinology 141, 3057-3064.

Vallejo, M., Ron, D., Miller, C.P., and Habener, J.F. (1993). C/ATF, a member of the activating transcription factor family of DNA-binding proteins, dimerizes with CAAT/enhancer-binding proteins and directs their binding to cAMP response elements. Proc Natl Acad Sci U S A 90, 4679-4683.

Vega, R.B., Huss, J.M., and Kelly, D.P. (2000). The coactivator PGC-1 cooperates with peroxisome proliferator-activated receptor alpha in transcriptional control of nuclear genes encoding mitochondrial fatty acid oxidation enzymes. Mol Cell Biol 20, 18681876.

Wahrenberg, H., Wennlund, A., and Arner, P. (1994). Adrenergic regulation of lipolysis in fat cells from hyperthyroid and hypothyroid patients. J Clin Endocrinol Metab 78, 898903.

Wang, J.C., Stromstedt, P.E., O'Brien, R.M., and Granner, D.K. (1996). Hepatic nuclear factor 3 is an accessory factor required for the stimulation of phosphoenolpyruvate carboxykinase gene transcription by glucocorticoids. Mol Endocrinol 10, 794-800.

Wang, Y.X., Lee, C.H., Tiep, S., Yu, R.T., Ham, J., Kang, H., and Evans, R.M. (2003). Peroxisome-proliferator-activated receptor delta activates fat metabolism to prevent obesity. Cell 113, 159-170.

Way, J.M., Harrington, W.W., Brown, K.K., Gottschalk, W.K., Sundseth, S.S., Mansfield, T.A., Ramachandran, R.K., Willson, T.M., and Kliewer, S.A. (2001). Comprehensive messenger ribonucleic acid profiling reveals that peroxisome proliferator-activated receptor gamma activation has coordinate effects on gene expression in multiple insulin-sensitive tissues. Endocrinology 142, 1269-1277.

Weiss, R.E., Xu, J., Ning, G., Pohlenz, J., O'Malley, B.W., and Refetoff, S. (1999). Mice deficient in the steroid receptor co-activator 1 (SRC-1) are resistant to thyroid hormone. EMBO J 18, 1900-1904.

Weitzel, J.M. (2003). Regulation of mitochondrial biogensis by thyroid hormone. Experimental Physiology 88, 121-128.

Weitzel, J.M., Hamann, S., Jauk, M., Lacey, M., Filbry, A., Radtke, C., Iwen, K.A., Kutz, S., Harneit, A., Lizardi, P.M., et al. (2003a). Hepatic gene expression patterns in thyroid hormone-treated hypothyroid rats. J Mol Endocrinol 31, 291-303. 
Weitzel, J.M., Iwen, K.A., and Seitz, H.J. (2003b). Regulation of mitochondrial biogenesis by thyroid hormone. Exp Physiol 88, 121-128.

Weitzel, J.M., Radtke, C., and Seitz, H.J. (2001). Two thyroid hormone-mediated gene expression patterns in vivo identified by cDNA expression arrays in rat. Nucleic Acids Res 29, 5148-5155.

Wende, A.R., Huss, J.M., Schaeffer, P.J., Giguere, V., and Kelly, D.P. (2005). PGC1alpha coactivates PDK4 gene expression via the orphan nuclear receptor ERRalpha: a mechanism for transcriptional control of muscle glucose metabolism. Mol Cell Biol 25, 10684-10694.

Wensaas, A.J., Rustan, A.C., Just, M., Berge, R.K., Drevon, C.A., and Gaster, M. (2009). Fatty acid incubation of myotubes from humans with type 2 diabetes leads to enhanced release of $\{$ beta $\}$-oxidation products because of impaired fatty acid oxidation: effects of tetradecylthioacetic acid and eicosapentaenoic acid. Diabetes 58, 527-535.

Williams, G., and Brent, G. (1995). Thyroid hormone response elements. In: Molecular Endocrinology: Basic Concepts and Clinical Correlations, 217-239.

Williams, G.R. (2000). Cloning and characterization of two novel thyroid hormone receptor beta isoforms. Mol Cell Biol 20, 8329-8342.

Williams, S.C., Cantwell, C.A., and Johnson, P.F. (1991). A family of C/EBP-related proteins capable of forming covalently linked leucine zipper dimers in vitro. Genes Dev $5,1553-1567$.

Wood, W.M., Ocran, K.W., Gordon, D.F., and Ridgway, E.C. (1991). Isolation and characterization of mouse complementary DNAs encoding alpha and beta thyroid hormone receptors from thyrotrope cells: the mouse pituitary-specific beta 2 isoform differs at the amino terminus from the corresponding species from rat pituitary tumor cells. Mol Endocrinol 5, 1049-1061.

$\mathrm{Wu}, \mathrm{P}$. (2007). Thyroid disorders and diabetes. It is common for a person to be affected by both thyroid disease and diabetes. Diabetes Self Manag 24, 80-82, 85-87.

Wu, P., Blair, P.V., Sato, J., Jaskiewicz, J., Popov, K.M., and Harris, R.A. (2000). Starvation increases the amount of pyruvate dehydrogenase kinase in several mammalian tissues. Arch Biochem Biophys 381, 1-7.

Wu, P., Sato, J., Zhao, Y., Jaskiewicz, J., Popov, K.M., and Harris, R.A. (1998). Starvation and diabetes increase the amount of pyruvate dehydrogenase kinase isoenzyme 4 in rat heart. Biochem J 329 ( Pt 1), 197-201.

Wu, Y., Delerive, P., Chin, W.W., and Burris, T.P. (2002). Requirement of helix 1 and the AF-2 domain of the thyroid hormone receptor for coactivation by PGC-1. J Biol Chem 277, 8898-8905. 
Wu, Z., Puigserver, P., Andersson, U., Zhang, C., Adelmant, G., Mootha, V., Troy, A., Cinti, S., Lowell, B., Scarpulla, R.C., et al. (1999). Mechanisms controlling mitochondrial biogenesis and respiration through the thermogenic coactivator PGC-1. Cell 98, 115-124.

Wulf, A., Harneit, A., and Weitzel, J.M. (2007). T3-mediated gene expression is independent of PGC-1alpha. Mol Cell Endocrinol 270, 57-63.

Xie, W., Hong, H., Yang, N.N., Lin, R.J., Simon, C.M., Stallcup, M.R., and Evans, R.M. (1999). Constitutive activation of transcription and binding of coactivator by estrogenrelated receptors 1 and 2. Mol Endocrinol 13, 2151-2162.

Xiong, S., Chirala, S.S., Hsu, M.H., and Wakil, S.J. (1998). Identification of thyroid hormone response elements in the human fatty acid synthase promoter. Proc Natl Acad Sci U S A 95, 12260-12265.

Xu, L., Glass, C.K., and Rosenfeld, M.G. (1999). Coactivator and corepressor complexes in nuclear receptor function. Curr Opin Genet Dev 9, 140-147.

$\mathrm{Xu}, \mathrm{W}$. (2005). Nuclear receptor coactivators: the key to unlock chromatin. Biochem Cell Biol 83, 418-428.

Yamada, K., Duong, D.T., Scott, D.K., Wang, J.C., and Granner, D.K. (1999). CCAAT/enhancer-binding protein beta is an accessory factor for the glucocorticoid response from the cAMP response element in the rat phosphoenolpyruvate carboxykinase gene promoter. J Biol Chem 274, 5880-5887.

Yeh, W.C., Cao, Z., Classon, M., and McKnight, S.L. (1995). Cascade regulation of terminal adipocyte differentiation by three members of the C/EBP family of leucine zipper proteins. Genes Dev 9, 168-181.

Yen, P.M. (2001). Physiological and molecular basis of thyroid hormone action. Physiol Rev 81, 1097-1142.

Yen, P.M., Ando, S., Feng, X., Liu, Y., Maruvada, P., and Xia, X. (2006). Thyroid hormone action at the cellular, genomic and target gene levels. Mol Cell Endocrinol 246, 121-127.

Yin, L., Wang, Y., Dridi, S., Vinson, C., and Hillgartner, F.B. (2005). Role of CCAAT/enhancer-binding protein, histone acetylation, and coactivator recruitment in the regulation of malic enzyme transcription by thyroid hormone. Mol Cell Endocrinol 245, 43-52.

Zhang, Y., Castellani, L.W., Sinal, C.J., Gonzalez, F.J., and Edwards, P.A. (2004a). Peroxisome proliferator-activated receptor-gamma coactivator 1alpha (PGC-1alpha) regulates triglyceride metabolism by activation of the nuclear receptor FXR. Genes Dev $18,157-169$. 
Zhang, Y., Ma, K., Sadana, P., Chowdhury, F., Gaillard, S., Wang, F., McDonnell, D.P., Unterman, T.G., Elam, M.B., and Park, E.A. (2006). Estrogen-related receptors stimulate pyruvate dehydrogenase kinase isoform 4 gene expression. J Biol Chem 281, 3989739906.

Zhang, Y., Ma, K., Song, S., Elam, M.B., Cook, G.A., and Park, E.A. (2004b). Peroxisomal proliferator-activated receptor-gamma coactivator-1 alpha (PGC-1 alpha) enhances the thyroid hormone induction of carnitine palmitoyltransferase I (CPT-I alpha). J Biol Chem 279, 53963-53971.

Zhang, Y., Yin, L., and Hillgartner, F.B. (2003). SREBP-1 integrates the actions of thyroid hormone, insulin, cAMP, and medium-chain fatty acids on ACCalpha transcription in hepatocytes. J Lipid Res 44, 356-368.

Zhang, Z., Burch, P.E., Cooney, A.J., Lanz, R.B., Pereira, F.A., Wu, J., Gibbs, R.A., Weinstock, G., and Wheeler, D.A. (2004c). Genomic analysis of the nuclear receptor family: new insights into structure, regulation, and evolution from the rat genome. Genome Res 14, 580-590.

Zong, H., Ren, J.M., Young, L.H., Pypaert, M., Mu, J., Birnbaum, M.J., and Shulman, G.I. (2002). AMP kinase is required for mitochondrial biogenesis in skeletal muscle in response to chronic energy deprivation. Proc Natl Acad Sci U S A 99, 15983-15987. 


\section{APPENDIX: SUPPLEMENTAL DATA FOR CHAPTER 4}

PGC-1 $\alpha$ is involved in the activation of different metabolic genes by thyroid hormone. To further investigate the role of the PGC- $1 \alpha$ in the T3 activation of other metabolic genes, we examined whether we could observe increased association of PGC$1 \alpha$ to PDK4, CPT-1a and PEPCK in hypothyroid and hyperthyroid rats. Rats were made hypothyroid by the administration of propylthiouracil (PTU) and then they were treated with 100nM of T3 for 24 hours. Pieces of the liver were minced in 1\% formaldehyde and then used in ChIP assays. Again we detected PGC-1 $\alpha$ in the proximal region of the PDK4 gene promoter, and this association was increased by $5.9 \pm 0.5$ fold after T3 treatment. However, we did not observe any association of PGC-1 $\alpha$ with the TRE region of the PDK 4 gene promoter. In addition, we observed increased association of the PGC- $1 \alpha$ both the first intron and the TRE region of the CPT-1a gene promoter after T3 treatment by $6.4 \pm 0.8$ fold and $2.2 \pm 0.5$ fold, respectively. Also, increased association of the PGC-1 $\alpha$ with proximal region of the PEPCK gene promoter by $3.6 \pm 0.8$ fold was detected after T3 treatment (Figure A.1A and A.1B).

T3 not only increased the association of the PGC- $1 \alpha$ with the above genes promoters, but it also increased the abundance of the PGC-1 $\alpha$ protein itself in these hyperthyroid rats by $2.8 \pm 0.3$ fold (Figure A.1C). The increased abundance and association of the PGC-1 $\alpha$ with different metabolic genes after T3 treatment suggests that $\mathrm{T} 3$ activation can work through the PGC- $1 \alpha$ in the activation PDK4 and other metabolic genes. 
Figure A.1: PGC-1a association with T3 responsive genes is elevated in hyperthyroid rats.

A. ChIP assays were conducted in liver samples from hypothyroid rats that were untreated or exposed to T3 for 24 hours. The ChIP assays were conducted as outlined in the materials and methods. Various portions of the PDK4, CPT-1a and PEPCK genes were analyzed for the binding of PGC-1 $\alpha$. Representative PCR reactions are shown. B. The binding of PGC- $1 \alpha$ to the various genes was quantified using quantity one software. The results are the summary of four independent hypothyroid and T3 rats. C. The abundance of PGC- $1 \alpha$ was quantified using western blot analysis. The PGC- $1 \alpha$ abundance was assessed using protein extracts from the same rats that were used for the ChIP assays. 
A.

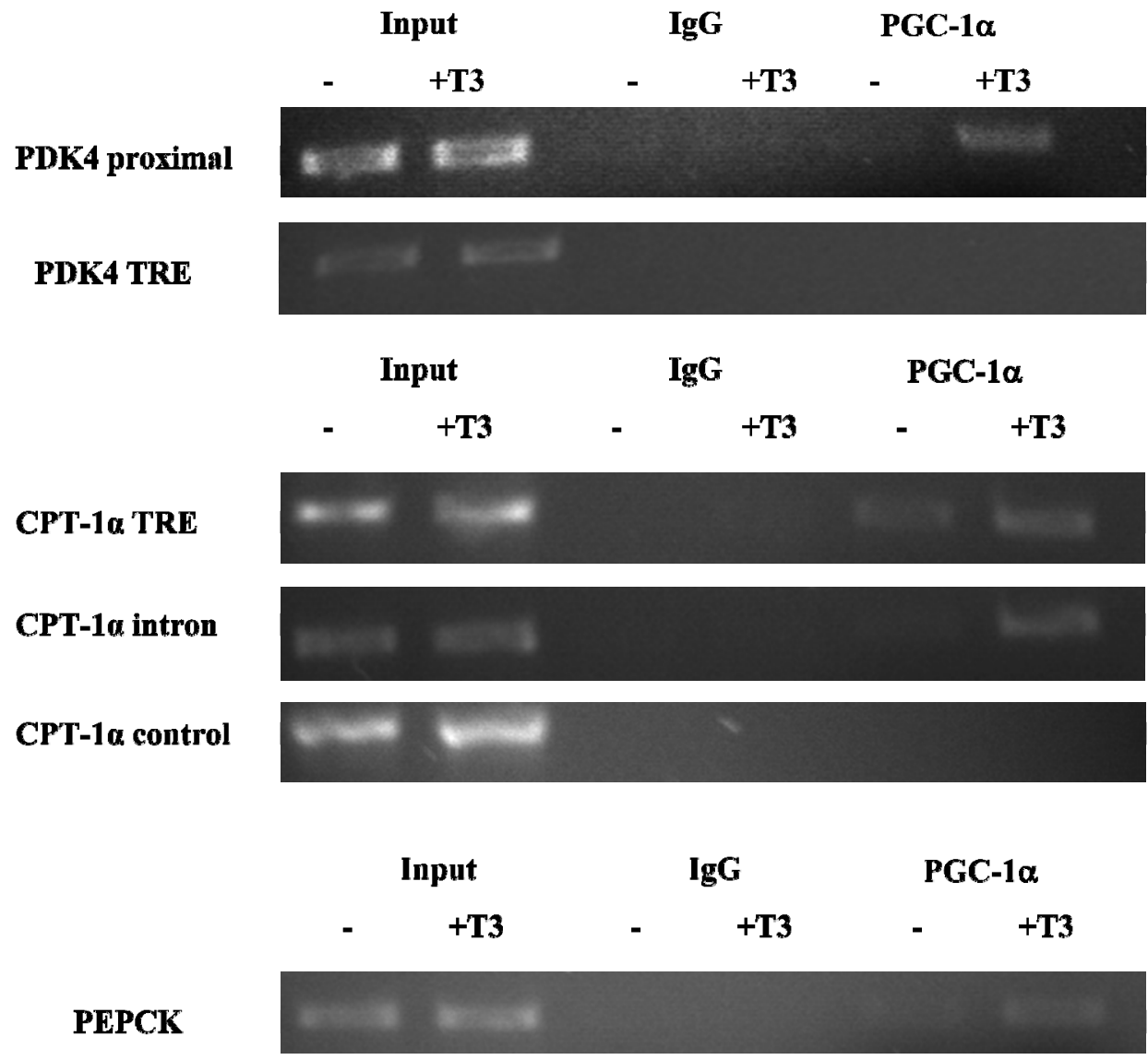

B.

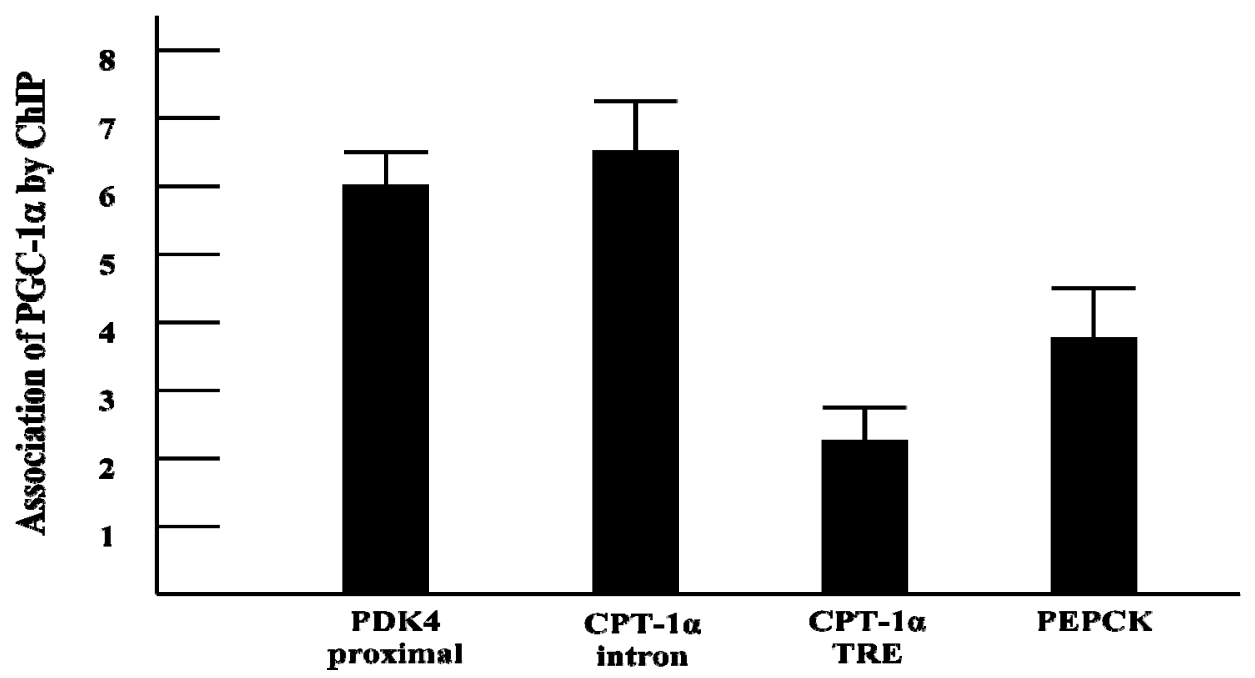


C.

PGC-1a $\quad$ Hypothyroid $\frac{\text { Hyperthyroid }}{-}$

Actin

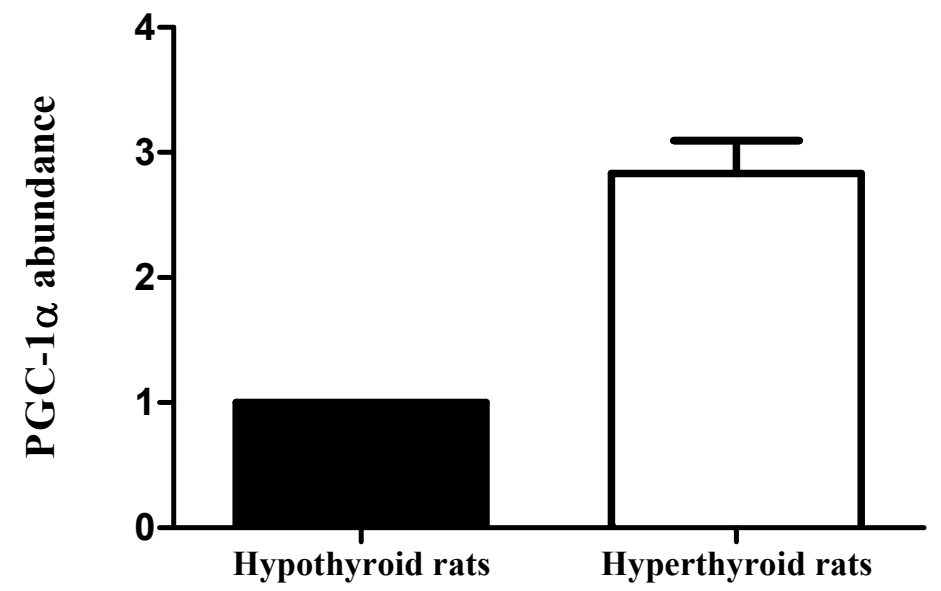

Figure A.1: (continued). 


\section{VITA}

Ramy Raafat Naguib Attia was born in Cairo, Egypt, in the year 1978. He received his bachelor degree in Pharmacy from Cairo University in 2001. He worked in EVA Pharmaceutical Incorporation in Egypt for the research and development department till May 2004. He joined the Ph.D. integrated program of biomedical science at University of Tennessee Health Science Center (UTHSC) in August 2004. During his

doctoral study, Ramy Naguib Attia received two travel awards from ASBMB to attend the FASEB meeting in 2008 and 2009. 